\title{
ZONEAMENTO DA PRODUTIVIDADE POTENCIAL CLIMÁTICA DA CANA-DE-AÇÚCAR NO ESTADO DO RIO DE JANEIRO
}

\author{
MARIA INÊS MOREIRA DE ARAUJO \\ Meteorologista
}

Orientador: Prof. Dr. ANTONIO ROBERTO PEREIRA

Dissertação apresentada à Escola superior de Agricultura "Luiz de Queiroz", da Universidade de São Paulo, para obtenção do título de Mestre em Agronomia, Área de Concentração: Agrometeorologia.

P I R A C I C A B A

Estado de São Paulo - Brasil

Abril - 1993 
Ficha catalografica preparada pela Seça de Livros da Divisăo de Biblioteca e Documentaçăo - FCLQ/USF

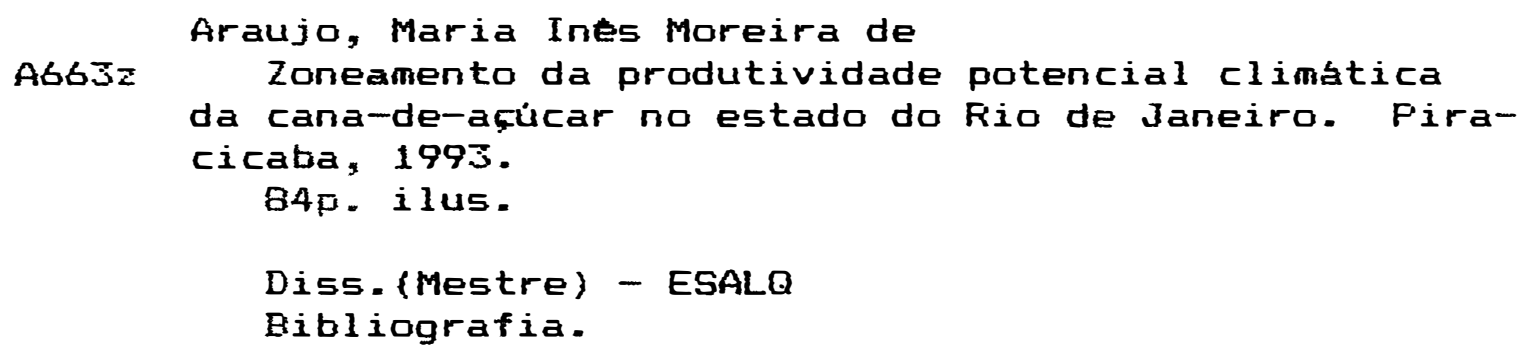

1. Cana-de-afúcar - Desenvolvimento - Efeito do clima 2. Cana-de-açucar - Frodutividade - Fio de Janeiro 3 . Meteorologia agricola - Rio de Janeiro I. Escola Superior de Agricultura Luiz de Queiroz, Piracicaba 


\section{ZONEAMENTO DA PRODUTIVIDADE POTENCIAL CLIMÁTICA DA CANA-DE-AÇÚCAR NO ESTADO DO RIO DE JANEIRO}

MARIA INÊS MOREIRA DE ARAUJO

Aprovado em: 28 de maio de 1993

COMISSÃO JULGADORA:

Prof. Dr. Antonio Roberto Pereira ESALQ/USP

Prof. Dr. Luiz Roberto Angelocci ESALQ/USP

Prof. Dr. José Marques DCM/UERJ

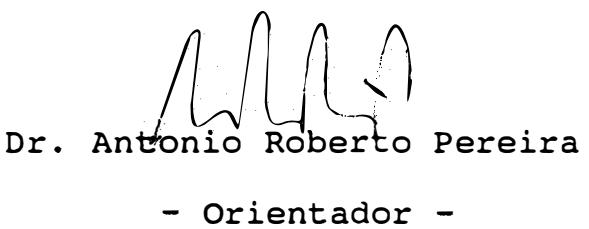




\section{ZONEAMENTO DA PRODUTIVIDADE POTENCIAL CLIMÁTICA DA CANA-DE-AÇÚCAR NO ESTADO DO RIO DE JANEIRO}

MARIA INÊS MOREIRA DE ARAUJO

Aprovado em: 28 de maio de 1993

COMISSÃO JULGADORA:

Prof. Dr. Antonio Roberto Pereira

ESALQ/USP

Prof. Dr. Luiz Roberto Angelocci

ESALQ/USP

Prof. Dr. José Marques

DCM/UERJ

Dr. Antonio Roberto Pereira

- Orientador - 
A Deus

À minha mãe, Thereza

A meu esposo, paulo cesar

Aos meus filhos, Thais, Thiago e Thadeu

Ofereço.

As memórias de meu pai, Paulo e do amigo David Dedico. 


\section{AGRADECIMENTOS}

- Ao Prof. Dr. Antonio Roberto Pereira pela orientação no desenvolvimento do presente trabalho.

- Ao Instituto Nacional de Meteorologia pela oportunidade oferecida para aprimorar meus conhecimentos profissionais.

- À Escola Superior de Agricultura " Luiz de Queiroz ", através do Departamento de Física e Meteorologia pela oportunidade de frequentar o Curso de Pós-graduação.

- Ao Prof. Dr. Nilson Augusto Villa Nova, pelo apoio e sugestões concedidas durante a execução deste trabalho.

- Aos professores do Curso de Pós-graduação do Departamento de Física e Meteorologia pelo meu desenvolvimento profissional.

- Aos colegas e funcionários do Departamento de Física e Meteorologia pelo apoio e colaboração.

- A Coordenação de Aperfeiçoamento de Pessoal de Nível Superior (CAPES), pelo apoio financeiro. 
INDICE

PÁGINA

LISTA DE FIGURAS. .................... vi

LISTA DE TABELAS....................... viii

RESUMO ............................

SUMMARY $\ldots \ldots \ldots \ldots \ldots \ldots \ldots \ldots \ldots \ldots \ldots \ldots \ldots \ldots \ldots$

1. INTRODUÇÃo. .......................... 1

2. REVISÃo dE Literatura................... 5

2.1. Origem e difusão da cana-de-açúcar........ 5

2.2. Efeitos dos fatores físicos ambientais... 7

2.2.1. Temperatura................. 8

2.2.2. Luz (Radiação e Fotoperíodo)....... 10

2.2 .3 . Chuva (Água) ................... 11

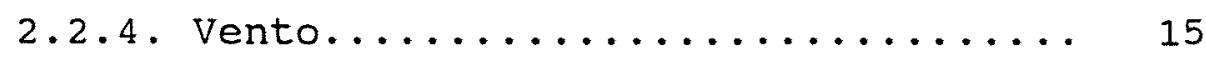

2.2 .5 . Fatores adversos que afetam a produtividade.............. 15

2.3. Modelos agrometeorológicos de estimativa da produtividade.................. 16

3. MATERIAL E MÉTOdo..................... 23

3.1. Material utilizado................ 23

3.1.1. Dados meteorológicos........... 23 
3.1.2. Dados de produtividade......... 27

3.2. Modelo utilizado.................. 27

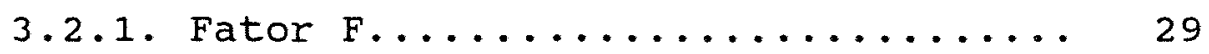

3.2.2. Produção média de matéria seca bruta em kg $\mathrm{CH}_{2} \mathrm{O} / \mathrm{ha}$.dia.......... 29

3.2.3. Fator de correção de temperatura

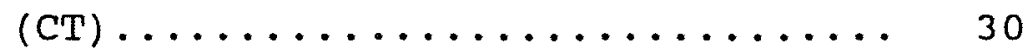

3.2.4. Fator de correção do índice de área foliar $(C L) \ldots \ldots \ldots \ldots \ldots \ldots \ldots$

3.2.5. Fator de correção da respiração de manutenção $(r) \ldots \ldots \ldots \ldots \ldots \ldots \ldots . \ldots \ldots$

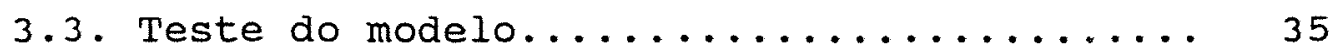

4. RESULTAdos E DISCUSSÃo................ 36

4.1. Aplicação do modelo para as condições

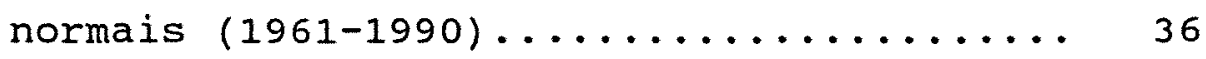

4.2. Aplicação do modelo quando há um aquecimento da região..............

4.3. Aplicação do modelo quando há um resfriamento da região............ 38

5. CONCLUSÕES................................ 65

REFERÊNCIAS BIBLIOGRÁFICAS.............. 66

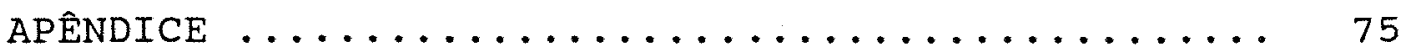




\section{LISTA DE FIGURAS}

Página

Figura

no

1 Regiões agroclimatológicas do Estado do

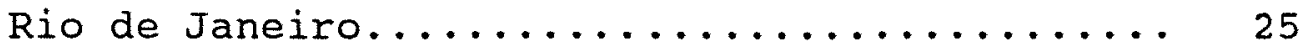

2 Zoneamento agroclimático da cana-de-açúcar no Estado do Rio de Janeiro............. 26

3 Isolinhas de produtividade potencial estimada da cana-de-açúcar para dados normais (1961-1990) em ton/ha - ciclo: 18 meses........................... 40

4 Isolinhas de produtividade potencial estimada da cana-de-açúcar para dados normais (1961-1990) em ton/ha - ciclo: 12

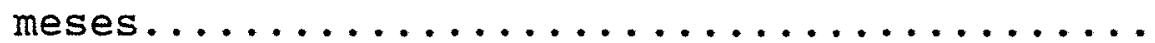

5 Isolinhas de produtividade potencial estimada da cana-de-açúcar para dados normais (1961-1990), com acréscimo da temperatura média em 10\% em ton/ha -

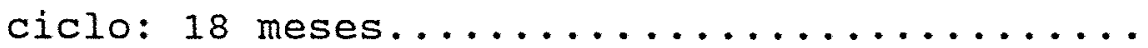


6 Isolinhas de produtividade potencial estimada da cana-de-açúcar para dados normais (1961 1990), com acréscimo de temperatura média em

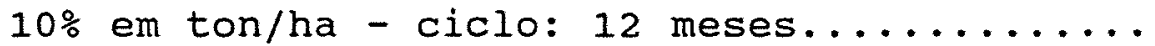

7 Isolinhas de produtividade potencial estimada da cana-de-açúcar para dados normais (1961 1990), com decréscimo da temperatura média em

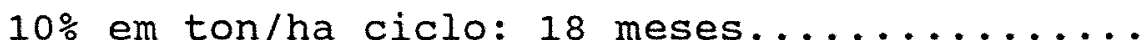

8 Isolinhas de produtividade potencial estimada da cana-de-açúcar para dados normais (1961 1990), com decréscimo da temperatura média em $10 \%$ em ton/ha - ciclo: 12 meses........... 


\section{LISTA DE TABELAS}

Página

\section{Tabela}

n으

1 Relação da estações meteorológicas utilizadas.

2 Dados meteorológicos normais (1961 - 1990) das estações de Angra dos reis e Bangu...... 76

3 Dados meteorológicos normais (1961 - 1990) das estações de Campos e Cabo Frio.......... 77

4 Dados meteorológicos normais (1961 - 1990) das estações de Ecologia Agrícola e Ilha Guaíba.

5 Dados meteorológicos normais (1961 - 1990) das estações de Itaperuna e Macaé.......... 79

6 Dados meteorológicos normais (1961 - 1990) das estações de Marambaia e Rio de Janeiro... 80

7 Dados meteorológicos normais (1961 - 1990) das estações de santa cruz e são fidelis...... 
8 Dados meteorológicos normais (1961 - 1990) das estações de Cataguases, MG e Cachoeira do Itapemirim, ES..................... 82

9 Dados meteorológicos normais (1961 - 1990) das estações de Ubatuba, SP e Piraí........ 83

10 Dados meteorológicos normais (1961 - 1990) da estação de vassouras................. 84

11 Produtividade de cana irrigada na localidade de Campos/RJ, para os períodos de abril/77 a setembro/78 e de setembro/78 a agosto/79.....

12 Produtividade potencial simulada para os dados meteorológicos normais (1961 - 1990) para Angra dos Reis.................. 46

13 Produtividade potencial simulada para os dados meteorológicos normais (1961 - 1990) para Bangu.

14 Produtividade potencial simulada para os dados meteorológicos normais (1961 - 1990)

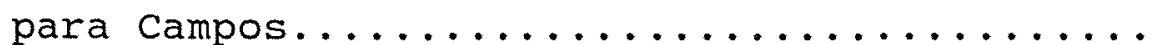


15 Produtividade potencial simulada para os dados meteorológicos normais (1961 - 1990) para Cabo Frio....................... 49

16 Produtividade potencial simulada para os dados meteorológicos normais (1961 - 1990) para Ecologia Agrícola.................

17 Produtividade potencial simulada para os dados meteorológicos normais (1961 - 1990) para Ilha Guaíba...................

18 Produtividade potencial simulada para os dados meteorológicos normais (1961 - 1990)

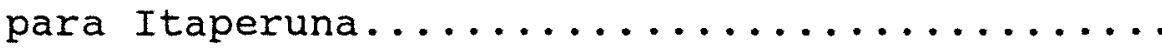

19 Produtividade potencial simulada para os dados meteorológicos normais (1961 - 1990)

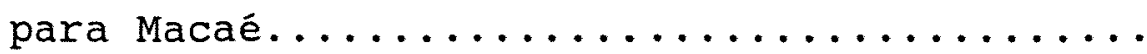

20 Produtividade potencial simulada para os dados meteorológicos normais (1961 - 1990)

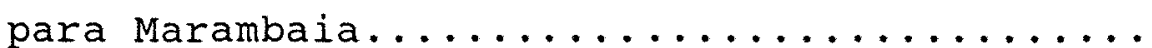


21 Produtividade potencial simulada para os dados meteorológicos normais (1961 - 1990) para Rio de Janeiro..................

22 Produtividade potencial simulada para os dados meteorológicos normais (1961 - 1990) para santa cruz....................

23 Produtividade potencial simulada para os dados meteorológicos normais (1961 - 1990)

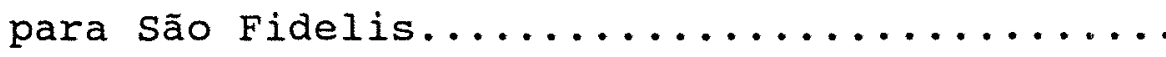

24 Produtividade potencial simulada para os dados meteorológicos normais (1961 - 1990) para Cataguases, MG.................

25 Produtividade potencial simulada para os dados meteorológicos normais (1961 - 1990) para Cachoeira do Itapemirim, ES..........

26 Produtividade potencial simulada para os dados meteorológicos normais (1961 - 1990) para Ubatuba, sp....................... 60 
27 Produtividade potencial simulada para os dados meteorológicos normais (1961 - 1990)

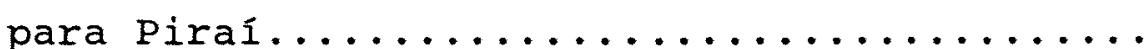

28 Produtividade potencial simulada para os dados meteorológicos normais (1961 - 1990)

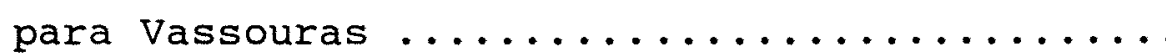

29 Produtividade real em ton/ha e produtividade

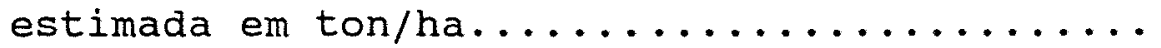

30 Porcentagem da produtividade estimada normal (Pen) em ton/ha, produtividade potencial estimada acrescida à temperatura em $10 \%$ (Pea) em ton/ha e produtividade potencial com decréscimo de $10 \%$ na temperatura (Ped)

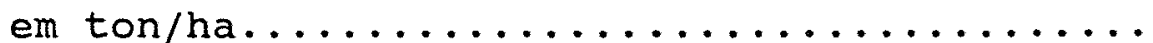


ZONEAMENTO DA PRODUTIVIDADE POTENCIAL CLIMÁTICA DA CANA-DE-AÇÚCAR NO ESTADO DO RIO DE JANEIRO

\section{Autora: MARIA INÊS MOREIRA DE ARAUJO Orientador: ANTONIO ROBERTO PEREIRA}

RESUMO

A produtividade potencial climática da cana-deaçúcar (Saccharum spp) foi estimada para diversas localidades do Estado do Rio de Janeiro utilizando um modelo matemáticofisiológico, do tipo dinâmico, proposto por De WIT (1965) e modificado por VILLA NOVA \& BARBIERI (1991). O modelo utiliza dados meteorológicos mensais de temperaturas do ar máxima, mínima e média $\left({ }^{\circ} \mathrm{C}\right)$, insolação e fotoperíodo (horas).

Os resultados mostram que a produtividade estimada pelo modelo foi bastante superior à produtividade atual relatada pelo IBGE, mas bem próxima da produtividade obtida em experimento de campos irrigados. Portanto, o fator mais Iimitante à produtividade da cana-de-açúcar na região é a falta de água, e isto indica que o uso adequado de irrigação pode aumentar significativamente a produtividade do estado. 
Admitindo-se que uma mudança climática está ocorrendo, dois novos cenários climáticos foram também avaliados. Se a temperatura da região sofrer um acréscimo de $10 \%$ do valor atual, o modelo prevê que a produtividade potencial aumentará em mais de $20 \%$, desde que a demanda por água seja plenamente atendida. Ao contrário, se houver um decréscimo de $10 \%$ na temperatura, a produtividade potencial será reduzida em mais de $25 \%$ não havendo restrição no suprimento de água. 
SUGARCANE POTENTIAL CLIMATIC YIELD ZONING FOR THE

RIO DE JANEIRO STATE, BRAZIL

Author: MARIA INÊS MOREIRA DE ARAUJO Adviser: ANTONIO ROBERTO PEREIRA

SUMMARY

The climatic potential yield for the sugarcane (Saccharum spp) was estimated for several regions in the Rio de Janeiro state, Brazil, using a mathematical-physiological model proposed by De wit (1965) and modified by VILLA NOVA \& BARBIERI (1991). The model inputs are the monthly means of the maximum, minimum and mean air temperature, hours of sunshine and photoperiod.

The results indicate that the estimated potential yield for the region is well above the actual yield. For some regions the actual yield is only half of that climatically possible. However, when the model predictions are compared with experimental results from 
irrigated fields the discrepancy is very small suggesting that the lack of irrigation is the single most restrictive factor to the sugarcane yield in the region.

Supposing that a climatic change is under way, two new scenarios were also used to simulate the response of the sugarcane plant to those possible changes. Assuming that the mean monthly temperature will change either way by as much as $10 \%$ of the current value it was found that the model predicts that the sugarcane yield will be more affected if the temperature arops. If the temperature increases, as predicted by many climatic models, the sugarcane yield will benefit with such change for the model indicates that a $10 \%$ increase in the temperature will improve the yield by more than $20 \%$ if the demand for water is fully satisfied. If the temperature decreases by $10 \%$ the potential yield will be reduced by as much as $25 \%$, also under optimum water supply. 


\section{INTRODUÇÃo}

A cana-de-açúcar é uma das culturas de maior expressão econômica no Estado do Rio de Janeiro, contribuindo na agroindústria açucareira como fonte alternativa na geração de energia, tornando-se a mais importante cultura alternativa na fabricação de etanol no Brasil.

Estatisticas mostram que a produtividade da cana-de-açúcar no Estado do Rio de Janeiro é considerada baixa, quando comparada com outras regiōes produtoras do país e do mundo. Segundo estudos da Fundação Norte Fluminense de Desenvolvimento Regional (FUNDENOR), citado por souzA et alii (1980), os fatores que concorrem para que a produtividade seja baixa naquela região são: o plantio em solos não adequadamente preparados; utilização de mudas não tratadas; controle ineficiente de ervas daninhas; uso inadequado de fertilizantes; cortes da cana em épocas fora do período ótimo de coIheita, bem como a ocorrência de déficits hídricos nos períodos de seca, e problemas de drenagem nas épocas de chuvas.

A produção agrícola é dependente, dentre outros fatores, das condições climáticas sendo sua variação apontada como a principal responsável pela variação anual da produtividade. 
As relações entre os elementos climáticos e a produtividade são bastante complexas, pois o ambiente pode afetar o crescimento e desenvolvimento das plantas sob diferentes formas, nas diversas fases do ciclo da cultura. A temperatura, por exemplo, afeta diferentemente o processo de fotossintese e de respiração resultando em ganhos e perdas diferentes de fitomassa.

Modelos matemático-fisiológicos estão sendo desenvolvidos para melhor entendimento das interações climaplanta. Tais modelos procuram descrever os efeitos climáticos sobre o desenvolvimento, o crescimento e a produtividade da cultura.

A interpretação numérica desses modelos tem sido usada para planejamento de uso da terra, para zoneamento agrícola, manejo da irrigação, estudos morfofisiológicos das culturas, engenharia genética da planta, avaliação do impacto das possiveis mudanças climáticas, previsões do desenvolvimento e rendimento das culturas.

Os modelos mais utilizados para estimativa da produtividade, conforme classificação de ROBERTSON (1983a), são os empirico-estatísticos, os físico-estatísticos e os dinâmicos. Os modelos empírico-estatísticos utilizam séries históricas de produtividade e de elementos meteorológicos, para estimativa de coeficientes, através de técnicas de regressão. Os físico-estatísticos descrevem matemáticamente os processos envolvidos na formação do rendimento, também 
através de regressão. Os modelos dinâmicos, diferem normalmente dos outros devido ao grau de detalhamento descrito por cada processo individualmente, e também pela quantidade de variáveis meteorológicas e biológicas necessárias ao modelo.

o presente trabalho utiliza o modelo matemático - fisiológico, do tipo dinâmico, proposto por De WIT (1965) e modificado por VILLA NOVA \& BARBIERI (1991), para estimativa da produtividade potencial da cana-de-açúcar no Estado do Rio de Janeiro.

Entende-se por produtividade potencial àquela que pode ocorrer numa região se as condições de umidade do solo forem adequadas, e não houver nem impedimento nutricional nem ocorrência de moléstias e pragas.

As estimativas serão feitas em três cenários climáticos. o primeiro, considera o clima atual, isto é, média das variações interanuais obtidas no período 1961-1990. o segundo, admite que está havendo mudança climática com consequente aquecimento da região. o terceiro cenário, assume que a mudança climática é no sentido inverso, ou seja, haverá um resfriamento na região.

Previsões com modelos atmosféricos de circulação global indicam que a temperátura planetária aumentará algo em torno de $1^{\circ} \mathrm{C}$ a $5^{\circ} \mathrm{C}$. Evidentemente esse aquecimento não será igual em todas as partes. Em algumas latitudes, principalmente as intermediárias no hemisfério 
norte, parece que os efeitos serão maiores. Para o hemisfério sul, no entanto, a falta de informações reais aumentam o grau de incerteza das previsões para esta região. Essa incerteza é responsável pela utilização do terceiro cenário.

Para cada cenário climático será elaborado um mapa indicando regiões de idêntico potencial de produtividade, ou seja, um zoneamento da cana-de-açúcar para que se obtenha as regiões de maior produção do Estado do Rio de Janeiro. 


\section{REVISÃO DE LITERATURA}

\subsection{Origem e difusão da cana-de-açúcar}

A literatura é ampla mas bastante discordante sobre a origem da cana-de-açúcar. BISWAS (1988) cita que BARBER $^{1}$ e CHATURVEDI ${ }^{2}$ são da opinião que a origem da canade-açúcar é a Índia, e que a cultura já era mencionada desde 1400 a 1000 a.C, e que BRANDES ${ }^{3}$, após estudar vários registros concluiu que a cana pode ter sido originada na Nova Guiné.

Segundo BARBER (1931), a cana-de-açúcar foi levada da Índia para a china em torno do ano 400 . Os chineses levaram-na para o Japão, Java e Filipinas, e esses países difundiram a cultura em pequenas ilhas como o Havaí, no Pacífico. No final do século XVIII foi levada para a Austrália.

${ }^{1}$ BARBER, C.A., 1931: Proc. I.M.P. Sugare-cane Res. Conf., London

${ }^{2}$ CHATURVEDI, H. S., 1951: The sugar industry of India. Ind. Sugar-cane Jour. March edition.

${ }^{3}$ BRANDES, E.W., 1956: origin, dispersal and use in breeding of the Melansian Garden sugar-canes and their derivative. Proc. 9th Cong. Int. Soc. Sugar-cane Technol., $709-750$. 
Para o Oriente Médio (Egito, Irã e norte da Arábia Saudita), a cana-de-açúcar foi levada por Alexandre, o Grande, sendo ali cultivada por algum tempo; mas a cultura fracassou devido ao clima ser inapto.

A cultura alcançou a Espanha em torno do ano 600, propagando-se por outros países europeus. Em 1494, Colombo introduziu a planta em São Domingos, dali espalhandose para Cuba e outras ilhas do Caribe.

No inicio do século $X V$, a cultura foi estabelecida no México, com rendimentos elevados devido ao clima. Hoje, muitos desses países possuem prósperas indústrias açucareiras devido à qualidade do açúcar produzido, sendo suas economias dependentes da produção de cana-de-açúcar e indústrias associadas. No século XVIII a cultura estava estabelecida em aproximadamente 50 países.

No Brasil, a indústria açucareira data do século XVI. Foi trazida da Ilha da Madeira e cultivada quase simultaneamente em Pernambuco e são Paulo. Os primeiros engenhos foram construídos perto de santos (SP). Durante 150 anos a cana-de-açúcar foi o principal produto agrícola brasileiro. A cana-de-açúcar é cultivada em todos os Estados brasileiros, mas é no Estado de São Paulo que se concentra a maioria das lavouras dessa cultura. 


\subsection{Efeitos dos fatores físicos do ambiente}

A cana-de-açúcar é uma cultura essencialmente tropical. Atualmente ela é cultivada em mais de 90 países localizados entre os paralelos $37^{\circ} \mathrm{N}$ e $32^{\circ} \mathrm{S}$, sendo assim adaptada em diversas condiçōes de clima e solo. A duração de seu período de crescimento varia de 10 meses, em alguns países, a 24 meses em outros e, no Havai, de 2 a 3 anos, dependendo do solo, das condições climáticas e das características varietais. o rendimento da cana varia consideravelmente de lugar para lugar e também de estação para estação. Um dos principais fatores que contribui para esta variação é o clima, que tem influência direta na germinação, crescimento, rendimento e no conteúdo de açúcar.

- Brasil é, possivelmente, o único país com duas colheitas anuais de cana-de-açúcar. Uma, na região Norte-Nordeste, que começa em setembro extendendo-se até abril. Outra, na região Centro-sul, que vai de junho a dezembro. Isso se deve à sua grande extensão territorial no sentido norte-sul, a qual proporciona ao desenvolvimento da cultura canavieira as mais variadas condições climáticas.

os elementos climáticos, tais como: temperatura, chuva, radiação solar, vento e fenômenos meteorológicos adversos como, geada, granizo e ventos tornádicos têm influências decisivas no crescimento e desenvolvimento de uma cultura. 


\subsubsection{Temperatura}

A temperatura é um dos elementos do clima que controlam o crescimento e desenvolvimento das plantas. Existe uma temperatura abaixo da qual a planta não mais se desenvolve, e a esse limite inferior define-se como temperatura base. Existe também uma faixa considerada ótima para o seu desenvolvimento.

Para a cana-de açúcar alguns autores chegaram a resultados como: FAUCONIER ${ }^{4}$, citado por BARBIERI \& VILLA NOVA (1981), cita que em temperatura abaixo de $25^{\circ} \mathrm{C}$ e acima de $35^{\circ} \mathrm{C}$ o crescimento da cana é muito lento, e que o crescimento é máximo quando a temperatura varia de 30 a $34^{\circ} \mathrm{C}$, sendo praticamente nulo para temperatura superior a $38^{\circ} \mathrm{C}$. BACCHI \& SOUZA (1977) determinaram que o crescimento torna-se praticamente nulo para temperaturas inferiores a $19-20^{\circ} \mathrm{C}$ para cana não irrigada, e $18-19^{\circ} \mathrm{C}$, para condições irrigadas. BARBIERI et alii (1979) encontraram que a temperatura base para a cana-de-açúcar está em torno de $20^{\circ} \mathrm{C}$ e que seu ponto ótimo para a fase de germinação esta por volta de $32^{\circ} \mathrm{C}$, sendo a temperatura base para esta fase $21^{\circ} \mathrm{C}$.

Para que ocorra o florescimento da cana é necessário a ocorrência de uma sequência de dias com temperaturas mínimas acima de $18^{\circ} \mathrm{C}$ e máximas abaixo de $31^{\circ} \mathrm{C}$ no

${ }^{4}$ FAUCONIER, R. \& BASSEREAU, D. La caña de azucar. Barcelona, Blume, 1975. $433 \mathrm{p}$. 
período indutivo, conforme concluíram PEREIRA et alii (1983), quando estudaram os efeitos da temperatura sobre 0 florescimento da cana-de-açúcar, variedade NA56-79, para a regiāo de Araras-SP.

A ação da temperatura no desenvolvimento da planta pode ser quantificada pelo acúmulo diário da temperatura média descontando-se a temperatura base da cultura. A esse acúmulo de temperatura denomina-se de grausdia, unidades térmicas ou unidades de calor. Neste trabalho utilizar-se-á a nomenclatura de graus-dia e considerar-se-á a temperatura base para a cana-de-açúcar igual a $18^{\circ} \mathrm{C}$.

VILLA NOVA et alii (1972) obtiveram graficamente equações para estimativa do graus-dia em função das temperaturas base, máxima e mínima.

Para estimativa de graus-dia acumulados, MANIERO (1980) utilizou os métodos propostos por VILLA NOVA et alii (1972), por THOM (1954) e o método que utiliza a diferença entre a temperatura média do ar e a temperatura base da cultura. Correlacionou estatisticamente os valores de graus-dia acumulados pelos três métodos citados com a altura da planta, altura do colmo e a área foliar para algumas variedades de cana-de-açúcar, concluindo que o método proposto por VILLA NOVA et alii (1972), foi o que apresentouse mais correlato com o desenvolvimento da cultura. 


\subsubsection{Luz (Radiação e fotoperíodo)}

A cana-de-açúcar é uma das culturas de maior eficiência fotossintética e ponto de saturação Iuminosa elevado. Logo, quanto maior a quantidade de energia luminosa, maior será a taxa de fotossíntese realizada pela planta, ocasionando, maior crescimento e acúmulo de açúcares.

Segundo BARBIERI \& VILLA NOVA (1981), O comprimento do colmo aumenta quando o comprimento do dia varia entre 10 e 14 horas, mas se os fotoperíodos forem muito longos entre 16 e 18 horas, o comprimento do colmo é reduzido.

Um modelo de avaliação do crescimento da canade-açúcar, em função da ação combinada do fotoperíodo e da temperatura média do ar foi testado por VILLA NOVA et alii (1983), para Piracicaba-SP. Concluiram que esse modelo quando comparado com o desenvolvimento vegetativo real, representado pela variação de altura das plantas, mostrou-se bastante viável, para períodos de 30 dias.

Para a maioria das variedades de cana-deaçúcar, são necessárias entre 12 e 12,5 horas de fotoperíodo para a indução do florescimento (PEREIRA et alii, 1983). BARBIERI et alii (1984), apresentaram a épóca de ocorrência desse período favorável para latitudes de $0^{\circ}$ a $30^{\circ} \mathrm{S}$, e mostraram que esse período é maior nas baixas latitudes. 


\subsection{3. Ägua}

Um adequado suprimento de umidade é essencial para o crescimento da cana-de-açúcar e a sua origem pode ser tanto da chuva como da irrigação.

A cultura é cultivada amplamente sob diversos regimes de chuva. Em algumas partes do Peru por exemplo, a chuva é praticamente nula, sendo a cultura de completa dependência de irrigação. Em algumas áreas do Havaí, onde a cana-de-açúcar é cultivada, a média anual de chuva está em torno de $3500 \mathrm{~mm}$.

A cana-de-açúcar necessita em média de 1200 a $1500 \mathrm{~mm}$ de chuva por ano, mas esta quantidade deve ser bem distribuida durante todo ano, sendo importante que a precipitação seja maior no período de crescimento vegetativo e menor durante a época de maturação, pois o período seco ajuda o acúmulo maior de sacarose.

Existe correlação positiva marcante entre a produtividade da cana-de-açúcar e a disponibilidade hídrica, conforme os resultados de PEREIRA Jr. (1984), que estudando - efeito da irrigação na produtividade de três variedades de cana-de-açúcar, concluiu que a irrigação acarretou acréscimos médios na produtividade da cana e de açúcar da ordem de $40 \%$, para as variedades estudadas. TULLER et alii (1987), avaliando o comportamento de três variedades de cana-deaçúcar submetidas à irrigação suplementar, concluíram que 
houve efeito significativo da irrigação na produtividade da cana-da-açúcar em todas as variedades, chegando a obter uma variação na produtividade de $96 \%$ a mais do que a parcela não irrigada.

Os efeitos da seca no desenvolvimento e produtividade da cana-de-açúcar têm sido enfatizadas por vários autores. BRINHOLI (1975), em experimento de campo, estudando nove variedades de cana concluiu que o comportamento, em relação à seca, foi diferente nas diversas variedades e que a maior ou menor resistência das plantas à seca foi afetada pela idade. Estudando o comportamento à seca de três variedades de cana-de-açúcar, com a finalidade de determinar as variações do estado hídrico da planta, SANTos FILHO (1984) mostrou que as respostas das plantas foram semelhantes com relação à diminuição do crescimento à medida que o déficit hídrico se desenvolveu e tal comportamento foi associado à maior ou menor diminuição do potencial da água da folha. ROSENFELD (1989), estudando o comportamento da canade-açúcar quando submetida a período de deficiência hídrica acentuada em diversos estádios de crescimento e diferentes épocas do ano, concluiu que o início do estádio de máximo desenvolvimento da cana planta é o período mais sensível à déficit hídrico.

A evapotranspiração corresponde ao volume de água evaporada pela superfície do solo mais o transpirado pela planta. Essa perda de água pela cultura durante seu 
ciclo vegetativo é função de sua área foliar, estádio fisiológico e densidade do sistema radicular; sendo definida como evapotranspiração real. Quando a perda de água é de uma superficie plana coberta de grama em solo na capacidade de campo, denomina-se evapotranspiração potencial. Na prática a evapotranspiração real é também chamada de evapotranspiração da cultura. $\bar{E}$ de grande importância o conhecimento da evapotranspiração real para projetos de irrigação, pois representa a quantidade de água que deve ser adicionada ao solo para que seja mantido o crescimento e a produção em condições ideais, mas sua determinação é difícil, podendo acarretar muitos erros. Por isso, utiliza-se estimativas da evapotranspiração potencial para gramado, corrigidas por um coeficiente de cultura (Kc). Esse coeficiente de ajuste representa o quociente entre a evapotranspiração da cultura e a evapotranspiração potencial, sendo variável com o estádio de desenvolvimento. DOORENBOS \& KASSAN (1979) apresentaram os valores de Kc para a cana-de-açúcar em diferentes etapas do desenvolvimento, sendo que estes valores variam de 0,4 a 1,30, dependendo do estádio de desenvolvimento. BARBIERI (1981) determinou valores de Kc para a cana-de-açúcar, ao longo do ciclo, em relação à diferentes métodos de estimativa da evapotranspiração potencial e mostrou que os valores de Kc encontrados pelos diferentes métodos não diferiram estatisticamente entre si. 
Segundo CAMARGO (1962), a evapotranspiração potencial pode ser definida como a precipitação teoricamente necessária às plantas, ou como a chuva ideal para atender às necessidades de água da superfície vegetada de forma a não provocar nem excedentes nem deficiências de umidade no solo. A evapotranspiração da cana-de-açúcar tem sido estimada por diversos autores. TULLER et alii (1981), em experimento de campo, determinaram a evapotranspiração da cana-de açúcar em diferentes níveis de água do solo em Campos-RJ, utilizando a equação apresentada por SLATYER e $^{5}$ correlacionaram-na com a evaporação do tanque classe A e com outros métodos empiricos, Encontrando como valores médios da evapotranspiração medida $3,5,3,6$ e 3,7mm/dia para a cana planta, soca e ressoca, respectivamente e valores médios de Kc de $0,79,0,84$ e 0,87 para a cana planta, soca e ressoca, respectivamente.

Para a contabilização da quantidade de água retida no solo, utiliza-se o balanço hídrico. Um dos métodos de cálculo do balanço hídrico mais utilizado é o de THORNTHWAITE \& MATHER (1955), devido a facilidade na obtenção dos parâmetros climáticos utilizados no seu procedimento.

${ }^{5}$ SLATYER, R.O. Methodology of a water balance study conducted on a desert woodland (Acacia anema F. Moell) community in Central Austrália, 1967. UNEsCo. Arid Zone Res., 16:15-16. 


\section{2 .4 . Vento}

o vento quando considerado em microescala, influi diretamente no crescimento e desenvolvimento das culturas. Os ventos locais alteram a umidade do ar e do solo e são influenciados pela topografia da área cultivada.

WARREN \& WADSWORTH ${ }^{6}$, citado por BISWAS (1988), observaram que ventos com velocidade próxima de $30 \mathrm{~cm} / \mathrm{s}$, ajudam a cana a alcançar seu crescimento máximo, enquanto que velocidades superiores tendem a reduzir a taxa de crescimento. Ventos fortes prejudicam a cultura provocando o acamamento, especialmente quando a cultura está completamente desenvolvida, pois esta provoca uma resistência ao movimento do ar.

\subsubsection{Fatores adversos que afetam a produtividade}

Alguns dos fatores meteorológicos adversos importantes que afetam o cultivo da cana-de-açúcar são inundações, seca, geada e granizo. Mais recentemente, estudos têm sido feito sobre o impacto do El Niño na produção de açúcar mundial, sendo mostrado que o evento El Niño ocorrido

${ }^{6}$ WARREN, W.J. , \& WADSWORTH, R.M., 1958: The effect of wind speed on assimilation rate: a reassessment. Annals of Botany, $22,285-290$. 
em 1972/73 resultou em redução significativa na produção da cana-de-açúcar na Índia, África do Sul e Austrália. Em 1983, provocou seca no sul e oeste da África, Austrália e Índia, e inundações no sul da China e em partes da América do sul prejudicando a cana-de-açúcar. O El Niño 1991/92 começou fraco, mas desde dezembro de 1991 tem mostrơ aumento na sua severidade. Isto deverá ter importantes implicações para a produção de cana-de-açúcar de 1992/93 (MARCUS, 1992).

\subsection{Modelos agrometeorológicos de estimativa de produtividade.}

Um modelo matemático é a representação quantitativa das hipóteses feitas à respeito do sistema real. os modelos matemáticos podem ser excelentes mecanismo de previsão. A experiência tem mostrado que o modelo deve ser suficientemente simples para permitir sua manipulação e entendimento; e suficientemente complexo para permitir extrapolação das conclusões (PEREIRA, 1987).

Os modelos têm muitas utilizações práticas nas atividades agrícolas e agrometeorológicas. Cartas e mapas dos resultados de vários modelos têm sido usados para planejamento de uso da terra e zoneamento agrícola. Os modelos têm sido utilizados também para caracterizar a duração dos ciclos das culturas, permitindo assim planejamento das semeaduras e monitoramento das épocas de 
colheita, e estimativa de produção de safra baseado nos efeitos de vários elementos meteorológicos (ROBERTSON, $1983 b)$.

Diversas aproximaçōes têm sido sugeridas para modelar o efeito da variabilidade climática na produção vegetal. Neste trabalho comentar-se-á apenas as aproximações feitas por ROBERTSON (1983a) que definiu três tipos de modelos agroclimáticos:

a) modelo empirico-estatistico, em que as variáveis meteorológicas correspondem normalmente às condições pluviométricas reinantes durante o ciclo da cultura, como no trabalho de FISHER (1924), que desenvolveu uma técnica estatística especial para analisar a influência da chuva na produção de trigo em Rothamsted, na Inglaterra. A referida técnica leva em conta não somente o total de precipitação em um determinado período, mas também a sua distribuição.

b) modelo físico-estatistico, onde se procura descrever matematicamente os processos envolvidos na formação do rendimento da cultura através de análises de regressão, como o trabalho de BAIER (1973), usando o modelo para avaliação do rendimento do trigo de primavera no Canadá.

A desvantagem principal nà utilização de equaçōes Iineares de regressão é que os efeitos das variávíleis são considerados independentemente, enquanto na natureza existe interações entre precipitação, radiação solar 
e temperatura. Existe ainda o perigo de que tais relações sejam usadas fora dos limites para os quais foram determinados. Extrapolaçōes conduzem a resultados não confiáveis.

c) modelo dinâmico, que se diferencia dos demais através do grau de detalhamento individual para cada processo envolvido, necessitando ainda de um número muito maior de informações climatológicas, como o trabalho de SPLINTER (1974) em milho.

os modelos dinâmicos, também denominados de matemáticos-fisiológicos, são baseados nos processos fisiológicos e foram desenvolvidos visando-se simular o crescimento e o desenvolvimento das culturas.

A aplicação de alguns modelos de estimativa da produtividade será apresentada a seguir englobando tanto modelos estatísticos como modelos fisiológicos.

Utilizando como variáveis evapotranspiração, temperatura, insolação e umidade do ar, OMETTo (1974), aplicando o método de análise de regressão múltipla, encontrou uma equação para a previsão de rendimento agrícola e outra para rendimento industrial para a cana-de-açúcar na região de Piracicaba/SP.

DOORENBOS \& KASSAN (1979), apresentaram dois métodos que permitem quantificar a produtividade potencial de distintas regiões determinando assim as mais convenientes para a produtividade de um dado cultivo. Os dois métodos 
utilizam-se do conceito de De WIT (1965), o qual também é a base do presente estudo, e propuseram também um método para estimar a produtividade, o qual quantifica o efeito da falta de água no solo sobre o decréscimo da produtividade.

A partir de informações meteorológicas, MACHADO (1981) desenvolveu um modelo matemático-fisiológico para simular o acúmulo de matéria seca na cultura de cana-deaçúcar, mostrando que o modelo obteve um resultado teórico consistente com os resultados obtidos experimentalmente, embora nas fases inicial e final do desenvolvimento da cultura, o modelo subestime ligeiramente os resultados e na fase intermediária superestime.

SEGOVIA \& ANDRADE (1982) propuseram um modelo que evidencia a redução da produtividade máxima de uma cultura qualquer, quando a umidade do solo se afasta da que seria considerada ideal. o principal objetivo dos autores foi - de explicar as variações que uma cultura apresenta em sua produtividade, considerando-se os valores da precipitação pluvial. Tal modelo permite assim estimar as variações na safra, uma vez que se conheça a distribuição da precipitação e os limites de água disponível no solo que afetam o desenvolvimento da cultura.

Um modelo matemático-fisiológico para simulação dinâmica diária do crescimento da cana-de-açúcar foi desenvolvido por PEREIRA \& MACHADO (1986). O SIMCANA, como é denominado, condensa praticamente todos os conhecimentos 
sobre os processos fisiológicos da cultura da cana-de-açúcar. Através da radiação solar global, da temperatura máxima e mínima e da umidade do ar, o SIMCANA estima as taxas de fotossíntese, de respiração e de crescimento da cultura, as taxas de senescência das folhas e das raízes, a massa seca das folhas, dos colmos e das raizes e o índice de área foliar.

SILVA et alii (1987) apresentaram previsões dos rendimentos de diversas culturas, obtidas através de modelos estatísticos com variáveis climáticas, comparando-as interativamente com levantamento de campo. Os resultados indicaram que, via de regra, é possível obter boas indicações sobre a adaptação desses modelos às culturas anuais.

Desenvolvendo um modelo a ser utilizado na précolheita para a previsão do rendimento da cana-de-açúcar através de técnica de regressão múltipla e na seleção das características do rendimento utilizando a técnica de regressão Stepwise, SINGH \& BAPAT (1988) observaram que o número de canas, a altura da planta e o diâmetro da cana podem ser usados para a previsão de rendimento da cana-deaçúcar em torno de quatro meses antes da colheita.

GUPTA \& SINGH (1988) estabeleceram uma equação de regressão linear múltipla para estimativa da produtividade da cana-de-açúcar (cv.co.419), baseada em dados de produtividade, em dados do início dos diferentes estádios fenoló- 
gicos, dados semanais de temperatura máxima e mínima, duração do brilho solar, chuva, número de dias de chuva, sendo previsto valores de rendimento de 120,1 e 128,4 ton/ha e o rendimento real foi 134,3 e 138,3 ton/ha, respectivamente.

Estudos foram conduzidos por INMAN-BAMBER \& THOMPSON (1989) sobre o acúmulo de matéría seca no crescimento da cana-de-açúcar sem restrição de água e fertilizantes. Eles validaram dois modelos de fotossíntese e respiração e desenvolveram um modelo simples para as variedades N.C0.376 e N.14. Mostraram que os modelos ajustaram bem para a variedade N.C0.376 e indicaram que a eficiência fotossintética total desse cultivar está entre 8,2 $-8,8 \%$ da radiação fotossinteticamente ativa, pelo menos quando a cultura é jovem. A respiração de manutenção apresentou-se em torno de $0,3 \%$ da massa seca. Mas eles afirmam que muitos aspectos dos modelos requerem novas validações e refinamentos e concluem que os modelos podem ser usados para cálculo de produtividade potencial em relação a diferentes plantios e variações espaciais e temporais da radiação solar.

Um trabalho para avaliação do rendimento potencial da cana-de-açúcar foi apresentado por MUCHOW et alii (1991) em diferentes locais da Austrália. Calcularam os rendimentos de cana (ton/ha) para ciclos de 18 e 12 meses, usando dados de temperatura e radiação solar. A conclusão principal a que chegaram foi que a cana planta é 
biologicamente menos eficiente que a soca, mas dá alta produtividade por apresentar um ciclo maior e consequentemente maior acúmulo de energia.

O modelo matemático-fisiológico proposto por De WIT (1965) foi modificado por VILLA NOVA \& BARBIERI (1991), para a cultura da cana-de-açúcar. Esse modelo apresenta uma equação para relacionar a produtividade mensal de fitomassa e alguns elementos climáticos (as temperaturas extremas do ar, o fotoperíodo, a insolação) aliados a indices de déficit hídrico ao longo do ciclo. Aplicando esse modelo para a região de Araras/SP, com onze anos de dados experimentais de produção de cana irrigada, concluíram que o modelo adotado sugere uma razoável consistência, visto que, com o modelo estimou-se a produção de cana irrigada de 138 ton/ha e os dados experimentais mostram que a produção oscilou entre 132 e 140 ton/ha.

Neste trabalho é aplicada a metodologia proposta por De WIT (1965) e modificada por VILLA NOVA \& BARBIERI (1991) visando a estimativa da produtividade potencial da cana-de-açúcar e a sua aplicação para o Estado do Rio de Janeiro. 


\section{MATERIAL E MÉTODO}

\subsection{Material utilizado}

\subsubsection{Dados meteorológicos.}

Os dados meteorológicos mensais foram obtidos das estações meteorológicas pertencentes ao centro Regional de Meteorologia e Climatologia do Rio de Janeiro (CRMC/RJ) do Instituto Nacional de Meteorologia (INMET) e da publicação NORMAIS CLIMATOLÓGICAS (1961 - 1990).

A localização das estações meteorológicas, assim como o período estudado encontram-se na tabela 1 , e na figura 1 é apresentada a localização das estações meteorológicas nas regiões agroclimatológicas do Estado do Rio de Janeiro.

Os dados meteorológicos utilizados no trabalho foram temperaturas extremas (máxima e mínima), temperatura média, insolação e fotoperíodo. Estes dados se encontram nas tabelas de 2 a 10 .

Do Zoneamento Agroclimático da cana-de-açúcar (regiões aptas) do Estado do Rio de Janeiro, selecionou-se as estações meteorológicas a serem usadas no estudo (Figura 2). 
Tabela 1: Relação das estaçōes meteorológicas utilizadas

\begin{tabular}{|c|c|c|c|c|c|}
\hline & ESTAÇÕES & UF & LATITUDE (S) & LONGITUDE (W) & PERÍODO \\
\hline 12 & ANGRA DOS REIS & $\mathrm{RJ}$ & $23^{\circ} 01^{\prime}$ & $44^{\circ} 19^{\prime}$ & $61 / 90$ \\
\hline 21 & BANGU & $\mathrm{RJ}$ & $22^{\circ} 52^{\prime}$ & $43^{\circ} 28^{\prime}$ & $61 / 90$ \\
\hline $3 c$ & CABO FRIO & $\mathrm{RJ}$ & $22^{\circ} 59^{\prime}$ & $42^{\circ} 02^{\prime}$ & $70 / 87$ \\
\hline 4 & C. ITAPEMIRIM & ES & $20^{\circ} 51^{\prime}$ & $41^{\circ} 06^{\prime}$ & $61 / 90$ \\
\hline 5 & CAMPOS & RJ & $21^{\circ} 45^{\prime}$ & $41^{\circ} 20^{\prime}$ & $61 / 90$ \\
\hline 6 & CATAGUASES & MG & $21^{\circ} 23^{\prime}$ & $42^{\circ} 41^{\prime}$ & $61 / 79$ \\
\hline 7 & ECOL. AGRÍCOLA & $\mathrm{RJ}$ & $22^{\circ} 46^{\prime}$ & $43^{\circ} 41^{\prime}$ & $61 / 90$ \\
\hline $8:$ & ILHA GUAÍBA & $\mathrm{RJ}$ & $23^{\circ} 00^{\prime}$ & $44^{\circ} 02^{\prime}$ & $72 / 90$ \\
\hline 9 & ITAPERUNA & RJ & $21^{\circ} 12^{\prime}$ & $41^{\circ} 53^{\prime}$ & $68 / 90$ \\
\hline 10 & MACAÉ & RJ & $22^{\circ} 33^{\prime}$ & $41^{\circ} 46^{\prime}$ & $79 / 90$ \\
\hline 11 & MARAMBAIA & RJ & $23^{\circ} 03^{\prime}$ & $43^{\circ} 36^{\prime}$ & $84 / 90$ \\
\hline 12 & PIRAÍ & $\mathrm{RJ}$ & $22^{\circ} 38^{\prime}$ & $43^{\circ} 54^{\prime}$ & $61 / 90$ \\
\hline 13 & RIO DE JANEIRO & $\mathrm{RJ}$ & $22^{\circ} 55^{\prime}$ & $43^{\circ} 10^{\prime}$ & $73 / 90$ \\
\hline 14 & SANTA CRUZ & $\mathrm{RJ}$ & $22^{\circ} 55^{\prime}$ & $43^{\circ} 40^{\prime}$ & $64 / 90$ \\
\hline 15 & 5 SÃO FIDELIS & $\mathrm{RJ}$ & $21^{\circ} 39^{\prime}$ & $41^{\circ} 15^{\prime}$ & $73 / 90$ \\
\hline 16 & 5 UBATUBA & $S P$ & $24^{\circ} 26^{\prime}$ & $45^{\circ} 06^{\prime}$ & $61 / 90$ \\
\hline 17 & 7 VASSOURAS & RJ & $22^{\circ} 20^{\prime}$ & $43^{\circ} 40^{\prime}$ & $61 / 90$ \\
\hline
\end{tabular}

Fonte: INMET 


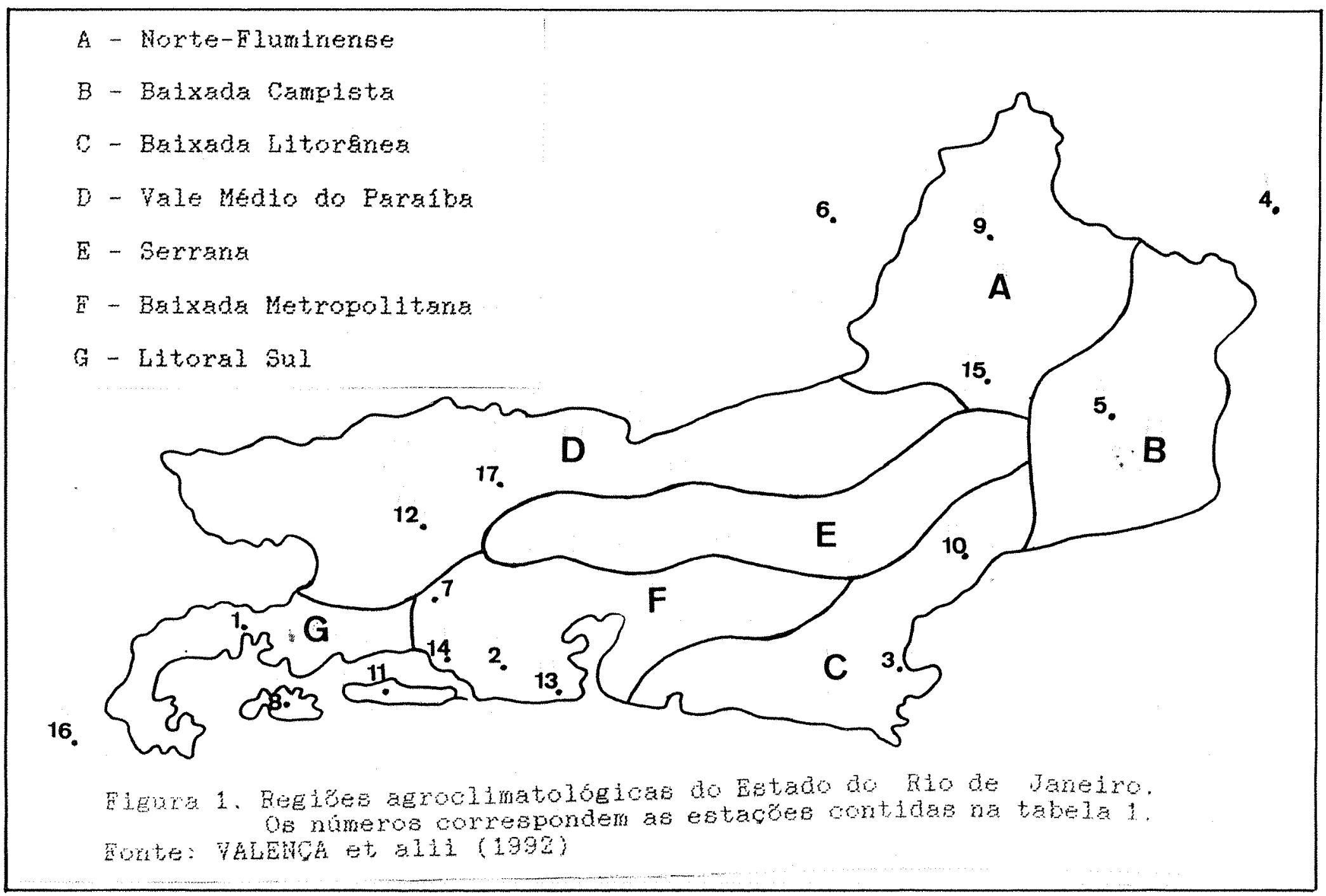




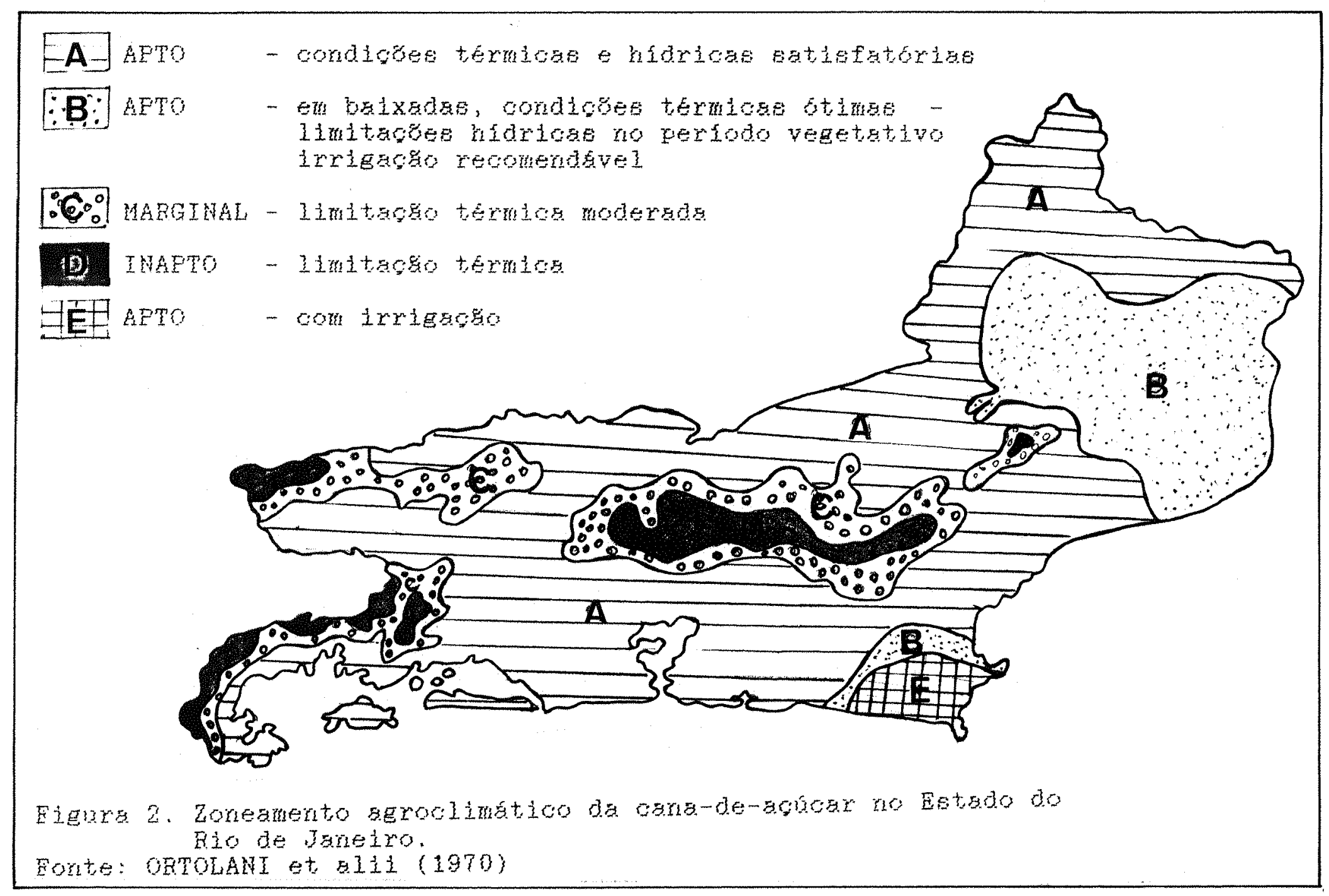




\subsubsection{Dados de produtividade}

Utilizou-se os dados de produtividade da canade-açúcar da localidade de Campos/RJ, com a finalidade de validar o modelo. Os dados de produtividade utilizados correspondem aos de cana irrigada para o periodo de abril/77 a setembro/78 para o ciclo de is meses e de setembro/78 a agosto/79 para o ciclo de 12 meses, dados estes encontrados por TULLER (1987), em experimento de campo. Estes dados encontram-se na tabela 11.

\subsection{Modelo utilizado}

- modelo aplicado, neste trabalho, parte do conceito de De WIT (1965), onde a produtividade bruta é ponderada pelas condições de nebulosidade, ou seja, pela disponibilidade de energia solar, isto é,

$$
P_{p}=F \cdot Y_{0}+(I-F) \cdot Y_{c}
$$

onde: $\mathrm{P}_{\mathrm{p}}=$ produção bruta de matéria seca de um determinado cultivo ( $\mathrm{kg} \mathrm{CH}_{2} \mathrm{O} / \mathrm{ha}$.dia);

$$
\begin{aligned}
\mathrm{F}= & \text { fração do tempo em que o dia está nublado; } \\
\mathrm{Y}_{0}= & \text { produção de matéria seca bruta em condições de } \\
& \text { céu encoberto ( } \mathrm{kg} \mathrm{CH}_{2} \mathrm{O} / \mathrm{ha} \cdot \text { dia); } \\
\mathrm{Y}_{0}= & \text { produção de matéria seca bruta em condições de } \\
& \text { céu claro }\left(\mathrm{kg} \mathrm{CH}_{2} \mathrm{O} / \mathrm{ha}\right. \text {.dia). }
\end{aligned}
$$


Essa equação, completada pelas correções de temperatura (CT), de índice de área foliar (CL) e de respiração de manutenção (r) permite estimar a produção potencial corrigida $\left(P_{p c}\right)$ de uma cultura, desde que esta esteja em condições ótimas de água disponível e de nutrientes e sem ocorrência de pragas e doenças.

No presente trabalho, a estimativa será feita para o período de um mês e serão utilizados valores médios mensais. Desse modo, facilita-se a aplicação do modelo visando o zoneamento da produtividade potencial visto que valores diários são disponíveis apenas para algumas localidades. Optou-se pela utilização de outras estações além das contidas nas normais climatológicas para que um número maior de localidades pudesse ser utilizado melhorando sobremodo o zoneamento.

As modificações feitas por VILLA NOVA \& BARBIERI (1991), para a cultura da cana-de-açúcar, encontramse na equação:

$$
P_{p c}=\left(F \cdot Y_{0}+(1-F) \cdot Y_{c}\right) \cdot N D \cdot C T \cdot C L \cdot I
$$

onde: $\mathrm{ND}=$ número de dias do mês;

Esta equação dá a produção de matéria seca bruta corrigida em $\mathrm{kg}$ de $\mathrm{CH}_{2} \mathrm{O} / \mathrm{ha}$. mês, e precisa ser convertida em matéria seca elaborada. Para tanto, é necessário multiplicá-la por um fator de conversão, que leva em consideração a qualidade da matéria seca formada, isto é, sua 
composição química. No caso da cana-de-açúcar, onde predomina a presença de carboidrato, MACHADO (1981) determinou que são necessários $1,27 \mathrm{~g}$ de $\mathrm{CH}_{2} \mathrm{O}$ fotossintetizado para produzir $1 \mathrm{~g}$ de matéria seca.

\subsubsection{Fator F}

o fator $F$ corresponde à fração do dia em que o tempo está nublado e é dado pela seguinte expressão:

$$
F=\left(1-\frac{I N S}{N}\right)
$$

onde: INS = insolação média (brilho solar) do mês (horas); $\mathrm{N}$ = fotoperíodo ou duração média do dia (horas)

\subsubsection{Produção média de matéria seca bruta em $\mathrm{kg}$ $\mathrm{CH}_{2} \mathrm{O} / \mathrm{ha} \cdot \mathrm{dia}$}

A produção média mensal de matéria seca bruta tanto em condições de céu claro $\left(Y_{c}\right)$ como em condições de céu encoberto $\left(Y_{0}\right)$ é dada em tabelas por De WIT (1965) em função da latitude. Para facilitar os cálculos, VILLA NovA \& BARBIERI (1991) utilizaram equações que substituem as tabelas.

Sob condições de céu encoberto, a produção média mensal de matéria seca bruta é dada pela equação 


$$
Y_{0}=409,1 \cdot \operatorname{In} \frac{\left(1+0,001305 \cdot \frac{Q_{0}}{N}\right)}{\left(1+0,000065 \cdot \frac{Q_{0}}{N}\right)} \cdot N
$$

onde: In = logarítimo neperiano;

$$
\begin{aligned}
Q_{0}= & \text { radiação solar extraterrestre média } \\
& \left(\mathrm{cal} / \mathrm{cm}^{2} \cdot d i a\right) ; \\
N= & \text { fotoperíodo médio em horas. }
\end{aligned}
$$

Para um dia totalmente claro, a produção média mensal de matéria seca bruta pode ser estimada através da equação

$$
Y_{C}=409,1 \cdot \ln \frac{\left(1+0,003479 \cdot \frac{Q_{0}}{N}\right)}{\left(1+0,0001732 \cdot \frac{Q_{0}}{N}\right)} \cdot N
$$

\subsubsection{Fator de correção de temperatura (CT)}

A taxa de fotossintese em plantas de cana-deaçúcar aproximadamente dobra a cada aumento de $10^{\circ} \mathrm{C}$, em temperaturas variando de 15 a $30^{\circ} \mathrm{C}$, segundo medidas efetuadas por GLOVER (1974) em plantas inteiras.

MACHADO (1981), construiu um gráfico do efeito instantâneo da temperatura do ar sobre a fotossíntese, onde se verifica que entre as temperaturas de 30 e $35^{\circ} \mathrm{C}$, o fator é 1,0 (fotossíntese máxima), de 0 a $12^{\circ} \mathrm{C}$ o fator é 0,0 e entre 
12 e $30^{\circ} \mathrm{C}$, o fator é descrito por uma equação, que neste trabalho é dado pela seguinte expressão:

$$
C T=0,0495 . T M D-0,51
$$

onde: $\mathrm{TMD}=$ temperatura média mensal $\left({ }^{\circ} \mathrm{C}\right)$

\subsubsection{Fator de correção do indice de área foliar (CL)}

É aplicado devido a diferentes intensidades de radiação solar que interage com o dossel vegetativo, pois a taxa de fotossintese é menor nas folhas inferiores que nas superiores, pois com o sombreamento as folhas inferiores recebem menos radiação. A taxa de fotossíntese total de uma comunidade aumenta com o índice de área foliar (IAF), mas em razão do autossombreamento, há um declínio na taxa de fotossíntese média por unidade de área foliar. Este declínio é compensado, até determinado limite, pelo contínuo aumento no IAF. Foi utilizada a equação dada por VILLA NOVA \& BARBIERI (1991) .

$$
C L=[1-\exp (-0,8 . I A F)]
$$

- IAF representa a superfície disponível para a fotossintese, isto é, o tamanho do apareiho transformador da energia solar em carboidratos. Sua evolução com a idade da cultura foi estimada em função do graus-dia. Dessa forma, substitui-se a escala temporal (dias) pela escala térmica 
(GDC), pois dias com condiçōes térmicas diferentes têm efeitos distintos sobre os processos fisiológicos. Utilizando dados de MACHADO (1981) foi encontrada a seguinte equação.

$$
I A F=4,093-\left(\frac{555,16}{S G D C}\right)
$$

onde: $\operatorname{SGDC}=$ somatório dos graus-dia corrigido em função do fotoperíodo desde a data do plantio.

Para o cálculo mensal de graus-dia foi utilizada a seguinte fórmula:

$$
G D=N D\left(T M D-T_{b}\right)
$$

onde: $\mathrm{GD}=$ graus-dia acumulado no mês;

$$
\begin{aligned}
\mathrm{T}_{\mathrm{b}}=\text { temperatura base para a cana-de-açúcar (igual a } \\
\left.18^{\circ} \mathrm{C}\right) .
\end{aligned}
$$

Para os casos em que a TMD foi menor que $18^{\circ} \mathrm{C}$ calculou-se os graus-dia pelo método proposto por VILLA NOVA et alii (1972), usando a seguinte expressão:

$$
G D=N D \cdot \frac{\left(T X-T_{b}\right)^{2}}{2(T X-T M)}
$$

onde: $\mathrm{TX}=$ média das temperaturas máximas diárias do mês $\left({ }^{\circ} \mathrm{C}\right)$ $\mathrm{TM}=$ média das temperaturas mínimas diárias do mês $\left({ }^{\circ} \mathrm{C}\right)$ Graus-dia pode ter efeito tanto amplificador como redutor. Isso depende das condições do fotoperíodo, isto é, se o fotoperíodo for crescente durante o mês, então, graus-dia terá efeito amplificador sobre o processo fisiológico. Se, ao contrário, o fotoperíodo estiver 
decrescendo durante o mês, daí o efeito será redutor. Para levar esse fato em consideração VILLA NOVA $(1992)^{7}$ sugere a utilização de uma correção que é dada pela seguinte expressão:

$$
G D C=G D \cdot C
$$

onde: $\mathrm{C}=$ fator de correção.

$$
\begin{gathered}
C \text { é dado pela seguinte equação: } \\
\qquad \begin{array}{c}
C=\left(\frac{N_{f}}{N_{i}}\right)^{2}
\end{array}
\end{gathered}
$$

onde: $N_{f}=$ fotoperiodo do último dia do mês;

$N_{i}=$ fotoperíodo do primeiro dia do mês.

Para aplicação do modelo foi utilizado o índice de área foliar médio do período (IAFM), calculado pela média aritmética do IAF do mês e o IAF do mês anterior. Isso porque - IAF calculado pela equação (8), superestima o valor do IAF no início e no fim do ciclo da cultura. Tal equação é válida para valores de SGDC > 120. Para valores menores, O IAF é considerado igual a zero.

\footnotetext{
${ }^{7}$ VILLA NOVA, N.A. (ESALQ/USP - Departamento de Física e Meteorologia), comunicação pessoal, 1992.
} 
3.2.5. Fator de correção da respiração de manutenção (r)

A respiração de manutenção se aplica a matéria seca originária do carboidrato bruto corrigido. ocorre devido ao consumo de energia para manutenção dos processos fisiológicos vitais da planta. A correção de respiração é multiplicativa e expressa por:

$$
I=1-0,01\left(\frac{P_{p c}}{S P_{p c}}\right)
$$

onde: $\mathrm{P}_{\mathrm{pc}}=$ produção bruta de matéria seca corrigida ( $\mathrm{kg} \mathrm{CH}_{2} \mathrm{O} /$ ha.mês)

$$
\mathrm{SP}_{\mathrm{pc}}=\text { produção bruta total de matéria seca corrigida }
$$$$
\text { desde o início do ciclo da cultura }
$$$$
\text { ( } \mathrm{kg} \mathrm{CH}_{2} \mathrm{O} / \mathrm{ha} . \mathrm{ciclo} \text { ). }
$$

Neste trabalho o fator de correção da respiração de manutenção foi considerado igual a 0,99. Mas esta correção deve ser introduzida na produção de matéria seca acumulada em cada período. 
3.3. Teste do modelo

- modelo foi testado para a estação de Campos/RJ para os anos de 1977, 1978 e 1979, correspondendo aos ciclos de 18 meses que foi de abril/77 a setembro/78 e o de 12 meses de setembro/78 a agosto/79. Os resultados encontram-se na tabela 11.

A produtividade potencial estimada para a canade-açúcar no ciclo 77-78, foi de 154,7 ton /ha e para o ciclo 78-79, encontrou-se 102,2 ton/ha.

O modelo foi aplicado em 17 localidades dos Estados do Rio de Janeiro, são Paulo, Minas Gerais e Espirito Santo, para dois ciclos diferentes da cultura (18 e 12 meses). 


\section{RESULTAdos E DISCUSSÃo}

Comparando os valores de produtividade estimada com a produtividade da cana irrigada (tabela 11), para os dois ciclos, verifica-se que estes valores estiveram bem próximos, mostrando a boa consistência do modelo, permitindo assim a extrapolação do mesmo para outras localidades do estado onde não se tem dados disponíveis para comparação.

Os resultados das estimativas da produtividade utilizando o modelo de De WIT (1965), modificado por VILLA NOVA \& BARBIERI (1991), são apresentados separadamente para cada cenário estudado.

\subsection{Aplicação do modelo para as condições médias} normais (1961-1990).

Os resultados encontram-se nas tabelas de 12 a 28 , e nas figuras 3 e 4 .

Analisando os resultados observou-se que os maiores valores de produtividade potencial para os dois ciclos estudados são encontrados no norte fluminense e nas Baixadas Campista, Litorânea e Metropolitana, e os menores são encontrados no Vale médio do paraíba e litoral sul do 
estado. As produtividades potenciais variaram de 123 a 151 ton/ha na cana planta e de 88 a 108 ton/ha na cana soca.

Quando se compara os resultados da produtividade potencial estimada com a produtividade média ocorrida nas diversas regiōes do Estado verifica-se que os valores estimados são bastante superiores a produtividade real, sendo que esta variação chega até mais do dobro em algumas localidades (tabela 29). Os valores estimados superiores ao real é fato esperado porque o modelo estima a produtividade potencial, ou seja, aquela que a cultura não sofre nem deficiência hídrica, nem nutricional e não há ocorrência de pragas e doenças. No campo não acontece a alta produtividade devido a não existência de bons métodos de preparo do solo, de plantio, épocas de plantio e colheita e sobre tudo na utilização adequada da irrigação (SOUZA et alii, 1980)

\subsection{Aplicação do modelo quando há um aquecimento da região.}

Para tal foi necessário elevar a temperatura média mensal de cada localidade em $10 \%$ do seu valor, aumento este que correspondeu a uma elevação de mais de $2,0^{\circ} \mathrm{C}$.

Os resultados são encontrados nas figuras 5 e 6 para os dois ciclos estudados. 
Observou-se um aumento na produtividade potencial em torno de $21 \%$ para a cana com ciclo de 18 meses e de $24 \%$ para a cana de 12 meses (tabela 30).

A produtividade potencial variou de 150 a 182 ton/ha na cana planta e 106 a 134 ton/ha na cana soca.

\subsection{Aplicação do modelo quando há um resfriamento} da região.

Efetuou-se um decréscimo de $10 \%$ na temperatura média mensal em todo o ciclo da cultura, correspondendo um decréscimo de mais de $2,0^{\circ} \mathrm{C}$.

Os resultados encontram-se nas figuras 7 e 8 , para os ciclos de 18 e 12 meses respectivamente.

Analisando os resultados encontrados observa-se que há um decréscimo na produtividade potencial em torno de 26\% tanto para a cana com ciclo de 18 meses como para a de 12 meses (tabela 30).

Os valores de produtividade potencial variaram de 88 a 115 ton/ha na cana planta e de 64 a 83 ton/ha na cana soca. 
Tabela 11. Dados de produtividade de cana irrigada e produtividade estimada da localidade de Campos/RJ, para os períodos de abril/77 a setembro/78 e setembro/78 a agosto/79 em ton/ha.

\begin{tabular}{|c|c|c|c|}
\hline \multirow[t]{2}{*}{ CICLO } & \multirow[t]{2}{*}{ VARIEDADE } & \multicolumn{2}{|c|}{ PRODUTIVIDADE } \\
\hline & & CANA IRRIGADA* & ESTIMADA \\
\hline \multicolumn{4}{|c|}{ 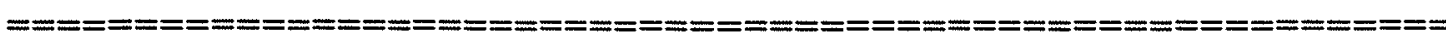 } \\
\hline \multirow{3}{*}{18} & $\mathrm{CB} 45-3$ & 153,8 & \\
\hline & NA56-79 & 143,6 & 154,7 \\
\hline & $\mathrm{CP} 51-22$ & 138,9 & \\
\hline \multirow{3}{*}{12} & CB45-3 & 100,2 & \\
\hline & NA 56-79 & 109,8 & 102,2 \\
\hline & CP51-22 & 99,6 & \\
\hline
\end{tabular}

* Fonte: TULLER (1987). 


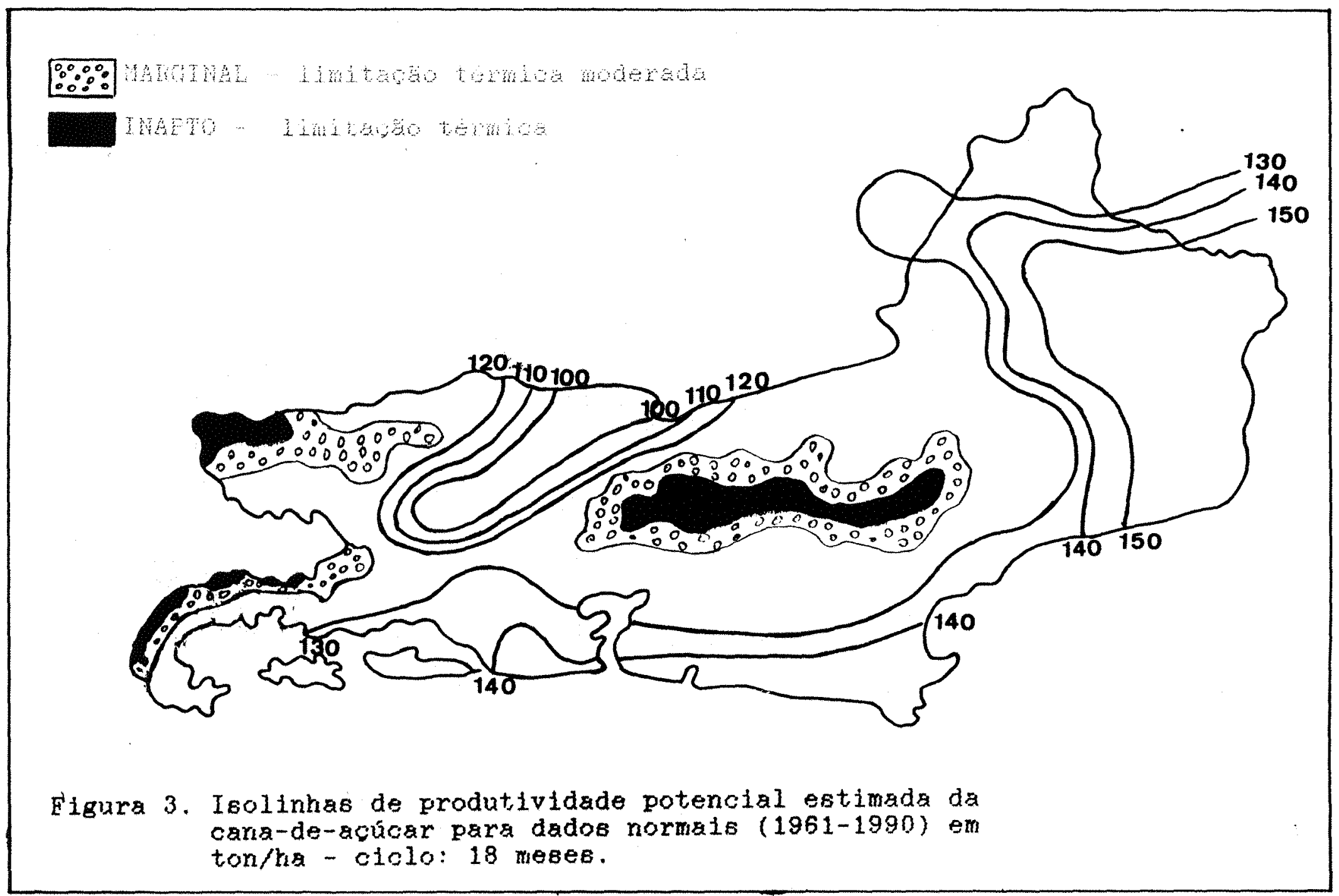




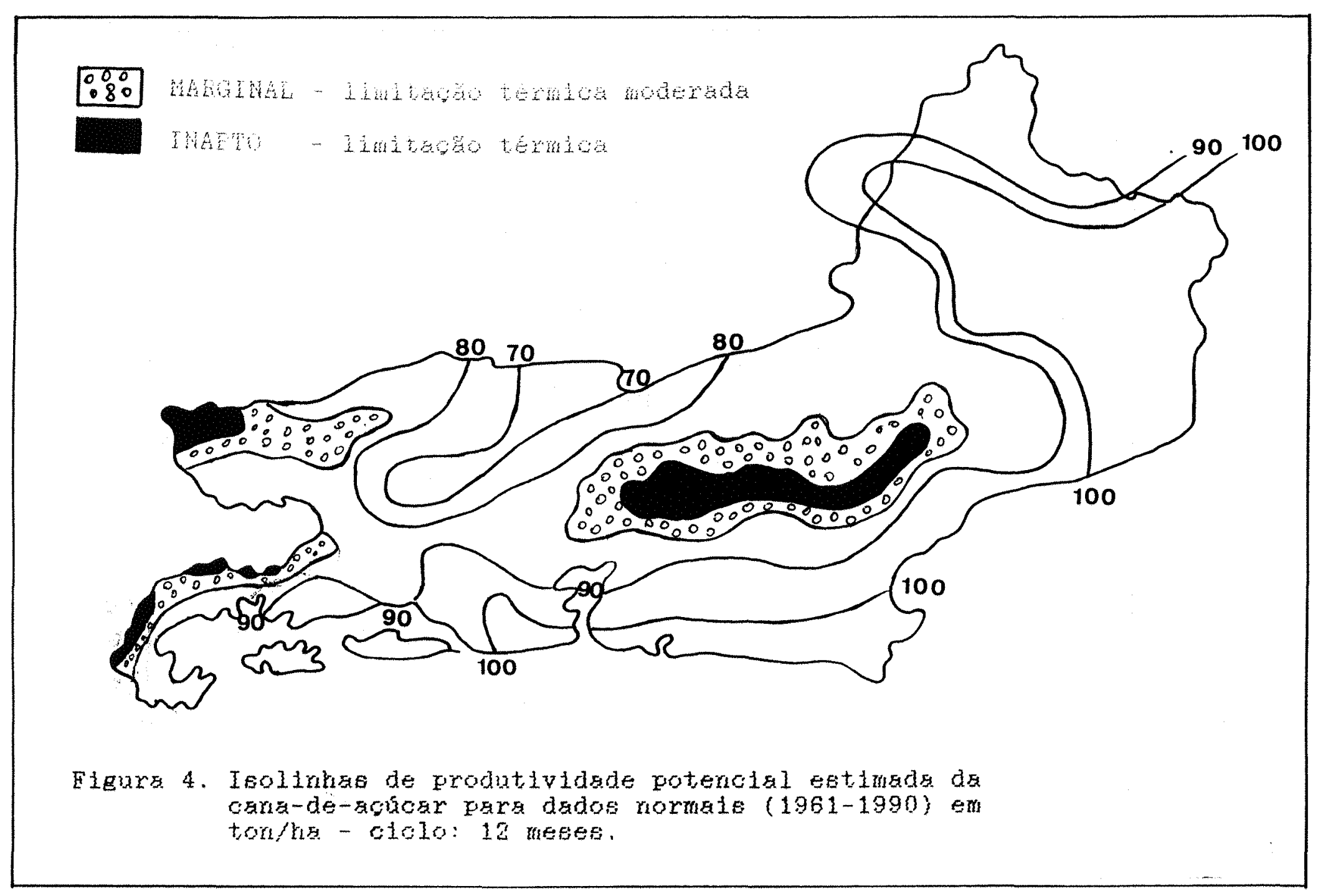




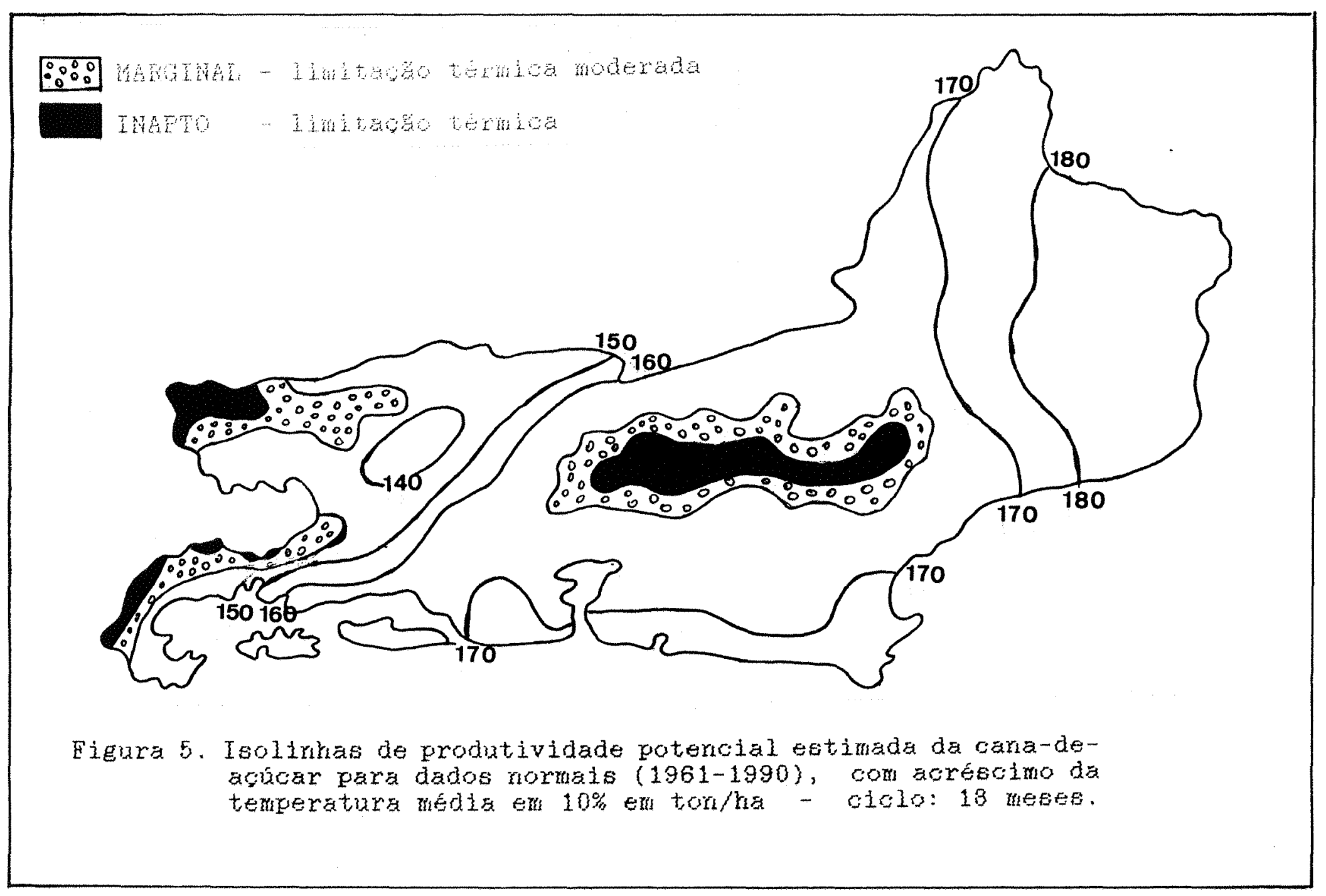




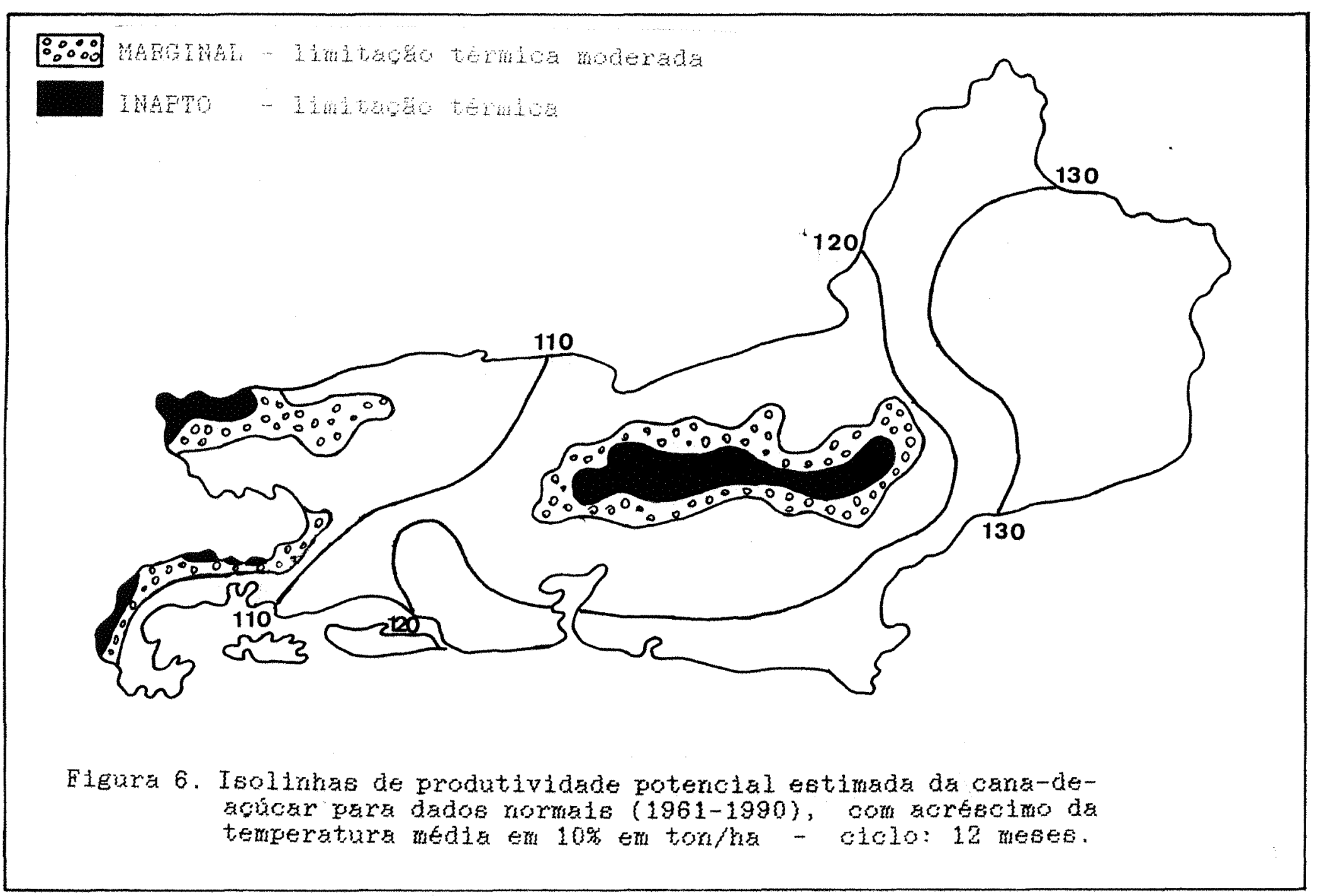




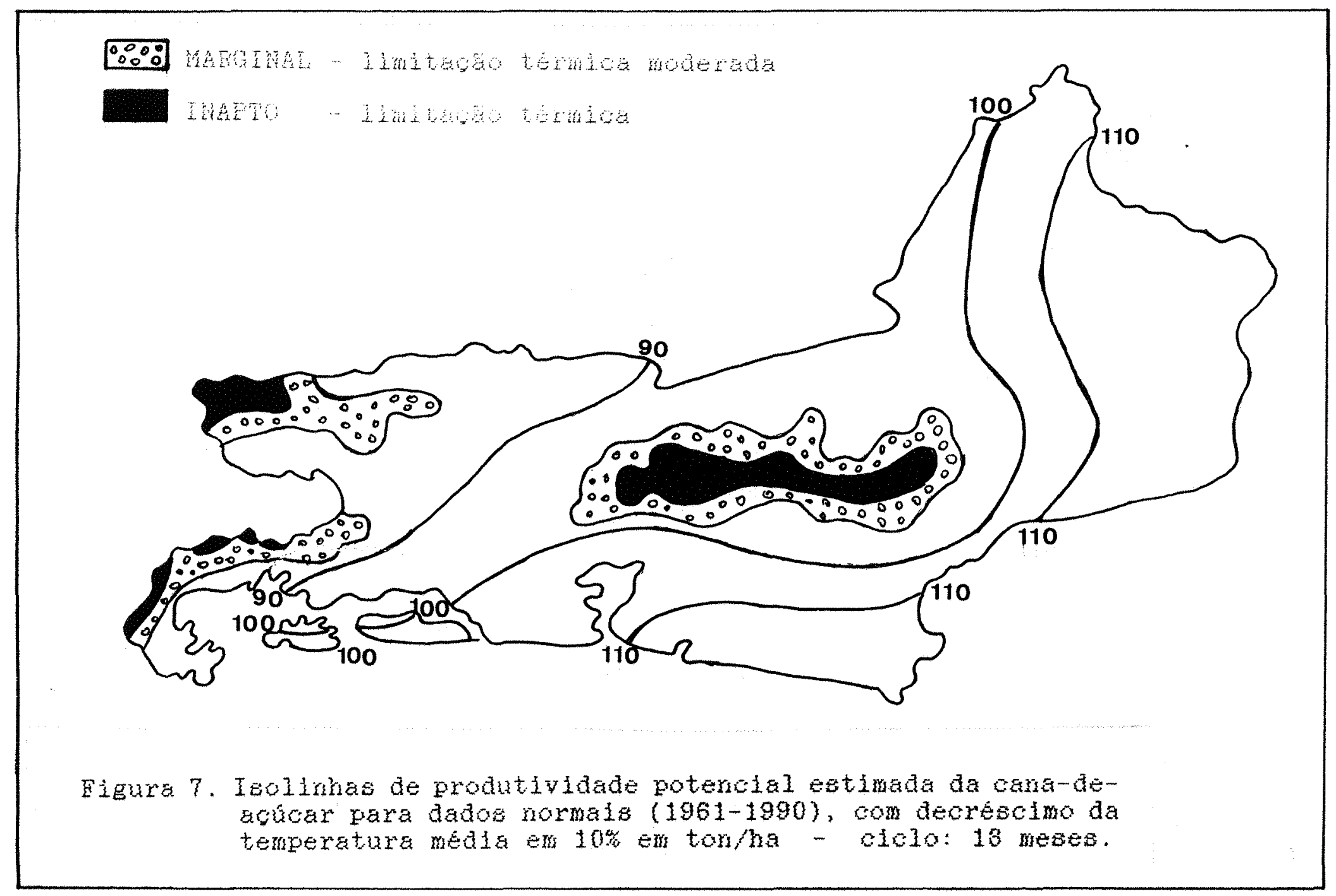




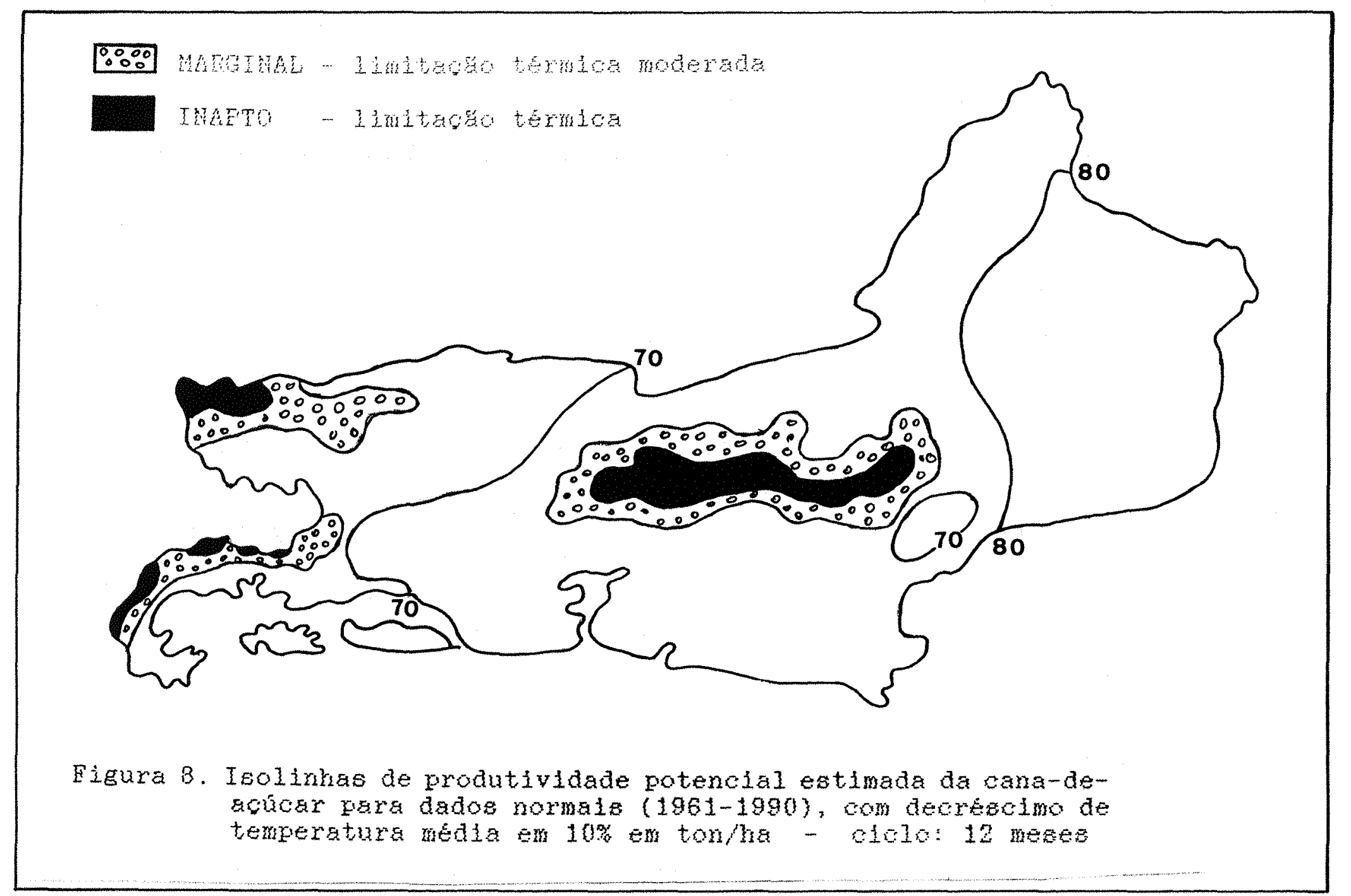


Tabela 12: Produtividade potencial simulada para os dados meteorológicos normais (1961-1990)

LOCAL: ANGRA DOS REIS-RJ

CICLO: 18 meses

\begin{tabular}{lrrrrrrrrrrrr}
\hline \hline MES & $n$ & SGDC & IAF & IAFM & $F$ & Yo & YC & Pp & CT & CL & PpC & SPpC*r \\
\hline \hline ABR & 30 & 162 & 0,67 & 0,34 & 0,57 & 181 & 561 & 10319 & 0,68 & 0,24 & 1645 & 1629 \\
MAI & 31 & 283 & 2,13 & 1,40 & 0,53 & 153 & 478 & 9516 & 0,59 & 0,67 & 3775 & 5349 \\
JUN & 30 & 361 & 2,55 & 2,34 & 0,54 & 138 & 432 & 8234 & 0,51 & 0,85 & 3553 & 8813 \\
JUL & 31 & 433 & 2,81 & 2,68 & 0,52 & 143 & 448 & 8950 & 0,49 & 0,88 & 3872 & 12558 \\
AGO & 31 & 526 & 3,04 & 2,92 & 0,57 & 165 & 515 & 9800 & 0,51 & 0,90 & 4557 & 16944 \\
SET & 30 & 638 & 3,22 & 3,13 & 0,67 & 196 & 604 & 9970 & 0,54 & 0,92 & 4984 & 21708 \\
OUT & 31 & 784 & 3,38 & 3,30 & 0,69 & 223 & 683 & 11303 & 0,59 & 0,93 & 6235 & 27664 \\
NOV & 30 & 958 & 3,51 & 3,45 & 0,67 & 243 & 739 & 12140 & 0,65 & 0,94 & 7428 & 34741 \\
DEZ & 31 & 1173 & 3,62 & 3,57 & 0,69 & 250 & 762 & 12666 & 0,72 & 0,94 & 8624 & 42932 \\
JAN & 31 & 1410 & 3,70 & 3,66 & 0,58 & 249 & 757 & 14400 & 0,78 & 0,95 & 10590 & 52986 \\
FEV & 28 & 1626 & 3,75 & 3,73 & 0,51 & 236 & 718 & 13240 & 0,80 & 0,95 & 10014 & 62370 \\
MAR & 31 & 1841 & 3,79 & 3,77 & 0,53 & 213 & 653 & 13067 & 0,77 & 0,95 & 9533 & 71184 \\
ABR & 30 & 2002 & 3,82 & 3,80 & 0,57 & 181 & 561 & 10319 & 0,68 & 0,95 & 6662 & 77068 \\
MAI & 31 & 2124 & 3,83 & 3,82 & 0,53 & 153 & 478 & 9516 & 0,59 & 0,95 & 5341 & 81585 \\
JUN & 30 & 2201 & 3,84 & 3,84 & 0,54 & 138 & 432 & 8234 & 0,51 & 0,95 & 4002 & 84731 \\
JUL & 31 & 2273 & 3,85 & 3,45 & 0,52 & 143 & 448 & 8950 & 0,49 & 0,94 & 4108 & 87950 \\
AGO & 31 & 2366 & 3,86 & 3,07 & 0,57 & 165 & 515 & 9800 & 0,51 & 0,91 & 4610 & 91634 \\
SET & 30 & 2479 & 3,87 & 2,68 & 0,67 & 196 & 604 & 9970 & 0,54 & 0,88 & 4791 & 95461 \\
\hline
\end{tabular}

Produtividade (kg/ha) : 123145

CICLO: 12 meses

\begin{tabular}{lrrrrrrrrrrrr}
\hline \hline MÊS & $n$ & SGDC & IAF & IAFM & $F$ & Yo & YC & Pp & CT & CL & PpC SPpC*r \\
\hline \hline SET & 30 & 113 & 0,00 & 0,00 & 0,67 & 196 & 604 & 9970 & 0,54 & 0,00 & 000 & 000 \\
OUT & 31 & 258 & 1,94 & 0,97 & 0,69 & 223 & 683 & 11303 & 0,59 & 0,54 & 3623 & 3587 \\
NOV & 30 & 433 & 2,81 & 2,38 & 0,67 & 243 & 739 & 12140 & 0,65 & 0,85 & 6746 & 10230 \\
DEZ & 31 & 648 & 3,24 & 3,02 & 0,69 & 250 & 762 & 12666 & 0,72 & 0,91 & 8336 & 18381 \\
JAN & 31 & 885 & 3,47 & 3,35 & 0,58 & 249 & 757 & 14400 & 0,78 & 0,93 & 10422 & 28515 \\
FEV & 28 & 1100 & 3,59 & 3,53 & 0,51 & 236 & 718 & 13240 & 0,80 & 0,94 & 9922 & 38052 \\
MAR & 31 & 1315 & 3,67 & 3,63 & 0,53 & 213 & 653 & 13067 & 0,77 & 0,95 & 9474 & 47051 \\
ABR & 30 & 1477 & 3,72 & 3,69 & 0,57 & 181 & 561 & 10319 & 0,68 & 0,95 & 6632 & 53146 \\
MAI & 31 & 1598 & 3,75 & 3,73 & 0,53 & 153 & 478 & 9516 & 0,59 & 0,95 & 5321 & 57882 \\
JUN & 30 & 1676 & 3,76 & 3,75 & 0,54 & 138 & 432 & 8234 & 0,51 & 0,95 & 3988 & 61252 \\
JUL & 31 & 1747 & 3,78 & 3,38 & 0,52 & 143 & 448 & 8950 & 0,49 & 0,93 & 4091 & 64689 \\
AGO & 31 & 1841 & 3,79 & 3,00 & 0,57 & 165 & 515 & 9800 & 0,51 & 0,91 & 4585 & 68582 \\
\hline \hline
\end{tabular}

Produtividade (kg/ha): 88470 
Tabela 13: Produtividade potencial simulada para os dados meteorológicos normais (1961-1990)

LOCAL: BANGU-RJ.

CICLO: 18 meses

\begin{tabular}{|c|c|c|c|c|c|c|c|c|c|c|c|c|}
\hline MÊS & $\mathrm{n}$ & SGDC & IAF & IAFM & $F$ & Yo & YC & $\mathrm{Pp}$ & $C T$ & $C L$ & Ppc & $S P p{ }^{*} r$ \\
\hline ABR & 30 & 167 & 0,77 & 0,39 & 0,48 & 181 & 561 & 11380 & 0,69 & 0,27 & 2075 & 2054 \\
\hline MAI & 31 & 282 & 2,13 & 1,45 & 0,42 & 153 & 478 & 10612 & 0,58 & 0,69 & 4215 & 6207 \\
\hline JUN & 30 & 375 & 2,61 & 2,37 & 0,45 & 138 & 432 & 9033 & 0,53 & 0,85 & 4103 & 10206 \\
\hline JUL & 31 & 456 & 2,88 & 2,74 & 0,45 & 143 & 448 & 9624 & 0,50 & 0,89 & 4317 & 14378 \\
\hline AGO & 31 & 588 & 3,15 & 3,01 & 0,42 & 165 & 515 & 11358 & 0,57 & 0,91 & 5883 & 20059 \\
\hline SET & 30 & 741 & 3,34 & 3,25 & 0,53 & 196 & 604 & 11674 & 0,60 & 0,93 & 6523 & 26316 \\
\hline OUT & 31 & 921 & 3,49 & 3,42 & 0,62 & 223 & 683 & 12269 & 0,64 & 0,94 & 7380 & 33359 \\
\hline NOV & 30 & 1123 & 3,60 & 3,54 & 0,56 & 243 & 739 & 13844 & 0,70 & 0,94 & 9093 & 42028 \\
\hline DEZ & 31 & 1367 & 3,69 & 3,64 & 0,58 & 250 & 762 & 14371 & 0,77 & 0,95 & 10426 & 51930 \\
\hline JAN & 31 & 1633 & 3,75 & 3,72 & 0,54 & 249 & 757 & 14937 & 0,83 & 0,95 & 11716 & 63009 \\
\hline FEV & 28 & 1866 & 3,80 & 3,77 & 0,49 & 236 & 718 & 13472 & 0,83 & 0,95 & 10654 & 72927 \\
\hline MAR & 31 & 2098 & 3,83 & 3,81 & 0,45 & 213 & 653 & 14152 & 0,80 & 0,95 & 10742 & 82832 \\
\hline ABR & 30 & 2265 & 3,85 & 3,84 & 0,48 & 181 & 561 & 11380 & 0,69 & 0,95 & 7465 & 89394 \\
\hline MAI & 31 & 2381 & 3,86 & 3,85 & 0,42 & 153 & 478 & 10612 & 0,58 & 0,95 & 5863 & 94304 \\
\hline JUN & 30 & 2473 & 3,87 & 3,86 & 0,45 & 138 & 432 & 9033 & 0,53 & 0,95 & 4608 & 97923 \\
\hline JUL & 31 & 2555 & 3,88 & 3,48 & 0,45 & 143 & 448 & 9624 & 0,50 & 0,94 & 4558 & 101457 \\
\hline AGO & 31 & 2686 & 3,89 & 3,09 & 0,42 & 165 & 515 & 11358 & 0,57 & 0,92 & 5920 & 106303 \\
\hline SET & 30 & 2839 & 3,90 & 2,70 & 0,53 & 196 & 604 & 11674 & 0,60 & 0,89 & 6238 & 111415 \\
\hline
\end{tabular}

Produtividade $(\mathrm{kg} / \mathrm{ha}): 143725$

CICLO: 12 meses

\begin{tabular}{lrrrrrrrrrrrr}
\hline \hline MESS & n & SGDC & IAF & IAFM & $F$ & Yo & YC & Pp & CT & CL & PpC & SPpc*r \\
\hline \hline SET & 30 & 154 & 0,49 & 0,25 & 0,53 & 196 & 604 & 11674 & 0,60 & 0,18 & 1254 & 1241 \\
OUT & 31 & 333 & 2,43 & 1,46 & 0,62 & 223 & 683 & 12269 & 0,64 & 0,69 & 5434 & 6609 \\
NOV & 30 & 536 & 3,06 & 2,74 & 0,56 & 243 & 739 & 13844 & 0,70 & 0,89 & 8583 & 15040 \\
DEZ & 31 & 779 & 3,38 & 3,22 & 0,58 & 250 & 762 & 14371 & 0,77 & 0,92 & 10185 & 24972 \\
JAN & 31 & 1046 & 3,56 & 3,47 & 0,54 & 249 & 757 & 14937 & 0,83 & 0,94 & 11577 & 36184 \\
FEV & 28 & 1279 & 3,66 & 3,61 & 0,49 & 236 & 718 & 13472 & 0,83 & 0,94 & 10578 & 46294 \\
MAR & 31 & 1511 & 3,73 & 3,69 & 0,45 & 213 & 653 & 14152 & 0,80 & 0,95 & 10688 & 56413 \\
ABR & 30 & 1678 & 3,76 & 3,74 & 0,48 & 181 & 561 & 11380 & 0,69 & 0,95 & 7437 & 63211 \\
MAI & 31 & 1793 & 3,78 & 3,77 & 0,42 & 153 & 478 & 10612 & 0,58 & 0,95 & 5844 & 68364 \\
JUN & 30 & 1886 & 3,80 & 3,79 & 0,45 & 138 & 432 & 9033 & 0,53 & 0,95 & 4595 & 72229 \\
JUL & 31 & 1967 & 3,81 & 3,41 & 0,45 & 143 & 448 & 9624 & 0,50 & 0,93 & 4541 & 76002 \\
AGO & 31 & 2098 & 3,83 & 3,03 & 0,42 & 165 & 515 & 11358 & 0,57 & 0,91 & 5891 & 81074
\end{tabular}

Produtividade $(\mathrm{kg} / \mathrm{ha}): 104586$ 
Tabela 14: Produtividade potencial simulada para os dados meteorológicos normais (1961-1990)

LOCAL: CAMPOS-RJ

CICLO: 18 meses

\begin{tabular}{|c|c|c|c|c|c|c|c|c|c|c|c|c|}
\hline MÊS & $\mathrm{n}$ & SGDC & IAF & IAFM & $\mathrm{F}$ & Yo & YC & $\mathrm{Pp}$ & $\mathrm{CT}$ & CL & Ppc & SPpc*r \\
\hline ABR & 30 & 179 & 0,99 & 0,50 & 0,41 & 181 & 561 & 12194 & 0,71 & 0,33 & 2825 & 2797 \\
\hline MAI & 31 & 318 & 2,35 & 1,67 & 0,37 & 153 & 478 & 11063 & 0,62 & 0,74 & 5045 & 7764 \\
\hline JUN & 30 & 420 & 2,77 & 2,56 & 0,42 & 138 & 432 & 9297 & 0,55 & 0,87 & 4448 & 12090 \\
\hline JUL & 31 & 511 & 3,01 & 2,89 & 0,40 & 143 & 448 & 10061 & 0,52 & 0,90 & 4709 & 16631 \\
\hline AGO & 31 & 634 & 3,22 & 3,11 & 0,39 & 165 & 515 & 11722 & 0,56 & 0,92 & 6011 & 22415 \\
\hline SET & 30 & 776 & 3,38 & 3,30 & 0,5 & 196 & 604 & 11215 & 0,59 & 0,93 & 6132 & 28262 \\
\hline OUT & 31 & 954 & 3,51 & 3,44 & 0,61 & 223 & 683 & 12425 & 0,64 & 0,94 & 7485 & 35390 \\
\hline NOV & 30 & 1157 & 3,61 & 3,56 & 0,57 & 243 & 739 & 13701 & 0,70 & 0,94 & 9008 & 43953 \\
\hline $\mathrm{DEZ}$ & 31 & 1388 & 3,69 & 3,65 & 0,55 & 250 & 762 & 14851 & 0,75 & 0,95 & 10501 & 53910 \\
\hline JAN & 31 & 1634 & 3,75 & 3,72 & 0,45 & 249 & 757 & 16336 & 0,79 & 0,95 & 12278 & 65525 \\
\hline FEV & 28 & 1860 & 3,79 & 3,77 & 0 , & 236 & 718 & 14812 & 0,82 & 0,95 & 11505 & 260 \\
\hline MAR & 31 & 2094 & 3,83 & & & 213 & 653 & 149 & & & 11351 & 867 \\
\hline ABR & 30 & 2273 & 3,85 & 3,84 & 0,41 & 181 & 561 & 12194 & 0,71 & 0,95 & 8229 & 94014 \\
\hline MAI & 31 & 2413 & 3,86 & 3,86 & 0,37 & 153 & 478 & 11063 & 0,62 & 0,95 & 6530 & 99539 \\
\hline JUN & 30 & 2514 & 3,87 & 3,87 & 0,42 & 138 & 432 & 9297 & 0,55 & 0,95 & 4875 & 103370 \\
\hline JUL & 31 & 2605 & 3,88 & 3,48 & 0,40 & 143 & 448 & 10061 & 0,52 & 0,94 & 4905 & 107192 \\
\hline AGO & 31 & 2729 & 3,89 & 3,09 & 0,39 & 165 & 515 & 11722 & 0,56 & 0,92 & 6002 & 112062 \\
\hline SET & 30 & 2870 & 3,90 & 2,70 & 0,56 & 196 & 604 & 11215 & 0,59 & 0,88 & 5844 & 116727 \\
\hline
\end{tabular}

Produtividade (kg/ha): 150578

CICLO: 12 meses

\begin{tabular}{lrrrrrrrrrrrr}
\hline \hline MES & $n$ & SGDC & IAF & IAFM & $F$ & Yo & YC & Pp & CT & CL & PpC & SPpC*r \\
\hline \hline SET & 30 & 142 & 0,18 & 0,09 & 0,56 & 196 & 604 & 11215 & 0,59 & 0,07 & 459 & 454 \\
OUT & 31 & 320 & 2,36 & 1,27 & 0,61 & 223 & 683 & 12425 & 0,64 & 0,64 & 5103 & 5501 \\
NOV & 30 & 523 & 3,03 & 2,70 & 0,57 & 243 & 739 & 13701 & 0,70 & 0,88 & 8454 & 13816 \\
DEZ & 31 & 754 & 3,36 & 3,19 & 0,55 & 250 & 762 & 14851 & 0,75 & 0,92 & 10236 & 23811 \\
JAN & 31 & 1000 & 3,54 & 3,45 & 0,45 & 249 & 757 & 16336 & 0,79 & 0,94 & 12115 & 35567 \\
FEV & 28 & 1227 & 3,64 & 3,59 & 0,39 & 236 & 718 & 14812 & 0,82 & 0,94 & 11410 & 46508 \\
MAR & 31 & 1460 & 3,71 & 3,68 & 0,39 & 213 & 653 & 14954 & 0,80 & 0,95 & 11286 & 57216 \\
ABR & 30 & 1640 & 3,75 & 3,73 & 0,41 & 181 & 561 & 12194 & 0,71 & 0,95 & 8194 & 64757 \\
MAI & 31 & 1779 & 3,78 & 3,77 & 0,37 & 153 & 478 & 11063 & 0,62 & 0,95 & 6508 & 70552 \\
JUN & 30 & 1880 & 3,80 & 3,79 & 0,42 & 138 & 432 & 9297 & 0,55 & 0,95 & 4860 & 74658 \\
JUL & 31 & 1971 & 3,81 & 3,41 & 0,40 & 143 & 448 & 10061 & 0,52 & 0,93 & 4886 & 78748 \\
AGO & 31 & 2095 & 3,83 & 3,03 & 0,39 & 165 & 515 & 11722 & 0,56 & 0,91 & 5973 & 83874 \\
\hline \hline
\end{tabular}

Produtividade $(\mathrm{kg} / \mathrm{ha}): 108197$ 
Tabela 15: Produtividade potencial simulada para os dados meteorológicos normais (1961-1990)

LOCAL: CABO FRIO-RJ

CICLO: 18 meses

\begin{tabular}{|c|c|c|c|c|c|c|c|c|c|c|c|c|}
\hline MES & $\mathrm{n}$ & SGDC & IAF & IAFM & $F$ & Yo & YC & $\mathrm{Pp}$ & $\mathrm{CT}$ & CL & Ppc & SPpc*r \\
\hline BR & 30 & 167 & 0,77 & 0,38 & 43 & 181 & 561 & & 0,69 & 0,26 & 2182 & 2160 \\
\hline AII & 31 & 306 & 2,28 & 1,52 & 0,36 & 153 & 478 & 11159 & 0,62 & 0,70 & 4861 & 6951 \\
\hline JUN & 30 & 413 & 2,75 & 2,51 & 0,37 & 138 & 432 & 9715 & 0,56 & 0,87 & 4705 & 11539 \\
\hline JUL & 31 & 521 & 3,03 & 2,89 & 0,35 & 143 & 448 & 10605 & 0,54 & 0,90 & 5200 & 16571 \\
\hline AGO & 31 & 631 & 3,21 & 3,12 & 0,41 & 165 & 515 & 11514 & 0,54 & 0,92 & 5699 & 22047 \\
\hline SET & 30 & 744 & 3,35 & 3,28 & 0,57 & 196 & 604 & 11194 & 0,54 & 0,93 & 5652 & 27422 \\
\hline OUT & 31 & 886 & 3,47 & 3,41 & & 223 & 683 & 13403 & 0,59 & 0,93 & 7376 & 34450 \\
\hline NOV & 30 & 1054 & 3,57 & 3,52 & 0,52 & 243 & 739 & 14469 & 0,64 & 0,94 & 8750 & 42767 \\
\hline DEZ & 31 & 1257 & 3,65 & 3,61 & 0,51 & 250 & 762 & 15449 & 0,70 & 0,94 & 10252 & 52489 \\
\hline JAN & 31 & 1467 & 3,71 & 3,68 & 0,41 & 249 & 757 & 16953 & 0,73 & 0,95 & 11765 & 63611 \\
\hline FEV & 28 & 1656 & 3,76 & 3,74 & 0,34 & 236 & 718 & 15465 & 0,75 & 0,95 & 10975 & 73840 \\
\hline MAR & 31 & 1860 & 3,79 & 3,78 & 0,39 & 213 & 653 & 14909 & 0,75 & 0,95 & 10598 & 83594 \\
\hline ABR & 30 & 2028 & 3,82 & 3,81 & 0,43 & 181 & 561 & 11981 & 0,69 & 0,95 & 7850 & 90530 \\
\hline MAI & 31 & 2166 & 3,84 & 3,83 & 0,36 & 153 & 478 & 11159 & 0,62 & 0,95 & 6580 & 96139 \\
\hline JUN & 30 & 2274 & 3,85 & 3,84 & 0,37 & 138 & 432 & 9715 & 0,56 & 0,95 & 5181 & 100307 \\
\hline JUL & 31 & 2381 & 3,86 & 3,46 & 0,35 & 143 & 448 & 10605 & 0,54 & 0,94 & 5410 & 104660 \\
\hline AGO & 31 & 2491 & 3,87 & 3,07 & 0,41 & 165 & 515 & 11514 & 0,54 & 0,91 & 5678 & 109234 \\
\hline SET & 30 & 2604 & 3,88 & 2,68 & 0,57 & 196 & 604 & 11194 & 0,54 & 0,88 & 5381 & 113470 \\
\hline
\end{tabular}

Produtividade ( $\mathrm{kg} / \mathrm{ha}): 146376$

CICLO: 12 meses

\begin{tabular}{lrrrrrrrrrrrr}
\hline \hline MÊS & n & SGDC & IAF & IAFM & F & YO & YC & Pp & CT & CL & PpC SPpC*r \\
\hline \hline SET & 30 & 113 & 0,00 & 0,00 & 0,57 & 196 & 604 & 11194 & 0,54 & 0,00 & 000 & 000 \\
OUT & 31 & 255 & 1,92 & 0,96 & 0,54 & 223 & 683 & 13403 & 0,59 & 0,54 & 4231 & 4189 \\
NOV & 30 & 423 & 2,78 & 2,35 & 0,52 & 243 & 739 & 14469 & 0,64 & 0,85 & 7886 & 11954 \\
DEZ & 31 & 626 & 3,21 & 2,99 & 0,51 & 250 & 762 & 15449 & 0,70 & 0,91 & 9866 & 21602 \\
JAN & 31 & 836 & 3,43 & 3,32 & 0,41 & 249 & 757 & 16953 & 0,73 & 0,93 & 11543 & 32814 \\
FEV & 28 & 1026 & 3,55 & 3,49 & 0,34 & 236 & 718 & 15465 & 0,75 & 0,94 & 10849 & 43226 \\
MAR & 31 & 1230 & 3,64 & 3,60 & 0,39 & 213 & 653 & 14909 & 0,75 & 0,94 & 10514 & 53203 \\
ABR & 30 & 1397 & 3,70 & 3,67 & 0,43 & 181 & 561 & 11981 & 0,69 & 0,95 & 7804 & 60397 \\
MAI & 31 & 1535 & 3,73 & 3,71 & 0,36 & 153 & 478 & 11159 & 0,62 & 0,95 & 6549 & 66277 \\
JUN & 30 & 1643 & 3,76 & 3,74 & 0,37 & 138 & 432 & 9715 & 0,56 & 0,95 & 5161 & 70723 \\
JUL & 31 & 1750 & 3,78 & 3,37 & 0,35 & 143 & 448 & 10605 & 0,54 & 0,93 & 5382 & 75345 \\
AGO & 31 & 1861 & 3,79 & 2,99 & 0,41 & 165 & 515 & 11514 & 0,54 & 0,91 & 5642 & 80177 \\
\hline \hline
\end{tabular}

Produtividade $(\mathrm{kg} / \mathrm{ha}): 103428$ 
Tabela 16: Produtividade potencial simulada para os dados meteorológicos normais (1961-1990)

LOCAL: ECOLOGIA AGRICOLA-RJ

CICLO: 18 meses

\begin{tabular}{lrrrrrrrrrrrrr}
\hline \hline MES & $n$ & SGDC & IAF & IAFM & F & Yo & YC & Pp & CT & CL & PpC & SPpc*r \\
\hline \hline ABR & 30 & 156 & 0,53 & 0,27 & 0,45 & 181 & 561 & 11671 & 0,67 & 0,19 & 1490 & 1475 \\
MAI & 31 & 269 & 2,03 & 1,28 & 0,40 & 153 & 478 & 10797 & 0,57 & 0,64 & 3972 & 5393 \\
JUN & 30 & 349 & 2,50 & 2,26 & 0,39 & 138 & 432 & 9482 & 0,51 & 0,84 & 4083 & 9381 \\
JUL & 31 & 424 & 2,78 & 2,64 & 0,39 & 143 & 448 & 10229 & 0,49 & 0,88 & 4451 & 13693 \\
AGO & 31 & 534 & 3,05 & 2,92 & 0,43 & 165 & 515 & 11290 & 0,54 & 0,90 & 5500 & 19002 \\
SET & 30 & 668 & 3,26 & 3,16 & 0,59 & 196 & 604 & 10960 & 0,57 & 0,92 & 5788 & 24542 \\
OUT & 31 & 830 & 3,42 & 3,34 & 0,63 & 223 & 683 & 12246 & 0,62 & 0,93 & 7053 & 31280 \\
NOV & 30 & 1020 & 3,55 & 3,49 & 0,59 & 243 & 739 & 13458 & 0,68 & 0,94 & 8564 & 39445 \\
DEZ & 31 & 1248 & 3,65 & 3,60 & 0,60 & 250 & 762 & 14111 & 0,74 & 0,94 & 9886 & 48838 \\
JAN & 31 & 1494 & 3,72 & 3,68 & 0,53 & 249 & 757 & 15187 & 0,79 & 0,95 & 11395 & 59631 \\
FEV & 28 & 1717 & 3,77 & 3,75 & 0,47 & 236 & 718 & 13788 & 0,81 & 0,95 & 10632 & 69560 \\
MAR & 31 & 1932 & 3,81 & 3,79 & 0,46 & 213 & 653 & 13960 & 0,77 & 0,95 & 10191 & 78954 \\
ABR & 30 & 2088 & 3,83 & 3,82 & 0,45 & 181 & 561 & 11671 & 0,67 & 0,95 & 7429 & 85519 \\
MAI & 31 & 2201 & 3,84 & 3,83 & 0,40 & 153 & 478 & 10797 & 0,57 & 0,95 & 5910 & 90515 \\
JUN & 30 & 2281 & 3,85 & 3,85 & 0,39 & 138 & 432 & 9482 & 0,51 & 0,95 & 4655 & 94218 \\
JUL & 31 & 2356 & 3,86 & 3,46 & 0,39 & 143 & 448 & 10229 & 0,49 & 0,94 & 4744 & 97972 \\
AGO & 31 & 2467 & 3,87 & 3,07 & 0,43 & 165 & 515 & 11290 & 0,54 & 0,91 & 5569 & 102505 \\
SET & 30 & 2600 & 3,88 & 2,69 & 0,59 & 196 & 604 & 10960 & 0,57 & 0,88 & 5558 & 106982 \\
\hline
\end{tabular}

Produtividade (kg/ha): 138007

CICLO: 12 meses

\begin{tabular}{lrrrrrrrrrrrrr}
\hline \hline MÊS & $n$ & SGDC & IAF & IAFM & F & Yo & YC & Pp & CT & CL & \multicolumn{2}{r}{ PpC SPpC*r } \\
\hline \hline SET & 30 & 133 & 0,00 & 0,00 & 0,59 & 196 & 604 & 10960 & 0,57 & 0,00 & 000 & 000 \\
OUT & 31 & 295 & 2,21 & 1,11 & 0,63 & 223 & 683 & 12246 & 0,62 & 0,59 & 4446 & 4401 \\
NOV & 30 & 485 & 2,95 & 2,58 & 0,59 & 243 & 739 & 13458 & 0,68 & 0,87 & 7967 & 12245 \\
DEZ & 31 & 713 & 3,31 & 3,13 & 0,60 & 250 & 762 & 14111 & 0,74 & 0,92 & 9620 & 21646 \\
JAN & 31 & 959 & 3,51 & 3,41 & 0,53 & 249 & 757 & 15187 & 0,79 & 0,93 & 11243 & 32560 \\
FEV & 28 & 1182 & 3,62 & 3,57 & 0,47 & 236 & 718 & 13788 & 0,81 & 0,94 & 10547 & 42676 \\
MAR & 31 & 1397 & 3,70 & 3,66 & 0,46 & 213 & 653 & 13960 & 0,77 & 0,95 & 10135 & 52284 \\
ABR & 30 & 1553 & 3,74 & 3,72 & 0,45 & 181 & 561 & 11671 & 0,67 & 0,95 & 7398 & 59085 \\
MAI & 31 & 1666 & 3,76 & 3,75 & 0,40 & 153 & 478 & 10797 & 0,57 & 0,95 & 5889 & 64324 \\
JUN & 30 & 1746 & 3,78 & 3,77 & 0,39 & 138 & 432 & 9482 & 0,51 & 0,95 & 4640 & 68275 \\
JUL & 31 & 1821 & 3,79 & 3,39 & 0,39 & 143 & 448 & 10229 & 0,49 & 0,93 & 4725 & 72270 \\
AGO & 31 & 1932 & 3,81 & 3,01 & 0,43 & 165 & 515 & 11290 & 0,54 & 0,91 & 5542 & 77034 \\
\hline \hline
\end{tabular}

Produtividade (kg/ha):99373 
Tabela 17: Produtividade potencial simulada para os dados meteorológicos normais (1961-1990)

LOCAL: ILHA GUAIBA-RJ

CICLO: 18 meses

\begin{tabular}{lrrrrrrrrrrrr}
\hline \hline MÊS & n & SGDC & IAF & IAFM & F & Yo & YC & Pp & CT & CL & Ppc & SPpc*r \\
\hline \hline ABR & 30 & 164 & 0,71 & 0,36 & 0,51 & 181 & 561 & 11070 & 0,68 & 0,25 & 1869 & 1850 \\
MAI & 31 & 297 & 2,22 & 1,47 & 0,45 & 153 & 478 & 10240 & 0,61 & 0,69 & 4303 & 6091 \\
JUN & 30 & 395 & 2,69 & 2,46 & 0,43 & 138 & 432 & 9174 & 0,54 & 0,86 & 4294 & 10281 \\
JUL & 31 & 500 & 2,98 & 2,84 & 0,41 & 143 & 448 & 10010 & 0,54 & 0,90 & 4840 & 14970 \\
AGO & 31 & 617 & 3,19 & 3,09 & 0,48 & 165 & 515 & 10706 & 0,55 & 0,92 & 5383 & 20150 \\
SET & 30 & 726 & 3,33 & 3,26 & 0,63 & 196 & 604 & 10470 & 0,54 & 0,93 & 5232 & 25128 \\
OUT & 31 & 865 & 3,45 & 3,39 & 0,64 & 223 & 683 & 11988 & 0,58 & 0,93 & 6536 & 31347 \\
NOV & 30 & 1042 & 3,56 & 3,51 & 0,62 & 243 & 739 & 12890 & 0,66 & 0,94 & 7971 & 38924 \\
DEZ & 31 & 1251 & 3,65 & 3,60 & 0,65 & 250 & 762 & 13270 & 0,71 & 0,94 & 8928 & 47373 \\
JAN & 31 & 1479 & 3,72 & 3,68 & 0,55 & 249 & 757 & 14782 & 0,76 & 0,95 & 10674 & 57467 \\
FEV & 28 & 1687 & 3,76 & 3,74 & 0,48 & 236 & 718 & 13693 & 0,78 & 0,95 & 10171 & 66961 \\
MAR & 31 & 1894 & 3,80 & 3,78 & 0,51 & 213 & 653 & 13350 & 0,75 & 0,95 & 9555 & 75751 \\
ABR & 30 & 2058 & 3,82 & 3,81 & 0,51 & 181 & 561 & 11070 & 0,68 & 0,95 & 7202 & 82123 \\
MAI & 31 & 2191 & 3,84 & 3,83 & 0,45 & 153 & 478 & 10240 & 0,61 & 0,95 & 5942 & 87185 \\
JUN & 30 & 2289 & 3,85 & 3,85 & 0,43 & 138 & 432 & 9174 & 0,54 & 0,95 & 4763 & 91029 \\
JUL & 31 & 2394 & 3,86 & 3,46 & 0,41 & 143 & 448 & 10010 & 0,54 & 0,94 & 5060 & 95128 \\
AGO & 31 & 2511 & 3,87 & 3,07 & 0,48 & 165 & 515 & 10706 & 0,55 & 0,91 & 5377 & 99501 \\
SET & 30 & 2620 & 3,88 & 2,69 & 0,63 & 196 & 604 & 10470 & 0,54 & 0,88 & 4988 & 103444 \\
\hline \hline
\end{tabular}

Produtividade ( $\mathrm{kg} / \mathrm{ha}): 133443$

CICLO: 12 meses

\begin{tabular}{lrrrrrrrrrrrr}
\hline \hline MES & n SGDC & IAF & IAFM & $F$ & YO & YC & Pp & CT & CL & \multicolumn{2}{l}{ PpC SPpC*r } \\
\hline \hline SET & 30 & 109 & 0,00 & 0,00 & 0,63 & 196 & 604 & 10470 & 0,54 & 0,00 & 000 & 000 \\
OUT & 31 & 248 & 1,85 & 0,93 & 0,64 & 223 & 683 & 11988 & 0,58 & 0,52 & 3660 & 3624 \\
NOV & 30 & 425 & 2,79 & 2,32 & 0,62 & 243 & 739 & 12890 & 0,66 & 0,84 & 7157 & 10673 \\
DEZ & 31 & 634 & 3,22 & 3,00 & 0,65 & 250 & 762 & 13270 & 0,71 & 0,91 & 8600 & 19080 \\
JAN & 31 & 862 & 3,45 & 3,33 & 0,55 & 249 & 757 & 14782 & 0,76 & 0,93 & 10483 & 29268 \\
FEV & 28 & 1070 & 3,57 & 3,51 & 0,48 & 236 & 718 & 13693 & 0,78 & 0,94 & 10062 & 38937 \\
MAR & 31 & 1276 & 3,66 & 3,62 & 0,51 & 213 & 653 & 13350 & 0,75 & 0,94 & 9486 & 47939 \\
ABR & 30 & 1441 & 3,71 & 3,68 & 0,51 & 181 & 561 & 11070 & 0,68 & 0,95 & 7163 & 54551 \\
MAI & 31 & 1574 & 3,74 & 3,72 & 0,45 & 153 & 478 & 10240 & 0,61 & 0,95 & 5916 & 59862 \\
JUN & 30 & 1672 & 3,76 & 3,75 & 0,43 & 138 & 432 & 9174 & 0,54 & 0,95 & 4745 & 63962 \\
JUL & 31 & 1776 & 3,78 & 3,37 & 0,41 & 143 & 448 & 10010 & 0,54 & 0,93 & 5036 & 68307 \\
AGO & 31 & 1894 & 3,80 & 2,99 & 0,48 & 165 & 515 & 10706 & 0,55 & 0,91 & 5345 & 72916 \\
\hline \hline
\end{tabular}

Produtividade $(\mathrm{kg} / \mathrm{ha}): 94061$ 
Tabela 18: Produtividade potencial simulada para os dados meteorológicos normais (1961-1990)

LOCAL: ITAPERUNA-RJ

CICLO: 18 meses

\begin{tabular}{lrrrrrrrrrrrr}
\hline \hline MES & $n$ & SGDC & IAF & IAFM & $F$ & Yo & YC & Pp & CT & CL & PpC & SPpC*r \\
\hline \hline ABR & 30 & 166 & 0,75 & 0,37 & 0,44 & 181 & 561 & 11812 & 0,68 & 0,26 & 2088 & 2067 \\
MAI & 31 & 285 & 2,14 & 1,45 & 0,42 & 153 & 478 & 10538 & 0,58 & 0,69 & 4220 & 6224 \\
JUN & 30 & 363 & 2,56 & 2,35 & 0,42 & 138 & 432 & 9290 & 0,51 & 0,85 & 4015 & 10136 \\
JUL & 31 & 431 & 2,80 & 2,68 & 0,43 & 143 & 448 & 9853 & 0,48 & 0,88 & 4220 & 14212 \\
AGO & 31 & 543 & 3,07 & 2,94 & 0,44 & 165 & 515 & 11201 & 0,54 & 0,90 & 5516 & 19531 \\
SET & 30 & 677 & 3,27 & 3,17 & 0,56 & 196 & 604 & 11212 & 0,58 & 0,92 & 5978 & 25254 \\
OUT & 31 & 855 & 3,44 & 3,36 & 0,59 & 223 & 683 & 12715 & 0,64 & 0,93 & 7623 & 32548 \\
NOV & 30 & 1057 & 3,57 & 3,51 & 0,56 & 243 & 739 & 13870 & 0,70 & 0,94 & 9093 & 41225 \\
DEZ & 31 & 1279 & 3,66 & 3,61 & 0,56 & 250 & 762 & 14683 & 0,73 & 0,94 & 10157 & 50868 \\
JAN & 31 & 1523 & 3,73 & 3,69 & 0,45 & 249 & 757 & 16362 & 0,79 & 0,95 & 12205 & 62442 \\
FEV & 28 & 1742 & 3,77 & 3,75 & 0,39 & 236 & 718 & 14789 & 0,80 & 0,95 & 11267 & 72972 \\
MAR & 31 & 1964 & 3,81 & 3,79 & 0,43 & 213 & 653 & 14446 & 0,77 & 0,95 & 10616 & 82753 \\
ABR & 30 & 2130 & 3,83 & 3,82 & 0,44 & 181 & 561 & 11812 & 0,68 & 0,95 & 7688 & 89536 \\
MAI & 31 & 2249 & 3,85 & 3,84 & 0,42 & 153 & 478 & 10538 & 0,58 & 0,95 & 5869 & 94450 \\
JUN & 30 & 2327 & 3,85 & 3,85 & 0,42 & 138 & 432 & 9290 & 0,51 & 0,95 & 4518 & 97978 \\
JUL & 31 & 2395 & 3,86 & 3,46 & 0,43 & 143 & 448 & 9853 & 0,48 & 0,94 & 4479 & 101433 \\
AGO & 31 & 2507 & 3,87 & 3,08 & 0,44 & 165 & 515 & 11201 & 0,54 & 0,91 & 5577 & 105940 \\
SET & 30 & 2641 & 3,88 & 2,69 & 0,56 & 196 & 604 & 11212 & 0,58 & 0,88 & 5737 & 110561 \\
\hline \hline
\end{tabular}

Produtividade ( $\mathrm{kg} / \mathrm{ha}): 142623$

CICLO: 12 meses

\begin{tabular}{lrrrrrrrrrrrrr}
\hline \hline MESS & n & SGDC & IAF & IAFM & $F$ & Yo & YC & Pp & CT & CL & \multicolumn{2}{r}{ Ppc SPpC*r } \\
\hline \hline SET & 30 & 134 & 0,00 & 0,00 & 0,56 & 196 & 604 & 11212 & 0,58 & 0,00 & 000 & 000 \\
OUT & 31 & 312 & 2,32 & 1,16 & 0,59 & 223 & 683 & 12715 & 0,64 & 0,60 & 4946 & 4897 \\
NOV & 30 & 514 & 3,01 & 2,66 & 0,56 & 243 & 739 & 13870 & 0,70 & 0,88 & 8530 & 13292 \\
DEZ & 31 & 736 & 3,34 & 3,18 & 0,56 & 250 & 762 & 14683 & 0,73 & 0,92 & 9907 & 22967 \\
JAN & 31 & 980 & 3,53 & 3,43 & 0,45 & 249 & 757 & 16362 & 0,79 & 0,94 & 12049 & 34666 \\
FEV & 28 & 1199 & 3,63 & 3,58 & 0,39 & 236 & 718 & 14789 & 0,80 & 0,94 & 11180 & 45388 \\
MAR & 31 & 1421 & 3,70 & 3,67 & 0,43 & 213 & 653 & 14446 & 0,77 & 0,95 & 10559 & 55387 \\
ABR & 30 & 1587 & 3,74 & 3,72 & 0,44 & 181 & 561 & 11812 & 0,68 & 0,95 & 7657 & 62413 \\
MAI & 31 & 1706 & 3,77 & 3,76 & 0,42 & 153 & 478 & 10538 & 0,58 & 0,95 & 5849 & 67579 \\
JUN & 30 & 1784 & 3,78 & 3,77 & 0,42 & 138 & 432 & 9290 & 0,51 & 0,95 & 4504 & 71363 \\
JUL & 31 & 1852 & 3,79 & 3,40 & 0,43 & 143 & 448 & 9853 & 0,48 & 0,93 & 4463 & 75067 \\
AGO & 31 & 1964 & 3,81 & 3,02 & 0,44 & 165 & 515 & 11201 & 0,54 & 0,91 & 5551 & 79812 \\
\hline \hline
\end{tabular}

Produtividade ( $\mathrm{kg} / \mathrm{ha}): 102957$ 
Tabela 19: Produtividade potencial simulada para os dados meteorológicos normais (1961-1990)

LOCAL: MACAÉ-RJ.

CICLO: 18 meses

\begin{tabular}{|c|c|c|c|c|c|c|c|c|c|c|c|c|}
\hline MÊS & $n$ & SGDC & IAF & IAFM & $F$ & Yo & YC & $\mathrm{Pp}$ & $C T$ & $\mathrm{CL}$ & Ppc & SPpc*r \\
\hline$A B R$ & 30 & 168 & 0,79 & 0,40 & 0,48 & 181 & 561 & 11385 & 0,69 & 0,27 & 2122 & 2101 \\
\hline IAI & 31 & 302 & 2,25 & 1,52 & 0,44 & 153 & 478 & 10362 & 0,61 & 0,70 & 4438 & 6473 \\
\hline JUN & 30 & 385 & 2,65 & 2,45 & 0,43 & 138 & 432 & 9123 & 0,52 & 0,86 & 4074 & 10442 \\
\hline JUL & 31 & 463 & 2,89 & 2,77 & 0,42 & 143 & 448 & 9913 & 0,50 & 0,89 & 4415 & 14709 \\
\hline AGO & 31 & 562 & 3,11 & 3,00 & 0,50 & 165 & 515 & 10594 & 0,52 & 0,91 & 5053 & 19564 \\
\hline SET & 30 & 670 & 3,26 & 3,19 & 0,65 & 196 & 604 & 10215 & 0,54 & 0,92 & 5079 & 24397 \\
\hline oUT & 31 & 828 & 3,42 & 3,34 & 0,63 & 223 & 683 & 12221 & 0,61 & 0,93 & 6983 & 31066 \\
\hline NOV & 30 & 1018 & 3,55 & 3,49 & 0,58 & 243 & 739 & 13530 & 0,68 & 0,94 & 8609 & 39278 \\
\hline $\mathrm{DEZ}$ & 31 & 1231 & 3,64 & 3,59 & 0,64 & 250 & 762 & 13502 & 0,72 & 0,94 & 9143 & 47937 \\
\hline JAN & 31 & 1459 & 3,71 & 3,68 & 0,53 & 249 & 757 & 15174 & 0,76 & 0,95 & 10954 & 58302 \\
\hline FEV & 28 & 1673 & 3,76 & 3,74 & 0,42 & 236 & 718 & 14376 & 0,79 & 0,95 & 10811 & 68422 \\
\hline MAR & 31 & 1884 & 3,80 & 3,78 & 0,49 & 213 & 653 & 13609 & 0,76 & 0,95 & 9804 & 77444 \\
\hline $\mathrm{ABR}$ & 30 & 2053 & 3,82 & 3,81 & 0,48 & 181 & 561 & 11385 & 0,69 & 0,95 & 7460 & 84055 \\
\hline MAI & 31 & 2186 & 3,84 & 3,83 & 0,44 & 153 & 478 & 10362 & 0,61 & 0,95 & 6013 & 89167 \\
\hline JUN & 30 & 2270 & 3,85 & 3,84 & 0,43 & 138 & 432 & 9123 & 0,52 & 0,95 & 4522 & 92752 \\
\hline JUL & 31 & 2348 & 3,86 & 3,46 & 0,42 & 143 & 448 & 9913 & 0,50 & 0,94 & 4643 & 96421 \\
\hline AGO & 31 & 2447 & 3,87 & 3,07 & 0,50 & 165 & 515 & 10594 & 0,52 & 0,91 & 5081 & 100487 \\
\hline SET & 30 & 2555 & 3,88 & 2,69 & 0,65 & 196 & 604 & 10215 & 0,54 & 0,88 & 4867 & 104300 \\
\hline
\end{tabular}

Produtividade (kg/ha):134548

CICLO: 12 meses

\begin{tabular}{lrrrrrrrrrrrr}
\hline \hline MES & $n$ & SGDC & IAF & IAFM & F & Yo & YC & Pp & CT & CL & \multicolumn{2}{r}{ PpC SPpC*r } \\
\hline \hline SET & 30 & 108 & 0,00 & 0,00 & 0,65 & 196 & 604 & 10215 & 0,54 & 0,00 & 000 & 000 \\
OUT & 31 & 266 & 2,01 & 1,01 & 0,63 & 223 & 683 & 12221 & 0,61 & 0,55 & 4143 & 4102 \\
NOV & 30 & 456 & 2,88 & 2,44 & 0,58 & 243 & 739 & 13530 & 0,68 & 0,86 & 7872 & 11854 \\
DEZ & 31 & 669 & 3,26 & 3,07 & 0,64 & 250 & 762 & 13502 & 0,72 & 0,91 & 8857 & 20504 \\
JAN & 31 & 897 & 3,47 & 3,37 & 0,53 & 249 & 757 & 15174 & 0,76 & 0,93 & 10783 & 30974 \\
FEV & 28 & 1110 & 3,59 & 3,53 & 0,42 & 236 & 718 & 14376 & 0,79 & 0,94 & 10710 & 41267 \\
MAR & 31 & 1322 & 3,67 & 3,63 & 0,49 & 213 & 653 & 13609 & 0,76 & 0,95 & 9742 & 50499 \\
ABR & 30 & 1490 & 3,72 & 3,70 & 0,48 & 181 & 561 & 11385 & 0,69 & 0,95 & 7425 & 57344 \\
MAI & 31 & 1624 & 3,75 & 3,74 & 0,44 & 153 & 478 & 10362 & 0,61 & 0,95 & 5990 & 62701 \\
JUN & 30 & 1707 & 3,77 & 3,76 & 0,43 & 138 & 432 & 9123 & 0,52 & 0,95 & 4506 & 66535 \\
JUL & 31 & 1785 & 3,78 & 3,38 & 0,42 & 143 & 448 & 9913 & 0,50 & 0,93 & 4623 & 70447 \\
AGO & 31 & 1885 & 3,80 & 3,00 & 0,50 & 165 & 515 & 10594 & 0,52 & 0,91 & 5054 & 74746 \\
\hline \hline
\end{tabular}

Produtividade (kg/ha):96422 
Tabela 20: Produtividade potencial simulada para os dados meteorológicos normais (1961-1990)

LOCAL: MARAMBAIA-RJ

CICLO: 18 meses

\begin{tabular}{lrrrrrrrrrrrr}
\hline \hline MES & n & SGDC & IAF & IAFM & F & Yo & YC & Pp & CT & CL & PpC & SPpC*r \\
\hline \hline ABR & 30 & 186 & 1,11 & 0,56 & 0,51 & 181 & 561 & 10960 & 0,72 & 0,36 & 2839 & 2811 \\
MAI & 31 & 330 & 2,41 & 1,76 & 0,52 & 153 & 478 & 9534 & 0,63 & 0,76 & 4527 & 7264 \\
JUN & 30 & 426 & 2,79 & 2,60 & 0,47 & 138 & 432 & 8825 & 0,54 & 0,88 & 4166 & 11315 \\
JUL & 31 & 517 & 3,02 & 2,90 & 0,50 & 143 & 448 & 9125 & 0,52 & 0,90 & 4277 & 15437 \\
AGO & 31 & 631 & 3,21 & 3,12 & 0,58 & 165 & 515 & 9663 & 0,54 & 0,92 & 4825 & 20060 \\
SET & 30 & 740 & 3,34 & 3,28 & 0,66 & 196 & 604 & 10103 & 0,54 & 0,93 & 5054 & 24862 \\
OUT & 31 & 896 & 3,47 & 3,41 & 0,59 & 223 & 683 & 12808 & 0,61 & 0,93 & 7286 & 31827 \\
NOV & 30 & 1079 & 3,58 & 3,53 & 0,55 & 243 & 739 & 13958 & 0,67 & 0,94 & 8770 & 40190 \\
DEZ & 31 & 1289 & 3,66 & 3,62 & 0,61 & 250 & 762 & 13921 & 0,71 & 0,94 & 9373 & 49068 \\
JAN & 31 & 1537 & 3,73 & 3,70 & 0,56 & 249 & 757 & 14674 & 0,80 & 0,95 & 11085 & 59551 \\
FEV & 28 & 1758 & 3,78 & 3,75 & 0,53 & 236 & 718 & 12924 & 0,81 & 0,95 & 9908 & 68765 \\
MAR & 31 & 1976 & 3,81 & 3,79 & 0,53 & 213 & 653 & 12977 & 0,77 & 0,95 & 9537 & 77519 \\
ABR & 30 & 2162 & 3,84 & 3,82 & 0,51 & 181 & 561 & 10960 & 0,72 & 0,95 & 7547 & 84216 \\
MAI & 31 & 2306 & 3,85 & 3,84 & 0,52 & 153 & 478 & 9534 & 0,63 & 0,95 & 5716 & 89033 \\
JUN & 30 & 2401 & 3,86 & 3,86 & 0,47 & 138 & 432 & 8825 & 0,54 & 0,95 & 4542 & 92639 \\
JUL & 31 & 2493 & 3,87 & 3,47 & 0,50 & 143 & 448 & 9125 & 0,52 & 0,94 & 4446 & 96115 \\
AGO & 31 & 2606 & 3,88 & 3,08 & 0,58 & 165 & 515 & 9663 & 0,54 & 0,92 & 4814 & 99919 \\
SET & 30 & 2716 & 3,89 & 2,69 & 0,66 & 196 & 604 & 10103 & 0,54 & 0,88 & 4818 & 103690 \\
\hline \hline
\end{tabular}

Produtividade $(\mathrm{kg} / \mathrm{ha}): 133760$

CICLO: 12 meses

\begin{tabular}{lrrrrrrrrrrrr}
\hline \hline MÊS & n & SGDC & IAF & IAFM & $F$ & Yo & YC & Pp & CT & CL & \multicolumn{2}{r}{ PpC SPpC*r } \\
\hline \hline SET & 30 & 109 & 0,00 & 0,00 & 0,66 & 196 & 604 & 10103 & 0,54 & 0,00 & 000 & 000 \\
OUT & 31 & 265 & 1,99 & 1,00 & 0,59 & 223 & 683 & 12808 & 0,61 & 0,55 & 4279 & 4236 \\
NOV & 30 & 448 & 2,85 & 2,42 & 0,55 & 243 & 739 & 13958 & 0,67 & 0,86 & 7984 & 12099 \\
DEZ & 31 & 657 & 3,25 & 3,05 & 0,61 & 250 & 762 & 13921 & 0,71 & 0,91 & 9057 & 20944 \\
JAN & 31 & 906 & 3,48 & 3,36 & 0,56 & 249 & 757 & 14674 & 0,80 & 0,93 & 10900 & 31526 \\
FEV & 28 & 1127 & 3,60 & 3,54 & 0,53 & 236 & 718 & 12924 & 0,81 & 0,94 & 9812 & 40924 \\
MAR & 31 & 1344 & 3,68 & 3,64 & 0,53 & 213 & 653 & 12977 & 0,77 & 0,95 & 9474 & 49894 \\
ABR & 30 & 1530 & 3,73 & 3,71 & 0,51 & 181 & 561 & 10960 & 0,72 & 0,95 & 7510 & 56830 \\
MAI & 31 & 1675 & 3,76 & 3,75 & 0,52 & 153 & 478 & 9534 & 0,63 & 0,95 & 5693 & 61898 \\
JUN & 30 & 1770 & 3,78 & 3,77 & 0,47 & 138 & 432 & 8825 & 0,54 & 0,95 & 4527 & 65761 \\
JUL & 31 & 1861 & 3,79 & 3,39 & 0,50 & 143 & 448 & 9125 & 0,52 & 0,93 & 4427 & 69486 \\
AGO & 31 & 1975 & 3,81 & 3,01 & 0,58 & 165 & 515 & 9663 & 0,54 & 0,91 & 4787 & 73531 \\
\hline \hline
\end{tabular}

Produtividade (kg/ha):94855 
Tabela 21: Produtividade potencial simulada para os dados meteorológicos normais (1961-1990)

LOCAL: RIO DE JANEIRO-RJ

CICLO: 18 meses

\begin{tabular}{|c|c|c|c|c|c|c|c|c|c|c|c|c|}
\hline MÊS & $\mathrm{n}$ & SGDC & IAF & IAFM & F & Yo & YC & $\mathrm{Pp}$ & CT & CL & Ppc & SPpc*r \\
\hline ABR & 30 & 175 & 0,92 & 0,46 & 0,51 & 181 & 561 & 10970 & 0,70 & 0,31 & 2373 & 2349 \\
\hline MAI & 31 & 319 & 2,35 & 1,64 & 0,49 & 153 & 478 & 9878 & 0,63 & 0,73 & 4533 & 6814 \\
\hline JUN & 30 & 424 & 2,78 & 2,57 & 0,48 & 138 & 432 & 8733 & 0,55 & 0,87 & 4220 & 10924 \\
\hline JUL & 31 & 531 & 3,05 & 2,92 & 0,45 & 143 & 448 & 9589 & 0,54 & 0,90 & 4713 & 15481 \\
\hline AGO & 31 & 662 & 3,25 & 3,15 & 0,48 & 165 & 515 & 10715 & 0,57 & 0,92 & 5608 & 20878 \\
\hline SET & 30 & 792 & 3,39 & 3,32 & 0,62 & 196 & 604 & 10531 & 0,57 & 0,93 & 5574 & 26187 \\
\hline OUT & 31 & 955 & 3,51 & 3,45 & 0,60 & 223 & 683 & 12651 & 0,62 & 0,94 & 7331 & 33183 \\
\hline NOV & 30 & 1151 & 3,61 & 3,56 & 0,57 & 243 & 739 & 13674 & 0,69 & 0,94 & 8861 & 41624 \\
\hline DEZ & 31 & 1376 & 3,69 & 3,65 & 0,61 & 250 & 762 & 13862 & 0,74 & 0,95 & 9670 & 50781 \\
\hline JAN & 31 & 1619 & 3,75 & 3,72 & 0,52 & 249 & 757 & 15271 & 0,79 & 0,95 & 11404 & 61563 \\
\hline$F E V$ & 28 & 1836 & 3,79 & 3,77 & 0,42 & 236 & 718 & 14400 & 0,80 & 0,95 & 10980 & 71817 \\
\hline MAR & 31 & 2057 & 3,82 & 3,81 & 0,48 & 213 & 653 & 13734 & 0,78 & 0,95 & 10163 & 81161 \\
\hline ABR & 30 & 2232 & 3,84 & 3,83 & 0,51 & 181 & 561 & 10970 & 0,70 & 0,95 & 7350 & 87626 \\
\hline MAI & 31 & 2376 & 3,86 & 3,85 & 0,49 & 153 & 478 & 9878 & 0,63 & 0,95 & 5923 & 92614 \\
\hline JUN & 30 & 2481 & 3,87 & 3,86 & 0,48 & 138 & 432 & 8733 & 0,55 & 0,95 & 4620 & 96262 \\
\hline JUL & 31 & 2588 & 3,88 & 3,48 & 0,45 & 143 & 448 & 9589 & 0,54 & 0,94 & 4897 & 100147 \\
\hline AGO & 31 & 2719 & 3,89 & 3,09 & 0,48 & 165 & 515 & 10715 & 0,57 & 0,92 & 5583 & 104672 \\
\hline SET & 30 & 2849 & 3,90 & 2,70 & 0,62 & 196 & 604 & 10531 & 0,57 & 0,88 & 5302 & 108874 \\
\hline
\end{tabular}

Produtividade (kg/ha): 140448

CICLO: 12 meses

\begin{tabular}{lrrrrrrrrrrrr}
\hline \hline MÊS & n & SGDC & IAF & IAFM & F & Yo & YC & Pp & CT & CL & PpC SPpC*r \\
\hline \hline SET & 30 & 130 & 0,00 & 0,00 & 0,62 & 196 & 604 & 10531 & 0,57 & 0,00 & 000 & 000 \\
OUT & 31 & 292 & 2,19 & 1,10 & 0,60 & 223 & 683 & 12651 & 0,62 & 0,58 & 4567 & 4521 \\
NOV & 30 & 489 & 2,96 & 2,58 & 0,57 & 243 & 739 & 13674 & 0,69 & 0,87 & 8208 & 12601 \\
DEZ & 31 & 713 & 3,31 & 3,14 & 0,61 & 250 & 762 & 13862 & 0,74 & 0,92 & 9390 & 21771 \\
JAN & 31 & 956 & 3,51 & 3,41 & 0,52 & 249 & 757 & 15271 & 0,79 & 0,93 & 11234 & 32675 \\
FEV & 28 & 1174 & 3,62 & 3,57 & 0,42 & 236 & 718 & 14400 & 0,80 & 0,94 & 10879 & 43119 \\
MAR & 31 & 1395 & 3,69 & 3,66 & 0,48 & 213 & 653 & 13734 & 0,78 & 0,95 & 10099 & 52686 \\
ABR & 30 & 1570 & 3,74 & 3,72 & 0,51 & 181 & 561 & 10970 & 0,70 & 0,95 & 7315 & 59401 \\
MAI & 31 & 1714 & 3,77 & 3,75 & 0,49 & 153 & 478 & 9878 & 0,63 & 0,95 & 5900 & 64648 \\
JUN & 30 & 1819 & 3,79 & 3,78 & 0,48 & 138 & 432 & 8733 & 0,55 & 0,95 & 4605 & 68560 \\
JUL & 31 & 1926 & 3,80 & 3,40 & 0,45 & 143 & 448 & 9589 & 0,54 & 0,93 & 4876 & 72702 \\
AGO & 31 & 2057 & 3,82 & 3,02 & 0,48 & 165 & 515 & 10715 & 0,57 & 0,91 & 5553 & 77472 \\
\hline \hline
\end{tabular}

Produtividade (kg/ha):99938 
Tabela 22: Produtividade potencial simulada para os dados meteorológicos normais (1961-1990)

LOCAL: SANTA CRUZ-RJ

CICLO: 18 meses

\begin{tabular}{lrrrrrrrrrrrrr}
\hline \hline MES & n & SGDC & IAF & IAFM & $F$ & Yo & YC & Pp & CT & CL & PpC & SPpC*r \\
\hline \hline ABR & 30 & 156 & 0,53 & 0,27 & 0,51 & 181 & 561 & 10970 & 0,67 & 0,19 & 1400 & 1386 \\
MAI & 31 & 269 & 2,03 & 1,28 & 0,49 & 153 & 478 & 9878 & 0,57 & 0,64 & 3634 & 4970 \\
JUN & 30 & 361 & 2,56 & 2,29 & 0,48 & 138 & 432 & 8733 & 0,53 & 0,84 & 3921 & 8802 \\
JUL & 31 & 449 & 2,86 & 2,71 & 0,45 & 143 & 448 & 9589 & 0,51 & 0,89 & 4369 & 13039 \\
AGO & 31 & 577 & 3,13 & 2,99 & 0,48 & 165 & 515 & 10715 & 0,56 & 0,91 & 5494 & 18347 \\
SET & 30 & 724 & 3,33 & 3,23 & 0,62 & 196 & 604 & 10531 & 0,59 & 0,92 & 5781 & 23887 \\
OUT & 31 & 876 & 3,46 & 3,39 & 0,60 & 223 & 683 & 12651 & 0,60 & 0,93 & 7132 & 30709 \\
NOV & 30 & 1050 & 3,56 & 3,51 & 0,57 & 243 & 739 & 13674 & 0,65 & 0,94 & 8394 & 38712 \\
DEZ & 31 & 1275 & 3,66 & 3,61 & 0,61 & 250 & 762 & 13862 & 0,74 & 0,94 & 9653 & 47881 \\
JAN & 31 & 1518 & 3,73 & 3,69 & 0,52 & 249 & 757 & 15271 & 0,79 & 0,95 & 11390 & 58679 \\
FEV & 28 & 1738 & 3,77 & 3,75 & 0,42 & 236 & 718 & 14400 & 0,81 & 0,95 & 11038 & 69020 \\
MAR & 31 & 1953 & 3,81 & 3,79 & 0,48 & 213 & 653 & 13734 & 0,77 & 0,95 & 10028 & 78257 \\
ABR & 30 & 2109 & 3,83 & 3,82 & 0,51 & 181 & 561 & 10970 & 0,67 & 0,95 & 6984 & 84388 \\
MAI & 31 & 2222 & 3,84 & 3,84 & 0,49 & 153 & 478 & 9878 & 0,57 & 0,95 & 5407 & 88897 \\
JUN & 30 & 2315 & 3,85 & 3,85 & 0,48 & 138 & 432 & 8733 & 0,53 & 0,95 & 4453 & 92416 \\
JUL & 31 & 2402 & 3,86 & 3,46 & 0,45 & 143 & 448 & 9589 & 0,51 & 0,94 & 4626 & 96072 \\
AGO & 31 & 2530 & 3,87 & 3,08 & 0,48 & 165 & 515 & 10715 & 0,56 & 0,91 & 5529 & 100585 \\
SET & 30 & 2677 & 3,89 & 2,69 & 0,62 & 196 & 604 & 10531 & 0,59 & 0,88 & 5526 & 105049 \\
\hline \hline
\end{tabular}

Produtividade (kg/ha):135513

CICLO: 12 meses

\begin{tabular}{lrrrrrrrrrrrrr}
\hline \hline MÊS & $n$ & SGDC & IAF & IAFM & $F$ & Yo & YC & Pp & CT & CL & \multicolumn{2}{r}{ Ppc SPpC*r } \\
\hline \hline SET & 30 & 147 & 0,32 & 0,16 & 0,62 & 196 & 604 & 10531 & 0,59 & 0,12 & 751 & 743 \\
OUT & 31 & 299 & 2,24 & 1,28 & 0,60 & 223 & 683 & 12651 & 0,60 & 0,64 & 4888 & 5575 \\
NOV & 30 & 473 & 2,92 & 2,58 & 0,57 & 243 & 739 & 13674 & 0,65 & 0,87 & 7797 & 13239 \\
DEZ & 31 & 698 & 3,30 & 3,11 & 0,61 & 250 & 762 & 13862 & 0,74 & 0,92 & 9372 & 22384 \\
JAN & 31 & 941 & 3,50 & 3,40 & 0,52 & 249 & 757 & 15271 & 0,79 & 0,93 & 11225 & 33274 \\
FEV & 28 & 1161 & 3,61 & 3,56 & 0,42 & 236 & 718 & 14400 & 0,81 & 0,94 & 10943 & 43774 \\
MAR & 31 & 1376 & 3,69 & 3,65 & 0,48 & 213 & 653 & 13734 & 0,77 & 0,95 & 9968 & 53205 \\
ABR & 30 & 1533 & 3,73 & 3,71 & 0,51 & 181 & 561 & 10970 & 0,67 & 0,95 & 6952 & 59555 \\
MAI & 31 & 1645 & 3,76 & 3,74 & 0,49 & 153 & 478 & 9878 & 0,57 & 0,95 & 5387 & 64292 \\
JUN & 30 & 1738 & 3,77 & 3,76 & 0,48 & 138 & 432 & 8733 & 0,53 & 0,95 & 4438 & 68043 \\
JUL & 31 & 1826 & 3,79 & 3,39 & 0,45 & 143 & 448 & 9589 & 0,51 & 0,93 & 4607 & 71923 \\
AGO & 31 & 1953 & 3,81 & 3,01 & 0,48 & 165 & 515 & 10715 & 0,56 & 0,91 & 5500 & 76648 \\
\hline \hline
\end{tabular}

Produtividade (kg/ha):98876 
Tabela 23: Produtividade potencial simulada para os dados meteorológicos normais (1961-1990)

LOCAL: SAO FIDELIS-RJ

CICLO: 18 meses

\begin{tabular}{lrrrrrrrrrrrr}
\hline \hline MÊS & n & SGDC & IAF & IAFM & F & Yo & YC & Pp & CT & CL & PpC & SPpC*I \\
\hline \hline ABR & 30 & 171 & 0,85 & 0,43 & 0,43 & 181 & 561 & 11944 & 0,69 & 0,29 & 2385 & 2361 \\
MAI & 31 & 284 & 2,14 & 1,49 & 0,47 & 153 & 478 & 10113 & 0,57 & 0,70 & 4047 & 6344 \\
JUN & 30 & 365 & 2,57 & 2,36 & 0,44 & 138 & 432 & 9057 & 0,51 & 0,85 & 3953 & 10194 \\
JUL & 31 & 446 & 2,85 & 2,71 & 0,42 & 143 & 448 & 9956 & 0,50 & 0,89 & 4451 & 14498 \\
AGO & 31 & 573 & 3,12 & 2,99 & 0,40 & 165 & 515 & 11586 & 0,56 & 0,91 & 5937 & 20231 \\
SET & 30 & 714 & 3,32 & 3,22 & 0,56 & 196 & 604 & 11266 & 0,59 & 0,92 & 6130 & 26097 \\
OUT & 31 & 893 & 3,47 & 3,39 & 0,60 & 223 & 683 & 12594 & 0,64 & 0,93 & 7566 & 33326 \\
NOV & 30 & 1092 & 3,58 & 3,53 & 0,60 & 243 & 739 & 13221 & 0,69 & 0,94 & 8616 & 41523 \\
DEZ & 31 & 1317 & 3,67 & 3,63 & 0,56 & 250 & 762 & 14755 & 0,74 & 0,95 & 10283 & 51288 \\
JAN & 31 & 1563 & 3,74 & 3,70 & 0,39 & 249 & 757 & 17307 & 0,79 & 0,95 & 12997 & 63642 \\
FEV & 28 & 1782 & 3,78 & 3,76 & 0,37 & 236 & 718 & 15141 & 0,80 & 0,95 & 11540 & 74430 \\
MAR & 31 & 2016 & 3,82 & 3,80 & 0,41 & 213 & 653 & 14593 & 0,80 & 0,95 & 11071 & 84646 \\
ABR & 30 & 2187 & 3,84 & 3,83 & 0,43 & 181 & 561 & 11944 & 0,69 & 0,95 & 7889 & 91609 \\
MAI & 31 & 2300 & 3,85 & 3,85 & 0,47 & 153 & 478 & 10113 & 0,57 & 0,95 & 5537 & 96175 \\
JUN & 30 & 2381 & 3,86 & 3,86 & 0,44 & 138 & 432 & 9057 & 0,51 & 0,95 & 4448 & 99617 \\
JUL & 31 & 2462 & 3,87 & 3,47 & 0,42 & 143 & 448 & 9956 & 0,50 & 0,94 & 4712 & 103286 \\
AGO & 31 & 2589 & 3,88 & 3,08 & 0,40 & 165 & 515 & 11586 & 0,56 & 0,92 & 5981 & 108174 \\
SET & 30 & 2730 & 3,89 & 2,69 & 0,56 & 196 & 604 & 11266 & 0,59 & 0,88 & 5865 & 112899 \\
\hline \hline
\end{tabular}

Produtividade ( $\mathrm{kg} / \mathrm{ha}): 145640$

CICLO: 12 meses

\begin{tabular}{lrrrrrrrrrrrr}
\hline \hline MES & n & SGDC & IAF & IAFM & F & Yo & YC & Pp & CT & CL & \multicolumn{2}{r}{ PpC SPpC*r } \\
\hline \hline SET & 30 & 142 & 0,18 & 0,09 & 0,56 & 196 & 604 & 11266 & 0,59 & 0,07 & 461 & 456 \\
OUT & 31 & 320 & 2,36 & 1,27 & 0,60 & 223 & 683 & 12594 & 0,64 & 0,64 & 5172 & 5572 \\
NOV & 30 & 520 & 3,02 & 2,69 & 0,60 & 243 & 739 & 13221 & 0,69 & 0,88 & 8097 & 13533 \\
DEZ & 31 & 745 & 3,35 & 3,19 & 0,56 & 250 & 762 & 14755 & 0,74 & 0,92 & 10030 & 23327 \\
JAN & 31 & 991 & 3,53 & 3,44 & 0,39 & 249 & 757 & 17307 & 0,79 & 0,94 & 12830 & 35796 \\
FEV & 28 & 1209 & 3,63 & 3,58 & 0,37 & 236 & 718 & 15141 & 0,80 & 0,94 & 11449 & 46772 \\
MAR & 31 & 1443 & 3,71 & 3,67 & 0,41 & 213 & 653 & 14593 & 0,80 & 0,95 & 11011 & 57205 \\
ABR & 30 & 1614 & 3,75 & 3,73 & 0,43 & 181 & 561 & 11944 & 0,69 & 0,95 & 7857 & 64411 \\
MAI & 31 & 1728 & 3,77 & 3,76 & 0,47 & 153 & 478 & 10113 & 0,57 & 0,95 & 5519 & 69230 \\
JUN & 30 & 1808 & 3,79 & 3,78 & 0,44 & 138 & 432 & 9057 & 0,51 & 0,95 & 4435 & 72928 \\
JUL & 31 & 1889 & 3,80 & 3,79 & 0,42 & 143 & 448 & 9956 & 0,50 & 0,95 & 4784 & 76935 \\
AGO & 31 & 2016 & 3,82 & 3,81 & 0,40 & 165 & 515 & 11586 & 0,56 & 0,95 & 6226 & 82329 \\
\hline \hline
\end{tabular}

Produtividade (kg/ha): 106205 
Tabela 24: Produtividade potencial simulada para os dados meteorológicos normais (1961-1990)

LOCAL: CATAGUASES-MG

CICLO: 18 meses

\begin{tabular}{lrrrrrrrrrrrr}
\hline \hline MÊS & n & SGDC & IAF & IAFM & $F$ & Yo & YC & Pp & CT & CL & PpC SPpC*r \\
\hline \hline ABR & 30 & 147 & 0,32 & 0,16 & 0,45 & 181 & 561 & 11712 & 0,65 & 0,12 & 912 & 903 \\
MAI & 31 & 228 & 1,66 & 0,99 & 0,42 & 153 & 478 & 10612 & 0,52 & 0,55 & 3013 & 3877 \\
JUN & 30 & 276 & 2,08 & 1,87 & 0,42 & 138 & 432 & 9274 & 0,46 & 0,78 & 3313 & 7118 \\
JUL & 31 & 328 & 2,40 & 2,24 & 0,47 & 143 & 448 & 9446 & 0,46 & 0,83 & 3624 & 10634 \\
AGO & 31 & 416 & 2,76 & 2,58 & 0,42 & 165 & 515 & 11365 & 0,51 & 0,87 & 5057 & 15535 \\
SET & 30 & 554 & 3,09 & 2,93 & 0,57 & 196 & 604 & 11192 & 0,58 & 0,90 & 5906 & 21226 \\
OUT & 31 & 742 & 3,34 & 3,22 & 0,64 & 223 & 683 & 11977 & 0,66 & 0,92 & 7282 & 28223 \\
NOV & 30 & 878 & 3,46 & 3,40 & 0,61 & 243 & 739 & 13045 & 0,59 & 0,93 & 7237 & 35106 \\
DEZ & 31 & 1034 & 3,56 & 3,51 & 0,51 & 250 & 762 & 15488 & 0,63 & 0,94 & 9146 & 43809 \\
JAN & 31 & 1257 & 3,65 & 3,60 & 0,52 & 249 & 757 & 15268 & 0,75 & 0,94 & 10843 & 54106 \\
FEV & 28 & 1456 & 3,71 & 3,68 & 0,52 & 236 & 718 & 13138 & 0,76 & 0,95 & 9486 & 62956 \\
MAR & 31 & 1677 & 3,76 & 3,74 & 0,45 & 213 & 653 & 14084 & 0,77 & 0,95 & 10327 & 72550 \\
ABR & 30 & 1824 & 3,79 & 3,78 & 0,45 & 181 & 561 & 11712 & 0,65 & 0,95 & 7223 & 78975 \\
MAI & 31 & 1906 & 3,80 & 3,80 & 0,42 & 153 & 478 & 10612 & 0,52 & 0,95 & 5249 & 83382 \\
JUN & 30 & 1953 & 3,81 & 3,81 & 0,42 & 138 & 432 & 9274 & 0,46 & 0,95 & 4065 & 86572 \\
JUL & 31 & 2005 & 3,82 & 3,42 & 0,47 & 143 & 448 & 9446 & 0,46 & 0,94 & 4066 & 89732 \\
AGO & 31 & 2094 & 3,83 & 3,04 & 0,42 & 165 & 515 & 11365 & 0,51 & 0,91 & 5284 & 94066 \\
SET & 30 & 2231 & 3,84 & 2,66 & 0,57 & 196 & 604 & 11192 & 0,58 & 0,88 & 5756 & 98824 \\
\hline \hline
\end{tabular}

Produtividade (kg/ha): 127482

CICLO: 12 meses

\begin{tabular}{lrrrrrrrrrrrr}
\hline \hline MES & $n$ & SGDC & IAF & IAFM & $F$ & Yo & YC & Pp & CT & CL & \multicolumn{2}{r}{ Ppc SPpC*r } \\
\hline \hline SET & 30 & 137 & 0,04 & 0,04 & 0,57 & 196 & 604 & 11192 & 0,58 & 0,03 & 206 & 204 \\
OUT & 31 & 325 & 2,39 & 1,21 & 0,64 & 223 & 683 & 11977 & 0,66 & 0,62 & 4898 & 5050 \\
NOV & 30 & 461 & 2,89 & 2,64 & 0,61 & 243 & 739 & 13045 & 0,59 & 0,88 & 6808 & 11739 \\
DEZ & 31 & 617 & 3,19 & 3,04 & 0,51 & 250 & 762 & 15488 & 0,63 & 0,91 & 8880 & 20413 \\
JAN & 31 & 840 & 3,43 & 3,31 & 0,52 & 249 & 757 & 15268 & 0,75 & 0,93 & 10675 & 30777 \\
FEV & 28 & 1039 & 3,56 & 3,50 & 0,52 & 236 & 718 & 13138 & 0,76 & 0,94 & 9402 & 39777 \\
MAR & 31 & 1261 & 3,65 & 3,61 & 0,45 & 213 & 653 & 14084 & 0,77 & 0,94 & 10266 & 49542 \\
ABR & 30 & 1408 & 3,70 & 3,68 & 0,45 & 181 & 561 & 11712 & 0,65 & 0,95 & 7192 & 56167 \\
MAI & 31 & 1489 & 3,72 & 3,71 & 0,42 & 153 & 478 & 10612 & 0,52 & 0,95 & 5230 & 60783 \\
JUN & 30 & 1537 & 3,73 & 3,73 & 0,42 & 138 & 432 & 9274 & 0,46 & 0,95 & 4051 & 64186 \\
JUL & 31 & 1589 & 3,74 & 3,35 & 0,47 & 143 & 448 & 9446 & 0,46 & 0,93 & 4050 & 67553 \\
AGO & 31 & 1677 & 3,76 & 2,98 & 0,42 & 165 & 515 & 11365 & 0,51 & 0,91 & 5257 & 72083 \\
\hline \hline
\end{tabular}

Produtividade (kg/ha):92987 
Tabela 25: Produtividade potencial simulada para os dados meteorológicos normais (1961-1990)

LOCAL: CACHOEIRA DO ITAPEMIRIM-ES

CICLO: 18 meses

\begin{tabular}{lrrrrrrrrrrrr}
\hline \hline MÊS & $n$ & SGDC & IAF & IAFM & $F$ & Yo & YC & Pp & CT & CL & Ppc & SPpC*r \\
\hline \hline ABR & 30 & 174 & 0,90 & 0,45 & 0,17 & 186 & 574 & 15268 & 0,70 & 0,30 & 3221 & 3189 \\
MAI & 31 & 302 & 2,25 & 1,58 & 0,40 & 159 & 495 & 11148 & 0,60 & 0,72 & 4786 & 7895 \\
JUN & 30 & 391 & 2,67 & 2,46 & 0,41 & 144 & 451 & 9758 & 0,53 & 0,86 & 4447 & 12218 \\
JUL & 31 & 473 & 2,92 & 2,80 & 0,41 & 149 & 466 & 10441 & 0,50 & 0,89 & 4708 & 16757 \\
AGO & 31 & 585 & 3,14 & 3,03 & 0,43 & 170 & 529 & 11651 & 0,54 & 0,91 & 5781 & 22312 \\
SET & 30 & 722 & 3,32 & 3,23 & 0,56 & 199 & 614 & 11466 & 0,58 & 0,92 & 6192 & 28219 \\
OUT & 31 & 904 & 3,48 & 3,40 & 0,60 & 224 & 685 & 12713 & 0,65 & 0,93 & 7699 & 35559 \\
NOV & 30 & 1109 & 3,59 & 3,54 & 0,58 & 241 & 735 & 13453 & 0,70 & 0,94 & 8895 & 44010 \\
DEZ & 31 & 1334 & 3,68 & 3,63 & 0,58 & 248 & 755 & 14279 & 0,74 & 0,95 & 9955 & 53425 \\
JAN & 31 & 1587 & 3,74 & 3,71 & 0,44 & 247 & 750 & 16370 & 0,80 & 0,95 & 12450 & 65216 \\
FEV & 28 & 1809 & 3,79 & 3,76 & 0,39 & 236 & 718 & 14778 & 0,81 & 0,95 & 11335 & 75785 \\
MAR & 31 & 2038 & 3,82 & 3,80 & 0,41 & 216 & 660 & 14827 & 0,79 & 0,95 & 11111 & 86027 \\
ABR & 30 & 2213 & 3,84 & 3,83 & 0,17 & 186 & 574 & 15268 & 0,70 & 0,95 & 10157 & 95222 \\
MAI & 31 & 2341 & 3,86 & 3,85 & 0,40 & 159 & 495 & 11148 & 0,60 & 0,95 & 6368 & 100574 \\
JUN & 30 & 2430 & 3,86 & 3,86 & 0,41 & 144 & 451 & 9758 & 0,53 & 0,95 & 4932 & 104451 \\
JUL & 31 & 2511 & 3,87 & 3,47 & 0,41 & 149 & 466 & 10441 & 0,50 & 0,94 & 4943 & 108300 \\
AGO & 31 & 2624 & 3,88 & 3,09 & 0,43 & 170 & 529 & 11651 & 0,54 & 0,92 & 5805 & 112964 \\
SET & 30 & 2761 & 3,89 & 2,70 & 0,56 & 199 & 614 & 11466 & 0,58 & 0,88 & 5922 & 117697
\end{tabular}

Produtividade ( $\mathrm{kg} / \mathrm{ha}): 151829$

CICLO: 12 meses

\begin{tabular}{lrrrrrrrrrrrr}
\hline \hline MES & n SGDC & IAF & IAFM & F & Yo & YC & Pp & CT & CL & \multicolumn{2}{r}{ PpC } & SPpC*r \\
\hline \hline SET & 30 & 137 & 0,04 & 0,04 & 0,56 & 199 & 614 & 11466 & 0,58 & 0,03 & 211 & 209 \\
OUT & 31 & 319 & 2,35 & 1,20 & 0,60 & 224 & 685 & 12713 & 0,65 & 0,62 & 5075 & 5231 \\
NOV & 30 & 524 & 3,03 & 2,69 & 0,58 & 241 & 735 & 13453 & 0,70 & 0,88 & 8356 & 13452 \\
DEZ & 31 & 749 & 3,35 & 3,19 & 0,58 & 248 & 755 & 14279 & 0,74 & 0,92 & 9711 & 22930 \\
JAN & 31 & 1002 & 3,54 & 3,45 & 0,44 & 247 & 750 & 16370 & 0,80 & 0,94 & 12291 & 34869 \\
FEV & 28 & 1224 & 3,64 & 3,59 & 0,39 & 236 & 718 & 14778 & 0,81 & 0,94 & 11246 & 45654 \\
MAR & 31 & 1453 & 3,71 & 3,68 & 0,41 & 216 & 660 & 14827 & 0,79 & 0,95 & 11050 & 56138 \\
ABR & 30 & 1628 & 3,75 & 3,73 & 0,17 & 186 & 574 & 15268 & 0,70 & 0,95 & 10116 & 65591 \\
MAI & 31 & 1756 & 3,78 & 3,76 & 0,40 & 159 & 495 & 11148 & 0,60 & 0,95 & 6347 & 71218 \\
JUN & 30 & 1845 & 3,79 & 3,78 & 0,41 & 144 & 451 & 9758 & 0,53 & 0,95 & 4917 & 75374 \\
JUL & 31 & 1926 & 3,80 & 3,40 & 0,41 & 149 & 466 & 10441 & 0,50 & 0,93 & 4924 & 79495 \\
AGO & 31 & 2039 & 3,82 & 3,02 & 0,43 & 170 & 529 & 11651 & 0,54 & 0,91 & 5777 & 84420
\end{tabular}

Produtividade (kg/ha): 108902 
Tabela 26: Produtividade potencial simulada para os dados meteorológicos normais (1961-1990)

LOCAL: UBATUBA-SP

CICLO: 18 meses

\begin{tabular}{|c|c|c|c|c|c|c|c|c|c|c|c|c|}
\hline MÊS & $n$ & SGDC & IAF & IAFM & F & Yo & YC & $\mathrm{Pp}$ & $C T$ & CL & Ppc & SPpc*r \\
\hline & & & & & & & & & & & 000 & 400 \\
\hline & 31 & 80 & 1,00 & 0,50 & 0,68 & 147 & 460 & 7710 &, 48 & 0,33 & 1224 & 1212 \\
\hline & 30 & 186 & 1,11 & 1,05 & 0,66 & 131 & 414 & 6779 & .39 & 7 & 1510 & \\
\hline $\mathrm{JL}$ & 31 & 240 & 1,78 & 1,44 & 0,67 & 137 & 43 & 7249 & 0 , & & & \\
\hline 30 & 31 & 314 & 2,33 & 2,05 & 0,70 & 160 & 499 & 8122 & 0 & 0, & 2722 & 92 \\
\hline $\mathrm{ET}$ & 30 & 398 & 2,70 & 2,51 & 0,78 & 193 & 595 & 8393 & 0 & 0 , & 3345 & 32 \\
\hline UT & 31 & 500 & 2,98 & 84 & 0,81 & 222 & 679 & 9510 & 0 & & 16 & 00 \\
\hline IOV & 30 & 621 & 3,20 & & 0,79 & 244 & 743 & 104 & & & & 14 \\
\hline $\mathrm{DEZ}$ & 31 & 793 & 3,39 & 3,30 & 0,78 & 253 & 769 & & 0 , & 0, & 89 & 34 \\
\hline JAN & 31 & 98 & 3,53 & 3,46 & 0,75 & 250 & 762 & & & & 25 & 015 \\
\hline FEV & 28 & 1186 & 3,62 & 3,58 & 0,70 & 235 & 718 & 10576 & 0 & 0 , & 7255 & 357 \\
\hline MAR & 31 & 1358 & 3,68 & 3,65 & 0,72 & 211 & 647 & 103 & 0,69 & 0 , & 6790 & 47171 \\
\hline $\mathrm{ABR}$ & 30 & 1480 & 3,72 & 3,70 & 0,69 & 177 & 548 & & 0,60 & 0,95 & 4967 & 616 \\
\hline MAI & 31 & 1538 & 3,73 & 3,72 & 0,68 & 147 & 460 & 7710 & 0,48 & 0,95 & 3513 & 54578 \\
\hline JUN & 30 & 1544 & 3,73 & 3,73 & 0,66 & 131 & 414 & 6779 & 0,39 & 0,95 & 2516 & 56523 \\
\hline JUL & 31 & 1598 & 3,75 & 3,36 & 0,67 & 137 & 430 & 7249 & 0,36 & 0,93 & 2440 & 58374 \\
\hline AGO & 31 & 1673 & 3,76 & 2,98 & 0,70 & 160 & 499 & 8122 & 0, & 0,91 & 3066 & 60825 \\
\hline SET & 30 & 1756 & 3,78 & 2,61 & 0,78 & 193 & 595 & 8393 & 0, & 0,88 & 3382 & 63565 \\
\hline
\end{tabular}

Produtividade ( $\mathrm{kg} / \mathrm{ha}): 81999$

CICLO: 12 meses

\begin{tabular}{lrrrrrrrrrrrr}
\hline \hline MES & $n$ & SGDC & IAF & IAFM & F & Yo & YC & Pp & CT & CL & Ppc & SPpC* \\
\hline \hline SET & 30 & 83 & 0,00 & 0,00 & 0,78 & 193 & 595 & 8393 & 0,46 & 0,00 & 000 & 000 \\
OUT & 31 & 185 & 1,09 & 0,55 & 0,81 & 222 & 679 & 9510 & 0,53 & 0,35 & 1781 & 1763 \\
NOV & 30 & 306 & 2,28 & 1,69 & 0,79 & 244 & 743 & 10482 & 0,56 & 0,74 & 4379 & 6080 \\
DEZ & 31 & 478 & 2,93 & 2,61 & 0,78 & 253 & 769 & 11358 & 0,65 & 0,88 & 6498 & 12452 \\
JAN & 31 & 674 & 3,27 & 3,10 & 0,75 & 250 & 762 & 11796 & 0,71 & 0,92 & 7649 & 19900 \\
FEV & 28 & 871 & 3,46 & 3,36 & 0,70 & 235 & 718 & 10576 & 0,73 & 0,93 & 7172 & 26801 \\
MAR & 31 & 1043 & 3,56 & 3,51 & 0,72 & 211 & 647 & 10356 & 0,69 & 0,94 & 6742 & 33208 \\
ABR & 30 & 1165 & 3,62 & 3,59 & 0,69 & 177 & 548 & 8748 & 0,60 & 0,94 & 4942 & 37768 \\
MAI 31 & 1223 & 3,64 & 3,63 & 0,68 & 147 & 460 & 7710 & 0,48 & 0,95 & 3498 & 40853 \\
JUN & 30 & 1229 & 3,64 & 3,64 & 0,66 & 131 & 414 & 6779 & 0,39 & 0,95 & 2506 & 42925 \\
JUL & 31 & 1283 & 3,66 & 3,28 & 0,67 & 137 & 430 & 7249 & 0,36 & 0,93 & 2428 & 44900 \\
AGO & 31 & 1358 & 3,68 & 2,91 & 0,70 & 160 & 499 & 8122 & 0,42 & 0,90 & 3046 & 47467 \\
\hline \hline
\end{tabular}

Produtividade (kg/ha):61232 
Tabela 27: Produtividade potencial simulada para os dados meteorológicos normais (1961-1990)

LOCAL: PIRAI-RJ.

CICLO: 18 meses

\begin{tabular}{lrrrrrrrrrrrr}
\hline \hline MES & n & SGDC & IAF & IAFM & F & Yo & YC & Pp & CT & CL & Ppc & SPpC*r \\
\hline \hline ABR & 30 & 104 & 0,00 & 0,00 & 0,58 & 181 & 561 & 10166 & 0,56 & 0,00 & 000 & 000 \\
MAI & 31 & 136 & 0,01 & 0,01 & 0,57 & 153 & 478 & 9116 & 0,44 & 0,01 & 032 & 031 \\
JUN & 30 & 198 & 1,28 & 0,65 & 0,56 & 138 & 432 & 8034 & 0,35 & 0,40 & 1140 & 1159 \\
JUL & 31 & 253 & 1,90 & 1,59 & 0,53 & 143 & 448 & 8887 & 0,32 & 0,72 & 2027 & 3155 \\
AGO & 31 & 260 & 1,96 & 1,93 & 0,59 & 165 & 515 & 9610 & 0,39 & 0,79 & 2955 & 6049 \\
SET & 30 & 316 & 2,34 & 2,15 & 0,67 & 196 & 604 & 9889 & 0,46 & 0,82 & 3735 & 9686 \\
OUT & 31 & 414 & 2,75 & 2,54 & 0,66 & 223 & 683 & 11700 & 0,52 & 0,87 & 5335 & 14871 \\
NOV & 30 & 551 & 3,09 & 2,92 & 0,67 & 243 & 739 & 12227 & 0,59 & 0,90 & 6503 & 21160 \\
DEZ & 31 & 714 & 3,32 & 3,20 & 0,69 & 250 & 762 & 12655 & 0,64 & 0,92 & 7454 & 28329 \\
JAN & 31 & 891 & 3,47 & 3,39 & 0,61 & 249 & 757 & 13927 & 0,68 & 0,93 & 8817 & 36774 \\
FEV & 28 & 1062 & 3,57 & 3,52 & 0,50 & 236 & 718 & 13335 & 0,68 & 0,94 & 8500 & 44821 \\
MAR & 31 & 1221 & 3,64 & 3,60 & 0,58 & 213 & 653 & 12378 & 0,66 & 0,94 & 7749 & 52045 \\
ABR & 30 & 1325 & 3,67 & 3,66 & 0,58 & 181 & 561 & 10166 & 0,56 & 0,95 & 5427 & 56897 \\
MAI & 31 & 1357 & 3,68 & 3,68 & 0,57 & 153 & 478 & 9116 & 0,44 & 0,95 & 3760 & 60051 \\
JUN & 30 & 1418 & 3,70 & 3,69 & 0,56 & 138 & 432 & 8034 & 0,35 & 0,95 & 2675 & 62099 \\
JUL & 31 & 1474 & 3,72 & 3,71 & 0,53 & 143 & 448 & 8887 & 0,32 & 0,95 & 2669 & 64121 \\
AGO & 31 & 1481 & 3,72 & 3,34 & 0,59 & 165 & 515 & 9610 & 0,39 & 0,93 & 3496 & 66941 \\
SET & 30 & 1537 & 3,73 & 2,96 & 0,67 & 196 & 604 & 9889 & 0,46 & 0,91 & 4126 & 70356 \\
\hline \hline
\end{tabular}

Produtividade (kg/ha):90760

CICLO: 12 meses

\begin{tabular}{lrrrrrrrrrrrr}
\hline \hline MES & n & SGDC & IAF & IAFM & $F$ & Yo & YC & Pp & CT & CL & PpC & SPpC*r \\
\hline \hline SET & 30 & 56 & 0,00 & 0,00 & 0,67 & 196 & 604 & 9889 & 0,46 & 0,00 & 000 & 000 \\
OUT & 31 & 154 & 0,48 & 0,24 & 0,66 & 223 & 683 & 11700 & 0,52 & 0,17 & 1065 & 1055 \\
NOV & 30 & 291 & 2,18 & 1,33 & 0,67 & 243 & 739 & 12227 & 0,59 & 0,66 & 4717 & 5714 \\
DEZ & 31 & 454 & 2,87 & 2,53 & 0,69 & 250 & 762 & 12655 & 0,64 & 0,87 & 7009 & 12595 \\
JAN & 31 & 631 & 3,21 & 3,04 & 0,61 & 249 & 757 & 13927 & 0,68 & 0,91 & 8614 & 20997 \\
FEV & 28 & 802 & 3,40 & 3,31 & 0,50 & 236 & 718 & 13335 & 0,68 & 0,93 & 8400 & 29103 \\
MAR & 31 & 961 & 3,52 & 3,46 & 0,58 & 213 & 653 & 12378 & 0,66 & 0,94 & 7692 & 36427 \\
ABR & 30 & 1065 & 3,57 & 3,54 & 0,58 & 181 & 561 & 10166 & 0,56 & 0,94 & 5398 & 41407 \\
MAI & 31 & 1097 & 3,59 & 3,58 & 0,57 & 153 & 478 & 9116 & 0,44 & 0,94 & 3743 & 44698 \\
JUN & 30 & 1158 & 3,61 & 3,60 & 0,56 & 138 & 432 & 8034 & 0,35 & 0,94 & 2664 & 46889 \\
JUL & 31 & 1214 & 3,64 & 3,24 & 0,53 & 143 & 448 & 8887 & 0,32 & 0,92 & 2603 & 48997 \\
AGO & 31 & 1221 & 3,64 & 2,87 & 0,59 & 165 & 515 & 9610 & 0,39 & 0,90 & 3380 & 51853 \\
\hline \hline
\end{tabular}

Produtividade $(\mathrm{kg} / \mathrm{ha}): 66890$ 
Tabela 28: Produtividade potencial simulada para os dados meteorológicos normais (1961-1990)

LOCAL: VASSOURAS-RJ

CICLO: 18 meses

\begin{tabular}{lrrrrrrrrrrrr}
\hline \hline MES & $n$ & SGDC & IAF & IAFM & $F$ & Yo & YC & Pp & CT & CL & PpC & SPpC*r \\
\hline \hline ABR & 30 & 90 & 0,00 & 0,00 & 0,51 & 181 & 561 & 11045 & 0,54 & 0,00 & 000 & 000 \\
MAI & 31 & 119 & 0,57 & 0,29 & 0,47 & 153 & 478 & 10067 & 0,43 & 0,20 & 884 & 875 \\
JUN & 30 & 177 & 0,95 & 0,76 & 0,47 & 138 & 432 & 8835 & 0,36 & 0,46 & 1456 & 2307 \\
JUL & 31 & 233 & 1,71 & 1,33 & 0,45 & 143 & 448 & 9608 & 0,34 & 0,66 & 2152 & 4415 \\
AGO & 31 & 254 & 1,91 & 1,81 & 0,47 & 165 & 515 & 10879 & 0,41 & 0,77 & 3418 & 7755 \\
SET & 30 & 311 & 2,31 & 2,11 & 0,61 & 196 & 604 & 10664 & 0,47 & 0,81 & 4042 & 11679 \\
OUT & 31 & 409 & 2,73 & 2,52 & 0,63 & 223 & 683 & 12198 & 0,52 & 0,87 & 5548 & 17054 \\
NOV & 30 & 532 & 3,05 & 2,89 & 0,62 & 243 & 739 & 13016 & 0,57 & 0,90 & 6733 & 23549 \\
DEZ & 31 & 686 & 3,28 & 3,17 & 0,62 & 250 & 762 & 13836 & 0,62 & 0,92 & 7943 & 31177 \\
JAN & 31 & 851 & 3,44 & 3,36 & 0,54 & 249 & 757 & 14898 & 0,66 & 0,93 & 9140 & 39914 \\
FEV & 28 & 1006 & 3,54 & 3,49 & 0,48 & 236 & 718 & 13685 & 0,68 & 0,94 & 8710 & 48138 \\
MAR & 31 & 1151 & 3,61 & 3,58 & 0,49 & 213 & 653 & 13621 & 0,64 & 0,94 & 8198 & 55772 \\
ABR & 30 & 1240 & 3,65 & 3,63 & 0,51 & 181 & 561 & 11045 & 0,54 & 0,95 & 5682 & 60840 \\
MAI & 31 & 1269 & 3,66 & 3,65 & 0,47 & 153 & 478 & 10067 & 0,43 & 0,95 & 4100 & 64291 \\
JUN & 30 & 1327 & 3,67 & 3,67 & 0,47 & 138 & 432 & 8835 & 0,36 & 0,95 & 3021 & 66639 \\
JUL & 31 & 1384 & 3,69 & 3,68 & 0,45 & 143 & 448 & 9608 & 0,34 & 0,95 & 3108 & 69049 \\
AGO & 31 & 1404 & 3,70 & 3,69 & 0,47 & 165 & 515 & 10879 & 0,41 & 0,95 & 4236 & 72552 \\
SET & 30 & 1461 & 3,71 & 3,71 & 0,61 & 196 & 604 & 10664 & 0,47 & 0,95 & 4704 & 76484 \\
\hline \hline
\end{tabular}

Produtividade ( $\mathrm{kg} / \mathrm{ha}): 98664$

CICLO: 12 meses

\begin{tabular}{lrrrrrrrrrrrr}
\hline \hline MES & n & SGDC & IAF & IAFM & F & Yo & YC & Pp & CT & CL & PpC & SPpC*r \\
\hline \hline SET & 30 & 57 & 0,00 & 0,00 & 0,61 & 196 & 604 & 10664 & 0,47 & 0,00 & 000 & 000 \\
OUT & 31 & 155 & 0,50 & 0,25 & 0,63 & 223 & 683 & 12198 & 0,52 & 0,18 & 1160 & 1148 \\
NOV & 30 & 278 & 2,10 & 1,30 & 0,62 & 243 & 739 & 13016 & 0,57 & 0,65 & 4826 & 5915 \\
DEZ & 31 & 444 & 2,84 & 2,47 & 0,62 & 250 & 762 & 13836 & 0,62 & 0,86 & 7431 & 13212 \\
JAN & 31 & 598 & 3,16 & 3,00 & 0,54 & 249 & 757 & 14898 & 0,66 & 0,91 & 8919 & 21910 \\
FEV & 28 & 743 & 3,35 & 3,26 & 0,48 & 236 & 718 & 13685 & 0,68 & 0,93 & 8593 & 30197 \\
MAR & 31 & 833 & 3,43 & 3,39 & 0,49 & 213 & 653 & 13621 & 0,64 & 0,93 & 8116 & 37930 \\
ABR & 30 & 862 & 3,45 & 3,44 & 0,51 & 181 & 561 & 11045 & 0,54 & 0,94 & 5628 & 43123 \\
MAI & 31 & 919 & 3,49 & 3,47 & 0,47 & 153 & 478 & 10067 & 0,43 & 0,94 & 4063 & 46714 \\
JUN & 30 & 976 & 3,52 & 3,51 & 0,47 & 138 & 432 & 8835 & 0,36 & 0,94 & 2998 & 49215 \\
JUL & 31 & 997 & 3,54 & 3,15 & 0,45 & 143 & 448 & 9608 & 0,34 & 0,92 & 3017 & 51710 \\
AGO & 31 & 1054 & 3,57 & 2,80 & 0,47 & 165 & 515 & 10879 & 0,41 & 0,89 & 3992 & 55145 \\
\hline \hline
\end{tabular}

Produtividade (kg/ha):71137 
Tabela 29. Produtividade real em ton/ha e Produtividade potencial estimada em ton/ha.

\begin{tabular}{|c|c|c|}
\hline \multirow{2}{*}{ ESTAÇŌES } & \multicolumn{2}{|c|}{ PRODUTIVIDADE } \\
\hline & $\begin{array}{l}\operatorname{REAL}(*) \\
======\end{array}$ & $\begin{aligned} & \text { ESTIMADA } \\
&=========\end{aligned}$ \\
\hline CABO FRIO & 50 & 103 \\
\hline CAMPOS & 25 & 108 \\
\hline ITAPERUNA & 40 & 103 \\
\hline MACAE & 34 & 96 \\
\hline PIRÁ̇ & 22 & 67 \\
\hline RIO DE JANEIRO & 77 & 100 \\
\hline SĀO FIDELIS & 20 & 106 \\
\hline VASSOURAS & 25 & 71 \\
\hline
\end{tabular}

(*) Fonte: IBGE (1990) 
Tabela 30. Porcentagem da Produtividade estimada normal (Pn) em ton/ha, Produtividade potencial estimada acrescida à temperatura em $10 \%$ (Pea) em ton/ha e Produtividade potencial com decréscimo de $10 \%$ na temperatura (Ped) em ton/ha.

\begin{tabular}{|c|c|c|c|c|c|c|}
\hline \multirow[t]{2}{*}{ ESTAÇÕES } & \multicolumn{2}{|r|}{ meses } & & \multicolumn{2}{|c|}{12 meses } & \multirow[b]{2}{*}{$\frac{\%}{0}$} \\
\hline & Pen & Pea & $\%$ & Pen & Pea & \\
\hline \multicolumn{7}{|c|}{ =" =" } \\
\hline A.dos Reis & 123,1 & 150,4 & 22 & 88,5 & 106,7 & 20 \\
\hline Bangu & 143,7 & 174,3 & 21 & 104,6 & 128,5 & 23 \\
\hline Cabo Frio & 146,4 & 177,9 & 22 & 103,4 & 129,1 & 25 \\
\hline Campos & 150,6 & 181,8 & 21 & 108,2 & 133,6 & 23 \\
\hline E. Agrícola & 138,0 & 169,0 & 22 & 99,4 & 124,4 & 25 \\
\hline I. Guaíba & 133,4 & 162,4 & 22 & 94,1 & 117,3 & 25 \\
\hline Itaperuna & 142,6 & 173,5 & 22 & 103,0 & 128,5 & 25 \\
\hline Macaé & 134,5 & 163,8 & 22 & 96,4 & 119,8 & 24 \\
\hline Marambaia & 133,8 & 161,6 & 21 & 94,8 & 118,0 & 24 \\
\hline R. Janeiro & 140,4 & 169,7 & 21 & 99,9 & 124,6 & 25 \\
\hline Santa Cruz & 135,5 & 165,5 & 22 & 98,9 & 124,6 & 24 \\
\hline São Fidelis & 145,6 & 176,6 & 21 & 106,2 & 131,5 & 24 \\
\hline
\end{tabular}

\begin{tabular}{|c|c|c|c|c|c|c|}
\hline \multirow[t]{2}{*}{ ESTAÇŌES } & \multicolumn{3}{|c|}{18 meses } & \multicolumn{3}{|c|}{12 meses } \\
\hline & Pen & Ped & $\%$ & Pen & Ped & $\%$ \\
\hline$==========$ & $:====$ & $=====$ & & & & \\
\hline A. dos Reis & 123,1 & 88,8 & 28 & 88,5 & 64,2 & 27 \\
\hline Bangu & 143,7 & 107,1 & 25 & 104,6 & 79,5 & 24 \\
\hline Cabo Frio & 146,4 & 110,6 & 24 & 103,4 & 74,6 & 28 \\
\hline Campos & 150,6 & 114,6 & 24 & 108,2 & 83,0 & 23 \\
\hline E. Àgrícola & 138,0 & 99,0 & 28 & 99,4 & 73,8 & 26 \\
\hline I. Guaíba & 133,4 & 100,1 & 25 & 94,1 & 68,1 & 28 \\
\hline Itaperuna & 142,6 & 103,0 & 28 & 103,0 & 78,4 & 24 \\
\hline Macaé & 134,5 & 99,4 & 26 & 96,4 & 70,1 & 27 \\
\hline Marambaia & 133,8 & 101,2 & 24 & 94,8 & 68,6 & 28 \\
\hline R. Janeiro & 140,4 & 107,4 & 24 & 99,9 & 74,0 & 26 \\
\hline Santa Cruz & 135,5 & 99,6 & 26 & 98,9 & 72,5 & 27 \\
\hline São Fidelis & 145,6 & 107,6 & 26 & 106,2 & 81,2 & 24 \\
\hline
\end{tabular}




\section{CONCLUSÕES}

- o modelo de De WIT (1965), modificado por VILLA NOVA \& BARBIERI (1991) foi testado para a estação de campos (RJ) e os resultados obtidos comparados com os dados experimentais em cana irrigada nesta mesma localidade, foram considerados consistentes.

- A produtividade estimada foi bastante superior à produtividade real relatada pelo IBGE, mas bem próximo da produtividade obtida em experimento de campos irrigados. Portanto o fator mais limitante à produtividade de cana-de-açúcar na região é a falta de água e que o uso adequado de irrigação pode aumentar significativamente a produtividade do estado. - A produtividade estimada apresentou sensibilidade quanto a mudanças climáticas, mostrando a tendência da cana-de- açúcar ser mais sensivel a decréscimo de temperatura, pois a produtividade foi mais afetada quando experimentou o decréscimo na temperatura média.

- Se as previsões com modelos atmosféricos se concretizarem e a temperatura da superficie da Terra se elevar, este aumento será benéfico para o cultivo da cana-de-açúcar, acarretando em aumentos superiores a $20 \%$ na produtividade do Estado. 


\section{REFERENCIAS BIBLIOGRÁFICAS}

BACCHI, O.O.S. \& SOUZA, J.A.G.C. Minimum threshold temperature for sugarcane growth. In: INTERNATIONAL CONGRESS OF THE SOCIETY OF SUGAR CANE TECHNOLOGISTS, 15, São Paulo,1977. Proceedings. p.1733-41.

BAIER, W., Crop-weather analysis model. International Journal of Biometeorol., 17: 313-20, 1973.

BARBIERI, V. Medidas e estimativas de consumo hídrico em cana-de-açúcar (Saccharum spp.). Piracicaba, 1981. 82p. (Mestrado - Escola superior de Agricultura "Luiz de Queiroz"/USP).

BARBIERI, V. \& VILLA NOVA, N.A. Climatologia e a cana-deaçúcar. In: CURSO INTENSIVO SOBRE CANA-DE-AÇÚCAR, Araras, 1981. Araras, IAA/PLANALSUCAR, 1981. p.1-100.

BARBIERI, V.; BACCHI, O.O.S.; VILLA NOVA, N.A. Análise do fator temperatura média do ar no desenvolvimento da canade-açúcar. In: CONGRESSO BRASILEIRO DE AGROMETEOROLOGIA, 1., Mossoró, 1979. Anais. Mossoró, 1979. p. 192-7. 
BARBIERI, V.; MANIERO, M.A.; MATSUOKA, S. o florescimento da cana-de-açúcar e suas implicações no manejo agrícola. In: CONGRESSO NACIONAL DA STAB, 3., São Paulo, 1984. Anais. São Paulo, STAB, 1984., p. 273-6.

BISWAS, B.C. Agroclimatology of the sugar-cane crop. Geneva, World Meteorological Organization, 1988. 90p. (Technical Note, 193. WMO, 703).

BRINHOLI, O. Resistência a seca de algumas variedades de cana-de-açúcar (Saccharum spp.). Piracicaba, 1975. 48p. (Mestrado - Escola Superior de Agricultura "Luiz de Queiroz"/USP).

BRASIL. Ministério da Agricultura e Reforma Agrária. Departamento Nacional de Meteorologia, Normais climatológicas: 1961 - 1990. Brasilia, 1992. 84p.

CAMARGo, A.P. Contribuição para a determinação da evapotranspiração potencial no Estado de são Paulo. Bragantia, Campinas, $21(12): 163-213,1962$.

De WIT, C.T. Photosynthesis of leaf canopies. Wageningen, Pudoc, 1965. 57p. (Agricultural Research Report, 663). 
DOORENBOS, J. \& KASSAM, A.H. Efectos del agua sobre el rendimiento de los cultivos. Roma, F.A.0., 1979. 212p. (FAO. Esțudio Riego Y Drenage, 33).

FISHER, R.A. The influence of rainfall on the yield of wheat at Rothamsted. Phil. Trans. Roy. Soc. London. Ser. B., London, $213: 89-142,1924$.

GLOVER, J., The rate of apparent photosynthesis of whole sugarcane plants. Annals of Botany, 38: 909-20, 1974.

GUPTA, B.R.D. \& SINGH, K.K. Estimating sugarcane yield at Padegaon in Maharashtra. Mausam, India, 39 (4): 421-4, 1988. (Resumo)

IBGE. Produção agrícola municipal do Estado do Rio de Janeiro, 1990 .

INMAN-BAMBER, N.G. \& THOMPSON, G.D. Models of dry matter accumulation by sugar cane. In: ANUAL CONGRESS - SOUTH AFRICAN SUGAR TECHNOLOGISTS. 63., South África, South Africa Sugar Technologists Association, 1989. p.212-6. (Resumo) 
MACHADO, E.C. Um modelo matemático-fisiológico para simular - acúmulo de matéria seca na cultura de cana-de-açúcar (Saccharum spp.). Campinas, 1981. 115p. (Mestrado Universidade Estadual de Campinas).

MANIERO, M.A. Aplicação de graus-dia em cana-de-açúcar (Saccharum spp). Piracicaba, 1980. 76p. (Mestrado-Escola Superior de Agricultura "Luiz de Queiroz"/USP).

MARCUS, K.G. El Niño - its impact on 1992 world sugar production. Sugar y Azucar, New Jerseys, 87 (4): p. 23-8, abr. 1992 .

MUCHOW, R.C.; HAMMER, G.L.; KINGSTON, G. Assessing the potential yield of sugar cane. AUSTRALIAN SOCIETY OF SUGAR CANE TECHNOLOGISTS. 13., Austrália, 1991. Proceedings. Austrália, Watson Ferguson \& Company, 1991. p.146-151.

OMETTO, J.C. Uma equação para a estimativa da evapotranspiração potencial; sua aplicação no cálculo das necessidades hidricas e do rendimento agroindustrial da cana-de-açúcar na região de Piracicaba. Piracicaba, 1974 . 129p. (Livre-docência - Escola Superior de Agricultura "Luiz de Queiroz"/USP). 
OMETTO, J.C. Bioclimatologia vegetal. São Paulo, Agrônomica Ceres, 1981. $425 \mathrm{p}$.

ORTOLANI, A.A.; PINTO, H.S. ; PEREIRA, A.R. Zoneamento agroclimático do Estado do Rio de Janeiro. In: Plano agropecuário de desenvolvimento do Estado do Rio de Janeiro. Rio de Janeiro, 1970. p.39-85.

PEREIRA, A.R. Simulação do crescimento e da produtividade. In: SIMPÓSIO SOBRE O MANEJO DE ĂGUA NA AGRICULTURA. Campinas, 1987. Anais. Campinas, 1987. p. 200-9.

PEREIRA, A.R. \& MACHADO, E.C. Um simulador dinâmico do crescimento de uma cultura de cana-de-açúcar. Bragantia, Campinas, $\underline{45}(1): 107-22,1986$.

PEREIRA, A.R.; BARBIERI, V.; VILLA NOVA, N.A. Condicionamento climático da indução ao florescimento em cana-de-açúcar. Boletim Técnico PLANALSUCAR, Piracicaba, $\underline{5}(3): 5-14$, mar. 1983

PEREIRA Jr, A.C. Efeitos da irrigação e do espaçamento no desenvolvimento e na produção de três variedades de canade-açúcar (Saccharum spp.) . Piracicaba, 1984.124p. (Mestrado

- Escola Superior de Agricultura "Luiz de Queiroz"/USP). 
ROBERTSON, G.W. Guidelines on crop-weather models; World climate programme, Geneva, WMO, 1983a. v.50, 113p.

ROBERTSON, G.W. Weather - based mathematical models for estimating development and ripening of crops. Geneva, WMO, 1983b. 158p. (WMO Agricultural Meteorology - CAgM, Report, 15)

ROSENFELD, U. Período crítico de deficiência hídrica para a cana-de-açúcar (Saccharum spp.). Piracicaba, 1989. 89p. (Mestrado - Escola Superior de Agricultura "Luiz de Queiroz"/USP).

SANTOS FILHO, B.G. dos. Parâmetros biofísicos e fisiológicos associados à economia de água em plantas de cana-de-açúcar (Saccharum spp.) submetidas à estresse hídrico. Campinas, 1984. 158p. (Doutorado - Universidade Estadual de Campinas).

SEGÓVIA, R.M. \& ANDRADE, E.G. de. Um modelo de determinação do efeito da precipitação pluviométrica na produtividade agrícola. Coleção Análise e Pesquisa, Brasilia, 24: 11-8, ago. 1982 . 
SILVA, G.L.S.P. da; VICENTE, J.R.; CASER, D.V. Avaliação de previsões de rendimentos de culturas do Estado de são Paulo, fornecidas por modelos agrometeorológicos, anos agrícolas 1984/85 e 1985/86. In: SIMPÓSIO SOBRE O MANEJO DA ÁGUA NA AGRICULTURA, Campinas, 1987. Anais. Campinas, 1987. p. 210-26.

SINGH, B.H. \& BAPAT, S.R. Pre-harvest forecast models for prediction of sugarcane yield. INDIAN JOURNAL OF AGRICULTURAL SCIENCES, New Delhi, 58 (6):465-9, 1988. (Resumo)

SOUZA, I.C.; LEME, E.J. A.; ROSENFELD, U.; BATISTELLA, J.R. ; BARBIERI, V. Irrigação da cana-de-açúcar na região norte Fluminense: viabilidade técnica - econômica. Boletim Técnico PLANalsucaR, Piracicaba, $\underline{2}(3)$ : 1-34, maio 1980.

SPLINTER, W.E. Modelling of plant growth for yield predicti on. Agricultural Meteorology, Amsterdam, 14: 243-53, 1974 .

THOM, H.C.S. The relational relationship between heating degree days and temperature. Monthly weather Review, 82 : $1-6,1954$. 
THORNTHWAITE, C.W. \& MATHER, J.R. The water balance. Drexel Institute of Technology, 8 (1): 1-14, 1955.

TULLER, V.V. Produtividade da cana-de-açúcar irrigada no norte fluminense. In: CONGRESSO NACIONAL DA STAB, 4., Olinda, 1987. Anais. Olinda, STAB, 1987, p.150-4.

TULLER, V.V.; NASCIF, D.; SOUZA, D. de; AZEVEDO, H.J. de. Determinação da evapotranspiração da cana-de-açúcar em solo de tabuleiro. In: CONGRESSO NACIONAL DA STAB, 2., Rio de Janeiro, 1981. Anais. Rio de Janeiro, STAB, 1981, p.15-36.

VALENÇA, A.S.; TAVARES, A.S.; DAMÁZIO, H.N.; MUELLER, K.E.K. Fatores ambientais redefinindo as regiōes de um informativo agrometeorológico - melhores subsidios ao agricultor, extencionista rural e educador ambiental. In: CONGRESSO BRASILEIRO DE METEOROLOGIA, 7, São Paulo, 1992. Anais. São Paulo, 1992, p.499-503.

VILLA NOVA, N.A. \& BARBIERI, V. Consideração sobre a viabilidade de irrigação da cana-de-açúcar na região de Piracicaba/SP. In: CURSO DE AGRICULTURA IRRIGADA. Piracicaba, 1991. p.76-82. 
VILLA NOVA, N.A.; CARRETERO, M.V.; SCARDUA, R. Um modelo de avaliação do crescimento da cana-de-açúcar (Saccharum spp.) em termos da ação combinada do fotoperíodo e da temperatura média do ar. In: CONGRESSO BRASILEIRO DE AGROMETEOROLOGIA, 3., Campinas, 1983. Anais. Campinas, 1983. p.31-48.

VILLA NOVA, N.A.; PEDRO Jr., M.J.; PEREIRA, A.R.; OMETTO, J.C. Estimativa de graus-dia acumulados acima de qualquer temperatura base, em função das temperaturas máxima e mínima. Caderno de Ciências da Terra, são Paulo, (30): 1-8, 1972 . 


\section{APÊNDICE}

Dados meteorológicos das estações utilizadas, onde:

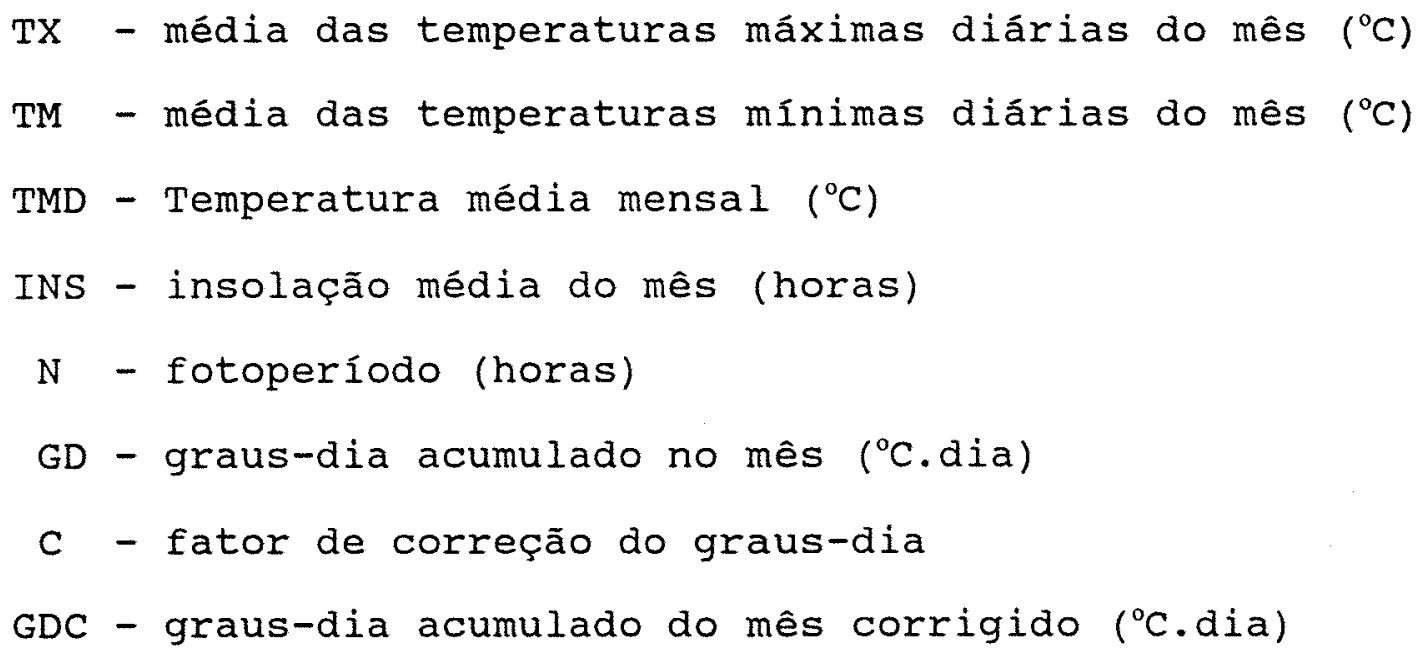


TABELA 2: Dados meteorológicos normais (1961-1990)

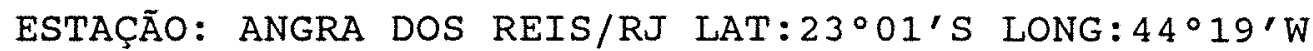

\begin{tabular}{lrrrrrrrr}
\hline \hline MESES & TX & TM & TMD & INS & N & GD & C & GDC \\
\hline \hline JAN & 29,8 & 22,6 & 26,0 & 5,60 & 13,20 & 248 & 0,96 & 237 \\
FEV & 30,4 & 23,1 & 26,4 & 6,29 & 12,80 & 235 & 0,91 & 215 \\
MAR & 29,5 & 22,5 & 25,8 & 5,72 & 12,07 & 242 & 0,89 & 215 \\
ABR & 27,6 & 20,8 & 24,0 & 4,88 & 11,38 & 180 & 0,90 & 162 \\
MAI & 26,2 & 18,9 & 22,2 & 5,14 & 10,85 & 130 & 0,93 & 121 \\
JUN & 25,0 & 17,1 & 20,6 & 4,92 & 10,60 & 78 & 1,00 & 78 \\
JUL & 24,6 & 16,5 & 20,2 & 5,16 & 10,80 & 68 & 1,05 & 72 \\
AGO & 25,0 & 17,2 & 20,7 & 4,81 & 11,14 & 84 & 1,11 & 93 \\
SET & 24,9 & 18,2 & 21,3 & 4,01 & 12,00 & 99 & 1,14 & 113 \\
OUT & 25,6 & 19,3 & 22,3 & 3,91 & 12,70 & 133 & 1,09 & 145 \\
NOV & 27,0 & 20,4 & 23,5 & 4,27 & 13,10 & 165 & 1,05 & 174 \\
DEZ & 28,6 & 21,7 & 24,9 & 4,15 & 13,40 & 214 & 1,01 & 216 \\
\hline \hline
\end{tabular}

ESTAÇÃO: BANGU/RJ LAT: $22^{\circ} 52^{\prime} \mathrm{S} \quad$ LONG: $43^{\circ} 28^{\prime} \mathrm{W}$

\begin{tabular}{lcccccccr}
\hline \hline MESES & TX & TM & TMD & INS & N & GD & C & GDC \\
\hline \hline JAN & 33,2 & 23,1 & 27,0 & 6,05 & 13,20 & 279 & 0,96 & 267 \\
FEV & 33,8 & 23,4 & 27,1 & 6,51 & 12,80 & 255 & 0,91 & 233 \\
MAR & 32,6 & 22,7 & 26,4 & 6,68 & 12,07 & 260 & 0,89 & 232 \\
ABR & 30,2 & 20,9 & 24,2 & 5,94 & 11,38 & 186 & 0,90 & 167 \\
MAI & 28,8 & 18,6 & 22,0 & 6,32 & 10,85 & 124 & 0,93 & 115 \\
JUN & 27,4 & 17,2 & 21,1 & 5,88 & 10,60 & 93 & 1,00 & 93 \\
JUL & 27,1 & 16,4 & 20,5 & 5,93 & 10,80 & 78 & 1,05 & 81 \\
AGO & 28,2 & 17,4 & 21,8 & 6,41 & 11,14 & 118 & 1,11 & 131 \\
SET & 28,3 & 18,4 & 22,5 & 5,68 & 12,00 & 135 & 1,14 & 154 \\
OUT & 29,1 & 19,8 & 23,3 & 4,77 & 12,70 & 164 & 1,09 & 179 \\
NOV & 30,7 & 21,1 & 24,4 & 5,77 & 13,10 & 192 & 1,05 & 203 \\
DEZ & 32,0 & 22,2 & 25,8 & 5,59 & 13,40 & 242 & 1,01 & 244 \\
\hline \hline
\end{tabular}


TABELA 3: Dados meteorológicos normais (1961-1990)

ESTAÇÃO: CAMPOS/RJ LAT: $21^{\circ} 45^{\prime} \mathrm{S}$ LONG: $41^{\circ} 20^{\prime} \mathrm{W}$

\begin{tabular}{lccccccrr}
\hline \hline MESES & TX & TM & TMD & INS & N & GD & C & GDC \\
\hline \hline JAN & 32,0 & 22,5 & 26,3 & 7,19 & 13,14 & 257 & 0,96 & 246 \\
FEV & 32,6 & 22,9 & 26,8 & 7,72 & 12,70 & 246 & 0,92 & 226 \\
MAR & 32,3 & 22,5 & 26,4 & 7,39 & 12,07 & 260 & 0,90 & 234 \\
ABR & 30,3 & 20,9 & 24,6 & 6,77 & 11,41 & 198 & 0,90 & 179 \\
MAI & 28,7 & 19,0 & 22,8 & 6,85 & 10,92 & 149 & 0,94 & 139 \\
JUN & 27,4 & 17,5 & 21,4 & 6,25 & 10,69 & 102 & 1,00 & 102 \\
JUL & 26,7 & 16,9 & 20,8 & 6,47 & 10,87 & 87 & 1,05 & 91 \\
AGO & 27,5 & 17,5 & 21,6 & 6,82 & 11,20 & 112 & 1,11 & 123 \\
SET & 27,3 & 18,5 & 22,2 & 5,23 & 12,00 & 126 & 1,12 & 142 \\
OUT & 28,0 & 19,9 & 23,3 & 4,87 & 12,60 & 164 & 1,08 & 178 \\
NOV & 29,4 & 21,0 & 24,4 & 5,61 & 13,02 & 192 & 1,06 & 203 \\
DEZ & 30,6 & 21,9 & 25,4 & 5,95 & 13,30 & 229 & 1,01 & 231 \\
\hline \hline
\end{tabular}

ESTAÇÃO: CABO FRIO/RJ LAT: $22^{\circ} 49^{\prime} \mathrm{S} \quad$ LONG: $42^{\circ} 02^{\prime} \mathrm{W}$

\begin{tabular}{lcccccccc}
\hline \hline MESES & TX & TM & TMD & INS & N & GD & C & GDC \\
\hline \hline JAN & 28,7 & 22,3 & 25,1 & 7,74 & 13,20 & 220 & 0,96 & 210 \\
FEV & 29,1 & 22,7 & 25,4 & 8,40 & 12,80 & 207 & 0,91 & 190 \\
MAR & 28,8 & 22,7 & 25,4 & 7,35 & 12,07 & 229 & 0,89 & 204 \\
ABR & 27,4 & 21,5 & 24,2 & 6,54 & 11,38 & 186 & 0,90 & 167 \\
MAI & 26,1 & 20,0 & 22,8 & 6,91 & 10,85 & 149 & 0,93 & 139 \\
JUN & 24,9 & 18,8 & 21,6 & 6,70 & 10,60 & 108 & 1,00 & 107 \\
JUI & 24,7 & 18,6 & 21,3 & 7,05 & 10,80 & 102 & 1,05 & 108 \\
AGO & 24,3 & 18,7 & 21,2 & 6,57 & 11,14 & 99 & 1,11 & 110 \\
SET & 24,3 & 19,0 & 21,3 & 5,21 & 12,00 & 99 & 1,14 & 113 \\
OUT & 25,2 & 19,7 & 22,2 & 5,78 & 12,70 & 130 & 1,09 & 142 \\
NOV & 26,5 & 20,7 & 23,3 & 6,32 & 13,10 & 159 & 1,05 & 168 \\
DEZ & 27,9 & 21,8 & 24,5 & 6,50 & 13,40 & 202 & 1,01 & 203 \\
\hline \hline
\end{tabular}


TABELA 4: Dados meteorológicos normais (1961-1990)

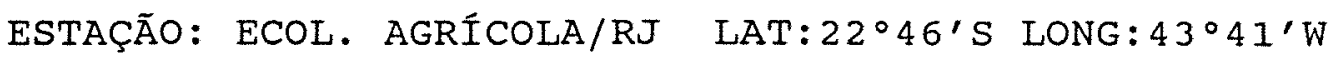

\begin{tabular}{lcccccccr}
\hline \hline MESES & TX & TM & TMD & INS & N & GD & C & GDC \\
\hline \hline JAN & 32,1 & 22,2 & 26,3 & 6,26 & 13,20 & 257 & 0,96 & 246 \\
FEV & 32,8 & 22,6 & 26,7 & 6,81 & 12,80 & 244 & 0,91 & 223 \\
MAR & 31,6 & 21,7 & 25,8 & 6,51 & 12,07 & 242 & 0,89 & 215 \\
ABR & 29,3 & 19,8 & 23,8 & 6,23 & 11,38 & 174 & 0,90 & 156 \\
MAI & 27,9 & 17,7 & 21,9 & 6,52 & 10,85 & 121 & 0,93 & 113 \\
JUN & 26,8 & 16,3 & 20,7 & 6,42 & 10,60 & 81 & 1,00 & 81 \\
JUL & 26,6 & 15,7 & 20,3 & 6,62 & 10,80 & 71 & 1,05 & 75 \\
AGO & 27,6 & 16,6 & 21,2 & 6,34 & 11,14 & 99 & 1,11 & 110 \\
SET & 27,8 & 17,7 & 21,9 & 4,98 & 12,00 & 117 & 1,14 & 133 \\
OUT & 28,2 & 18,9 & 22,8 & 4,75 & 12,70 & 149 & 1,09 & 162 \\
NOV & 29,4 & 20,1 & 24,0 & 5,43 & 13,10 & 180 & 1,05 & 190 \\
DEZ & 30,8 & 21,3 & 25,3 & 5,37 & 13,40 & 226 & 1,01 & 228 \\
\hline \hline
\end{tabular}

ESTAÇÃO: ILHA GUAIBA/RJ LAT: $23^{\circ} 00^{\prime} \mathrm{S}$ LONG: $44^{\circ} 02^{\prime} \mathrm{W}$

\begin{tabular}{lcccccrcr}
\hline \hline MESES & TX & TM & TMD & INS & N & GD & C & GDC \\
\hline \hline JAN & 30,1 & 22,4 & 25,7 & 5,92 & 13,20 & 239 & 0,96 & 228 \\
FEV & 30,6 & 22,9 & 26,1 & 6,72 & 12,80 & 227 & 0,91 & 208 \\
MAR & 29,5 & 22,5 & 25,5 & 5,97 & 12,07 & 233 & 0,89 & 207 \\
ABR & 27,8 & 21,1 & 24,1 & 5,63 & 11,38 & 183 & 0,90 & 164 \\
MAI & 26,2 & 19,6 & 22,6 & 5,92 & 10,85 & 143 & 0,93 & 133 \\
JUN & 25,0 & 18,4 & 21,3 & 6,05 & 10,60 & 99 & 1,00 & 99 \\
JUL & 25,1 & 18,0 & 21,2 & 6,37 & 10,80 & 99 & 1,05 & 104 \\
AGO & 25,3 & 18,3 & 21,4 & 5,74 & 11,14 & 105 & 1,11 & 117 \\
SET & 25,0 & 18,3 & 21,2 & 4,50 & 12,00 & 96 & 1,14 & 109 \\
OUT & 25,9 & 19,1 & 22,1 & 4,52 & 12,70 & 127 & 1,09 & 139 \\
NOV & 27,5 & 20,4 & 23,6 & 4,93 & 13,10 & 168 & 1,05 & 177 \\
DEZ & 28,9 & 21,4 & 24,7 & 4,66 & 13,40 & 208 & 1,01 & 209 \\
\hline \hline
\end{tabular}


TABELA 5: Dados meteorológicos normais (1961-1990)

ESTAÇÃO: ITAPERUNA/RJ LAT: $2^{\circ} 12^{\prime} \mathrm{S} \quad$ LONG: $41^{\circ} 53^{\prime} \mathrm{W}$

\begin{tabular}{lrrrrrrrr}
\hline \hline MESES & TX & TM & TMD & INS & N & GD & C & GDC \\
\hline \hline JAN & 32,0 & 21,7 & 26,2 & 7,19 & 13,10 & 254 & 0,96 & 244 \\
FEV & 32,9 & 21,9 & 26,5 & 7,68 & 12,67 & 238 & 0,92 & 219 \\
MAR & 32,2 & 21,4 & 25,9 & 6,94 & 12,07 & 245 & 0,90 & 221 \\
ABR & 30,0 & 19,8 & 24,1 & 6,41 & 11,45 & 183 & 0,91 & 166 \\
MAI & 28,4 & 17,5 & 22,1 & 6,31 & 10,97 & 127 & 0,94 & 119 \\
JUN & 27,3 & 15,7 & 20,6 & 6,26 & 10,72 & 78 & 1,00 & 78 \\
JUL & 26,9 & 15,0 & 20,1 & 6,26 & 10,92 & 65 & 1,05 & 68 \\
AGO & 28,0 & 15,8 & 21,3 & 6,31 & 11,25 & 102 & 1,10 & 112 \\
SET & 27,9 & 17,4 & 22,0 & 5,21 & 11,96 & 120 & 1,12 & 134 \\
OUT & 28,9 & 19,1 & 23,3 & 5,11 & 12,56 & 164 & 1,08 & 178 \\
NOV & 29,9 & 20,2 & 24,4 & 5,74 & 12,98 & 192 & 1,05 & 202 \\
DEZ & 30,6 & 21,0 & 25,1 & 5,77 & 13,21 & 220 & 1,01 & 222 \\
\hline \hline
\end{tabular}

ESTAÇÃO: MACAÉ/RJ LAT: $22^{\circ} 33^{\prime} \mathrm{S}$ LONG: $41^{\circ} 46^{\prime} \mathrm{W}$

\begin{tabular}{lcccccccr}
\hline MESES & TX & TM & TMD & INS & N & GD & C & GDC \\
\hline \hline JAN & 30,7 & 21,9 & 25,7 & 6,22 & 13,14 & 239 & 0,96 & 228 \\
FEV & 31,6 & 22,4 & 26,3 & 7,31 & 12,70 & 232 & 0,92 & 214 \\
MAR & 30,6 & 21,6 & 25,6 & 6,20 & 12,07 & 236 & 0,90 & 212 \\
ABR & 29,1 & 20,5 & 24,2 & 5,96 & 11,41 & 186 & 0,90 & 168 \\
MAI & 27,8 & 18,6 & 22,6 & 6,09 & 10,92 & 143 & 0,94 & 134 \\
JUN & 26,5 & 16,6 & 20,8 & 6,04 & 10,69 & 84 & 1,00 & 84 \\
JUL & 26,1 & 16,2 & 20,4 & 6,30 & 10,87 & 74 & 1,05 & 78 \\
AGO & 26,4 & 16,9 & 20,9 & 5,66 & 11,20 & 90 & 1,11 & 99 \\
SET & 26,0 & 17,6 & 21,2 & 4,25 & 12,00 & 96 & 1,12 & 108 \\
OUT & 27,2 & 19,1 & 22,7 & 4,69 & 12,60 & 146 & 1,08 & 158 \\
NOV & 28,4 & 20,3 & 24,0 & 5,46 & 13,02 & 180 & 1,06 & 190 \\
DEZ & 29,4 & 21,3 & 24,8 & 4,82 & 13,30 & 211 & 1,01 & 213 \\
\hline \hline
\end{tabular}


TABELA 6: Dados meteorológicos normais (1961-1990)

ESTAÇÃO: MARAMBAIA/RJ LAT: $23^{\circ} 03^{\prime} \mathrm{S} \quad$ LONG: $43^{\circ} 36^{\prime} \mathrm{W}$

\begin{tabular}{lcccccrrr}
\hline \hline MESES & TX & TM & TMD & INS & N & GD & C & GDC \\
\hline JAN & 31,2 & 22,3 & 26,4 & 5,83 & 13,20 & 260 & 0,96 & 249 \\
FEV & 31,2 & 22,9 & 26,6 & 5,99 & 12,80 & 241 & 0,91 & 220 \\
MAR & 30,2 & 22,2 & 25,9 & 5,64 & 12,07 & 245 & 0,89 & 218 \\
ABR & 29,5 & 21,1 & 24,9 & 5,52 & 11,38 & 207 & 0,90 & 186 \\
MAI & 27,4 & 19,1 & 23,0 & 5,16 & 10,85 & 155 & 0,93 & 144 \\
JUN & 26,4 & 16,9 & 21,2 & 5,63 & 10,60 & 96 & 1,00 & 96 \\
JUL & 25,8 & 16,4 & 20,8 & 5,36 & 10,80 & 87 & 1,05 & 91 \\
AGO & 26,2 & 17,2 & 21,3 & 4,67 & 11,14 & 102 & 1,11 & 114 \\
SET & 25,6 & 17,3 & 21,2 & 4,14 & 12,00 & 96 & 1,14 & 109 \\
OUT & 27,0 & 18,5 & 22,6 & 5,25 & 12,70 & 143 & 1,09 & 156 \\
NOV & 28,5 & 19,8 & 23,8 & 5,87 & 13,10 & 174 & 1,05 & 184 \\
DEZ & 29,5 & 20,7 & 24,7 & 5,21 & 13,40 & 208 & 1,01 & 209 \\
\hline \hline
\end{tabular}

ESTAÇÃO: RIO DE JANEIRO/RJ LAT: $22^{\circ} 55^{\prime} \mathrm{S}$ LONG: $43^{\circ} 10^{\prime} \mathrm{W}$

\begin{tabular}{lcccccccc}
\hline \hline MESES & TX & TM & TMD & INS & N & GD & C & GDC \\
\hline \hline JAN & 29,7 & 23,3 & 26,2 & 6,33 & 13,20 & 254 & 0,96 & 243 \\
FEV & 30,2 & 23,5 & 26,5 & 7,39 & 12,80 & 238 & 0,91 & 218 \\
MAR & 29,4 & 23,3 & 26,0 & 6,31 & 12,07 & 248 & 0,89 & 220 \\
ABR & 27,8 & 21,9 & 24,5 & 5,53 & 11,38 & 195 & 0,90 & 175 \\
MAI & 26,4 & 20,4 & 23,0 & 5,53 & 10,85 & 155 & 0,93 & 144 \\
JUN & 25,2 & 18,7 & 21,5 & 5,52 & 10,60 & 105 & 1,00 & 105 \\
JUL & 25,3 & 18,4 & 21,3 & 5,89 & 10,80 & 102 & 1,05 & 108 \\
AGO & 25,6 & 18,9 & 21,8 & 5,75 & 11,14 & 118 & 1,11 & 131 \\
SET & 25,0 & 19,2 & 21,8 & 4,56 & 12,00 & 114 & 1,14 & 130 \\
OUT & 26,0 & 20,2 & 22,8 & 5,11 & 12,70 & 149 & 1,09 & 162 \\
NOV & 27,4 & 21,4 & 24,2 & 5,62 & 13,10 & 186 & 1,05 & 196 \\
DEZ & 28,6 & 22,4 & 25,2 & 5,16 & 13,40 & 223 & 1,01 & 225 \\
\hline \hline
\end{tabular}


TABELA 7: Dados meteorológicos normais (1961-1990)

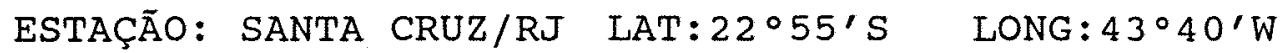

\begin{tabular}{lcccccccr}
\hline \hline MESES & TX & TM & TMD & INS & N & GD & C & GDC \\
\hline \hline JAN & 32,5 & 22,6 & 26,2 & 6,33 & 13,20 & 254 & 0,96 & 243 \\
FEV & 33,1 & 23,0 & 26,6 & 7,39 & 12,80 & 241 & 0,91 & 220 \\
MAR & 31,8 & 22,3 & 25,8 & 6,31 & 12,07 & 242 & 0,89 & 215 \\
ABR & 29,5 & 20,7 & 23,8 & 5,53 & 11,38 & 174 & 0,90 & 156 \\
MAI & 27,8 & 18,8 & 21,9 & 5,53 & 10,85 & 121 & 0,93 & 113 \\
JUN & 26,9 & 17,7 & 21,1 & 5,52 & 10,60 & 93 & 1,00 & 93 \\
JUL & 26,6 & 17,1 & 20,7 & 5,89 & 10,80 & 84 & 1,05 & 88 \\
AGO & 27,4 & 17,8 & 21,7 & 5,75 & 11,14 & 115 & 1,11 & 128 \\
SET & 27,2 & 18,3 & 22,3 & 4,56 & 12,00 & 129 & 1,14 & 147 \\
OUT & 28,0 & 19,4 & 22,5 & 5,11 & 12,70 & 140 & 1,09 & 152 \\
NOV & 29,6 & 20,4 & 23,5 & 5,62 & 13,10 & 165 & 1,05 & 174 \\
DEZ & 31,0 & 21,8 & 25,2 & 5,16 & 13,40 & 223 & 1,01 & 225 \\
\hline \hline
\end{tabular}

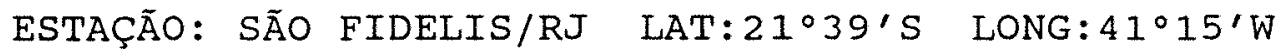

\begin{tabular}{lcccccccr}
\hline \hline MESES & TX & TM & TMD & INS & N & GD & C & GDC \\
\hline \hline JAN & 33,0 & 21,6 & 26,3 & 8,00 & 13,14 & 257 & 0,96 & 246 \\
FEV & 33,9 & 21,8 & 26,5 & 8,03 & 12,70 & 238 & 0,92 & 219 \\
MAR & 33,3 & 21,1 & 26,4 & 7,07 & 12,07 & 260 & 0,90 & 234 \\
ABR & 31,3 & 19,6 & 24,3 & 6,52 & 11,41 & 189 & 0,90 & 171 \\
MAI & 29,6 & 17,6 & 21,9 & 5,82 & 10,92 & 121 & 0,94 & 113 \\
JUN & 28,1 & 15,6 & 20,7 & 5,96 & 10,69 & 81 & 1,00 & 81 \\
JUL & 27,8 & 15,4 & 20,5 & 6,35 & 10,87 & 78 & 1,05 & 81 \\
AGO & 29,0 & 16,2 & 21,7 & 6,68 & 11,20 & 115 & 1,11 & 127 \\
SET & 29,0 & 17,2 & 22,2 & 5,28 & 12,00 & 126 & 1,12 & 142 \\
OUT & 30,2 & 19,1 & 23,3 & 5,02 & 12,60 & 164 & 1,08 & 178 \\
NOV & 31,0 & 20,4 & 24,3 & 5,19 & 13,02 & 189 & 1,06 & 199 \\
DEZ & 31,7 & 21,2 & 25,2 & 5,87 & 13,30 & 223 & 1,01 & 225 \\
\hline \hline
\end{tabular}


TABELA 8: Dados meteorológicos normais (1961-1990)

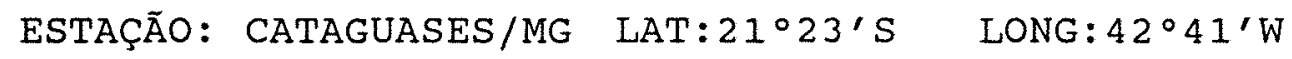

\begin{tabular}{lcccccccr}
\hline \hline MESES & TX & TM & TMD & INS & N & GD & C & GDC \\
\hline \hline JAN & 31,8 & 21,7 & 25,5 & 6,28 & 13,10 & 233 & 0,96 & 223 \\
FEV & 32,0 & 21,9 & 25,7 & 6,13 & 12,67 & 216 & 0,92 & 199 \\
MAR & 31,9 & 21,3 & 25,9 & 6,62 & 12,07 & 245 & 0,90 & 221 \\
ABR & 29,9 & 19,2 & 23,4 & 6,31 & 11,45 & 162 & 0,91 & 147 \\
MAI & 27,8 & 16,4 & 20,8 & 6,39 & 10,97 & 87 & 0,94 & 81 \\
JUN & 25,9 & 14,4 & 19,6 & 6,24 & 10,72 & 48 & 1,00 & 48 \\
JUL & 26,7 & 14,3 & 19,6 & 5,79 & 10,92 & 50 & 1,05 & 52 \\
AGO & 28,5 & 15,1 & 20,6 & 6,48 & 11,25 & 81 & 1,10 & 88 \\
SET & 29,0 & 17,2 & 22,1 & 5,19 & 11,96 & 123 & 1,12 & 137 \\
OUT & 29,8 & 19,4 & 23,6 & 4,46 & 12,56 & 174 & 1,08 & 188 \\
NOV & 30,5 & 21,3 & 22,3 & 5,02 & 12,98 & 129 & 1,05 & 136 \\
DEZ & 31,2 & 21,1 & 23,0 & 6,44 & 13,21 & 155 & 1,01 & 156 \\
\hline \hline
\end{tabular}

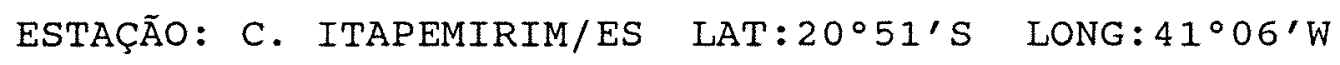

\begin{tabular}{lcccccccr}
\hline \hline MESES & TX & TM & TMD & INS & N & GD & C & GDC \\
\hline \hline JAN & 32,7 & 22,2 & 26,5 & 7,32 & 13,10 & 264 & 0,96 & 253 \\
FEV & 33,4 & 22,1 & 26,6 & 7,67 & 12,67 & 241 & 0,92 & 222 \\
MAR & 33,1 & 21,8 & 26,2 & 7,13 & 12,07 & 254 & 0,90 & 230 \\
ABR & 30,7 & 20,5 & 24,4 & 9,53 & 11,45 & 192 & 0,91 & 174 \\
MAI & 28,8 & 18,3 & 22,4 & 6,55 & 10,97 & 136 & 0,94 & 128 \\
JUN & 27,8 & 16,8 & 21,0 & 6,33 & 10,72 & 90 & 1,00 & 90 \\
JUL & 27,1 & 16,3 & 20,5 & 6,47 & 10,92 & 78 & 1,05 & 81 \\
AGO & 28,2 & 16,8 & 21,3 & 6,45 & 11,25 & 102 & 1,10 & 112 \\
SET & 28,4 & 18,0 & 22,1 & 5,28 & 11,96 & 123 & 1,12 & 137 \\
OUT & 29,0 & 19,7 & 23,4 & 5,07 & 12,56 & 167 & 1,08 & 182 \\
NOV & 30,2 & 20,6 & 24,5 & 5,45 & 12,98 & 195 & 1,05 & 205 \\
DEZ & 31,3 & 21,4 & 25,2 & 5,54 & 13,21 & 223 & 1,01 & 225 \\
\hline \hline
\end{tabular}


TABELA 9: Dados meteorológicos normais (1961-1990)

ESTAÇÃO: UBATUBA/SP LAT: $24^{\circ} 26^{\prime} \mathrm{S}$ LONG: $45^{\circ} 06^{\prime} \mathrm{W}$

\begin{tabular}{lcccccccrr}
\hline \hline MESES & TX & TM & TMD & INS & N & GD & C & GDC \\
\hline \hline JAN & 29,7 & 20,5 & 24,6 & 3,38 & 13,26 & 205 & 0,95 & 195 \\
FEV & 30,3 & 20,8 & 25,0 & 3,80 & 12,86 & 217 & 0,91 & 198 \\
MAR & 29,4 & 20,3 & 24,3 & 3,41 & 12,08 & 195 & 0,88 & 172 \\
ABR & 27,5 & 18,3 & 22,4 & 3,50 & 11,33 & 136 & 0,89 & 122 \\
MAI & 25,7 & 15,4 & 20,0 & 3,51 & 10,80 & 62 & 0,93 & 58 \\
JUN & 24,9 & 13,5 & 18,2 & 3,54 & 10,55 & 6 & 0,99 & 6 \\
JUL & 24,1 & 12,8 & 17,6 & 3,55 & 10,74 & 51 & 1,05 & 54 \\
AGO & 24,7 & 14,3 & 18,7 & 3,34 & 11,10 & 67 & 1,12 & 75 \\
SET & 24,5 & 15,5 & 19,6 & 2,59 & 12,00 & 73 & 1,15 & 83 \\
OUT & 25,4 & 17,3 & 21,0 & 2,36 & 12,72 & 93 & 1,10 & 102 \\
NOV & 26,1 & 18,0 & 21,7 & 2,78 & 13,16 & 115 & 1,06 & 121 \\
DEZ & 28,4 & 19,6 & 23,5 & 2,96 & 13,47 & 171 & 1,01 & 172 \\
\hline \hline
\end{tabular}

ESTAÇÃO: PIRAI/RJ LAT: $22^{\circ} 38^{\prime} \mathrm{S} \quad$ LONG: $43^{\circ} 54^{\prime} \mathrm{W}$

\begin{tabular}{lcccccrrr}
\hline \hline MESES & TX & TM & TMD & INS & N & GD & C & GDC \\
\hline \hline JAN & 30,6 & 19,4 & 24,0 & 5,18 & 13,14 & 186 & 0,96 & 178 \\
FEV & 30,8 & 19,3 & 24,0 & 6,33 & 12,70 & 186 & 0,92 & 171 \\
MAR & 30,5 & 19,1 & 23,7 & 5,11 & 12,07 & 177 & 0,90 & 159 \\
ABR & 28,1 & 17,4 & 21,7 & 4,74 & 11,41 & 115 & 0,90 & 104 \\
MAI & 26,3 & 14,5 & 19,1 & 4,74 & 10,92 & 34 & 0,94 & 32 \\
JUN & 25,3 & 12,4 & 17,4 & 4,72 & 10,69 & 62 & 1,00 & 62 \\
JUL & 24,9 & 11,5 & 16,7 & 5,12 & 10,87 & 53 & 1,05 & 56 \\
AGO & 26,3 & 12,6 & 18,2 & 4,64 & 11,20 & 6 & 1,11 & 7 \\
SET & 26,5 & 14,6 & 19,6 & 3,93 & 12,00 & 50 & 1,12 & 56 \\
OUT & 27,1 & 16,4 & 20,9 & 4,23 & 12,60 & 90 & 1,08 & 98 \\
NOV & 28,3 & 17,7 & 22,2 & 4,32 & 13,02 & 130 & 1,06 & 137 \\
DEZ & 29,4 & 18,8 & 23,2 & 4,11 & 13,30 & 161 & 1,01 & 163 \\
\hline \hline
\end{tabular}


TABELA 10: Dados meteorológicos normais (1961-1990)

ESTAÇÃO: VASSOURAS/RJ LAT: $22^{\circ} 20^{\prime} \mathrm{S}$ LONG: $43^{\circ} 40^{\prime} \mathrm{W}$

\begin{tabular}{lcccccccr}
\hline \hline MESES & TX & TM & TMD & INS & N & GD & C & GDC \\
\hline \hline JAN & 30,1 & 19,7 & 23,6 & 5,99 & 13,14 & 174 & 0,96 & 166 \\
FEV & 30,8 & 19,9 & 24,0 & 6,66 & 12,70 & 168 & 0,92 & 154 \\
MAR & 29,9 & 19,3 & 23,2 & 6,21 & 12,07 & 161 & 0,90 & 145 \\
ABR & 27,7 & 17,5 & 21,3 & 5,62 & 11,41 & 99 & 0,90 & 90 \\
MAI & 25,9 & 14,7 & 19,0 & 5,77 & 10,92 & 31 & 0,94 & 29 \\
JUN & 24,7 & 13,1 & 17,6 & 5,69 & 10,69 & 58 & 1,00 & 58 \\
JUL & 24,6 & 12,5 & 17,2 & 5,95 & 10,87 & 54 & 1,05 & 57 \\
AGO & 26,0 & 13,7 & 18,6 & 5,95 & 11,20 & 19 & 1,11 & 21 \\
SET & 26,3 & 15,4 & 19,7 & 4,69 & 12,00 & 51 & 1,12 & 57 \\
OUT & 27,2 & 17,1 & 20,9 & 4,67 & 12,60 & 90 & 1,08 & 98 \\
NOV & 28,0 & 18,1 & 21,9 & 5,01 & 13,02 & 117 & 1,06 & 123 \\
DEZ & 29,0 & 19,2 & 22,9 & 5,10 & 13,30 & 152 & 1,01 & 153 \\
\hline \hline
\end{tabular}

